\title{
Three Essays in Industrial Organization with a Focus on Innovation, Advertising, Welfare, and Firm Performance
}

\author{
by \\ Parisa Pourkarimi
}

A thesis submitted to the Faculty of Graduate and Postdoctoral Affairs in partial fulfillment of the requirements for the degree of

Doctor of Philosophy

in

Economics

Carleton University

Ottawa, Ontario

(C) 2018, Parisa Pourkarimi 


\section{Abstract}

This thesis is comprised of three essays on the economic impacts of market structure, R\&D and advertising activities. The first studies the impact of cooperative R\&D on innovation, welfare, and profitability in vertically related industries where products are differentiated. The model incorporates two vertically related industries, with horizontal spillovers within each industry and vertical spillovers between the two industries. Upstream firms produce a homogeneous intermediate good. Downstream firms provide differentiated products. Three types of R\&D cooperation are studied: no cooperation, horizontal cooperation, and vertical cooperation. Vertical spillovers always increase R\&D, and welfare, whereas horizontal spillovers may increase or decrease them. The comparison of cooperation settings in terms of $\mathrm{R} \& \mathrm{D}$ shows that vertical cooperation dominates the other types of cooperation. Vertical cooperation may lead firms to overinvest in $R \& D$. The ranking of cooperation settings rests on the sign and magnitudes of product differentiation, vertical and horizontal competitive externalities which reflect the impact of R\&D of a firm on the profits of other firms. Higher product substitutability increases firms' concerns about the flow of technological information to the rival, affects firms' strategies of output and R\&D.

The second area of focus is the impact of cooperative R\&D and advertising on innovation and welfare in a duopolistic industry. The model incorporates two symmetric firms which produce differentiated products. Firms participate in R\&D and advertising activities in the presence of R\&D spillovers and advertising spillovers. Advertising spillovers may be positive or negative. Four types of cooperative structures are studied: no cooperation, R\&D cooperation, advertising cooperation, $\mathrm{R} \& \mathrm{D}$ and advertising 
cooperation. R\&D spillovers and advertising spillovers always increase innovation and welfare if products are highly differentiated and (or) spillovers are sufficiently high. The comparison of cooperation settings in terms of R\&D shows that no cooperation setting uniformly dominates the others. The ranking of cooperation settings rests on the sign and magnitudes of product differentiation, $R \& D$ and advertising externalities. Higher product substitutability affects the externalities. Strategic interaction among firms shows that firms always benefit from higher innovation efforts and advertising activities of the rival if spillovers are high enough and (or) product substitutability is low enough.

Lastly, the effectiveness of $R \& D$ and advertising on market share is examined. Advertising and innovation are two major functions to beat the competition and boost profitability. Surprisingly, however, the importance of the qualitative characteristics of the industry and its strategic initiatives has not yet been adequately addressed in the literature. This chapter empirically examines the critical role of innovation and advertising in the marketing strategy of advanced technological companies. The analysis considers a key marketing metric (market share). The focus of the empirical setting is the U.S. Information and Communications Technology industry including 150 manufacturing and nonmanufacturing companies over a 10 -year time period. It was shown that R\&D has a significant positive effect on companies' performance. Increasing R\&D share in advanced technological companies increases market share and revenue, whereas increasing advertising has no significant effect on market share and revenue. Advertising effectiveness in this industry is systematically moderated over a short time. The results show that maintaining innovation efforts in advanced technological industries is necessary to yield a better performance. 
To my daughter, Artina

for her patience, love, inspiration, and support 


\section{Acknowledgements}

They say "it takes an entire village to raise a child" - the same can be mentioned for completing a doctorate. This thesis could not have accomplished without the support and encouragement of many.

First, I would like to express my special appreciation and gratitude to my co-supervisors, Professors Marcel Voia and Gamal Atallah, for their persistent guidance in this process. They supported and encouraged me with their knowledge and patience. I am grateful to the members of my thesis committee who have provided helpful comments and support along the way - Professors Zhiqi Chen from Carleton University, and Professor Aggey Semenov from the University of Ottawa. I also wish to thank other faculty and staff from the department, including Professor Till Gross for helpful discussions in developing my first thesis chapter, Marge Brooks, Alison Dailey, Renee Lortie, Dawn Bjornson, and Sabrina Robineau for their continuous encouragement, and my fellow classmates. I would like to thank Professor Eric Kam from Ryerson University for his helpful comments and continuous encouragement. I am thankful for my external and internal thesis examiners, Professors David Brown and Meredith Lilly, who gave very helpful comments and with no doubt made this thesis stronger.

I also would like to express my gratitude to the department's Ph.D. program supervisors, Professors Lynda Khalaf, Patrick Coe, and Hashmat Khan, for their continued support of my academic life.

I would have never completed my thesis without the support of my family. I thank my parents, Mahmoud Pourkarimi and Parivash Khanjari, my sisters, Atoosa and Anahita Pourkarimi, as well as my husband Ramtin Madani, and my lovely daughter, Artina Madani. The depth of my gratitude for them is impossible to put in words. They provided unbeatable support throughout this long and often challenging process, and have been my biggest cheerleaders at every point along the way. 
Table of Contents

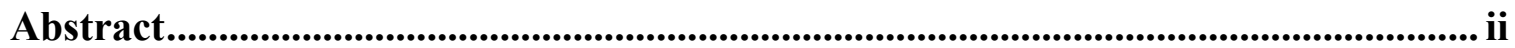

Acknowledgements ........................................................................................................... V

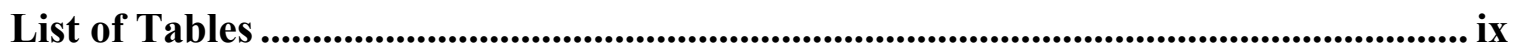

List of Appendices ....................................................................................................................... xi

Chapter 1: Cooperative R\&D with Differentiated Products in Vertically Related

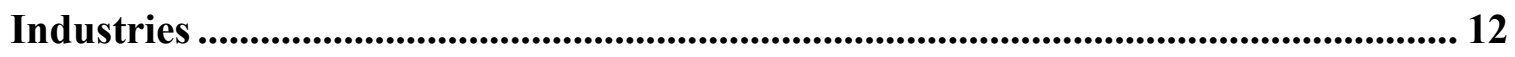

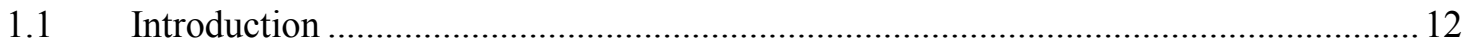

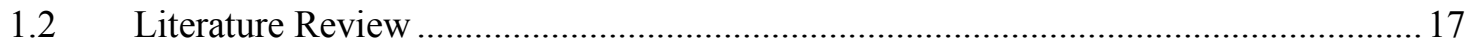

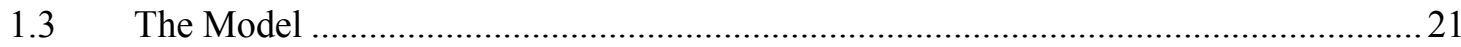

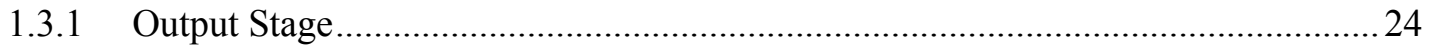

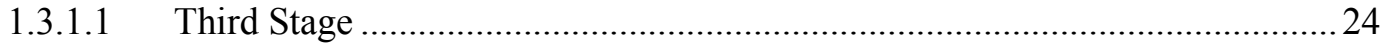

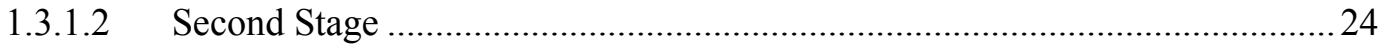

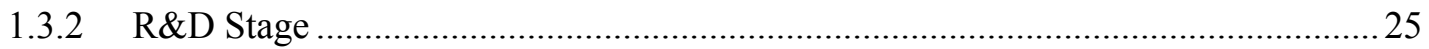

1.4 The Impacts of Spillovers and Product Differentiation on R\&D and Welfare.............28

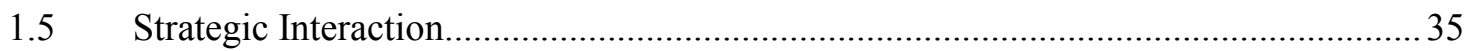

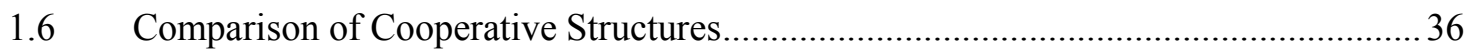

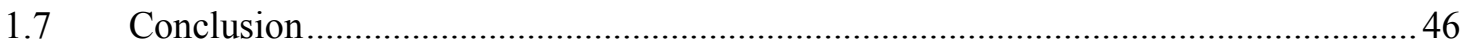

Chapter 2: The Impact of Cooperative R\&D and Advertising on Innovation ........ 52

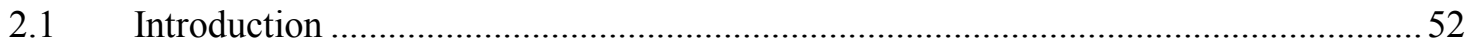

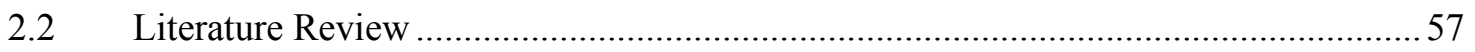

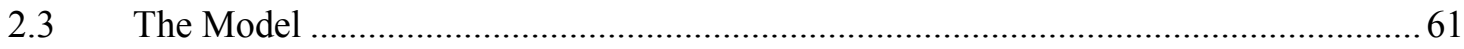

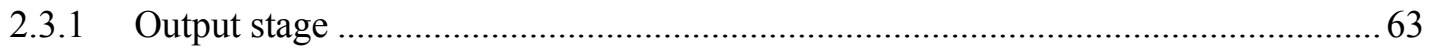

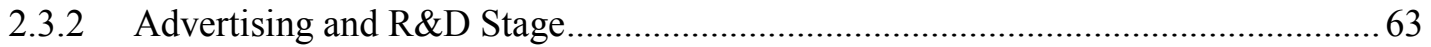




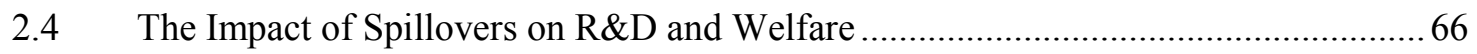

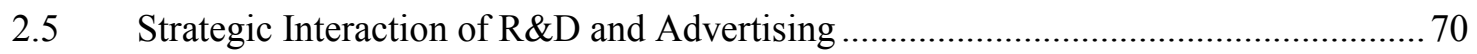

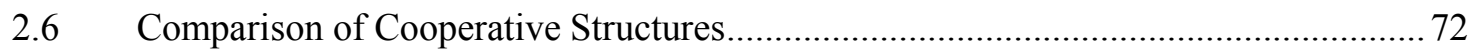

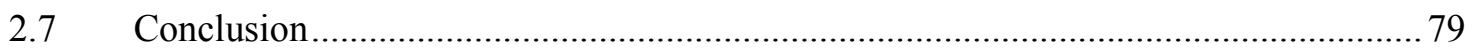

Chapter 3: The Effectiveness of R\&D and Advertising ............................................ 86

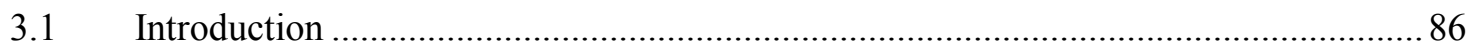

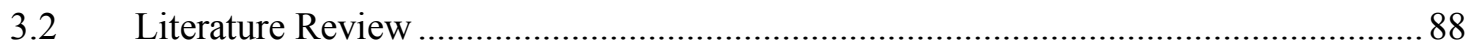

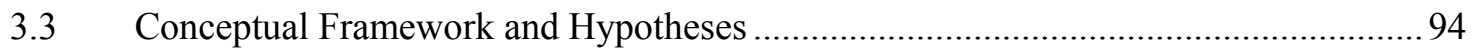

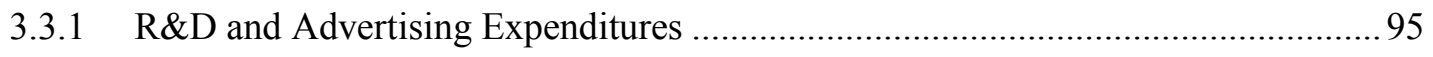

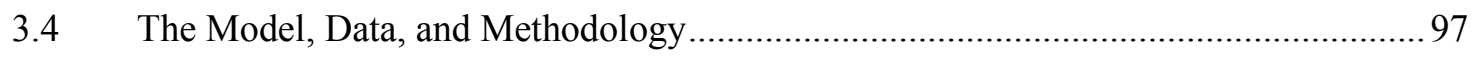

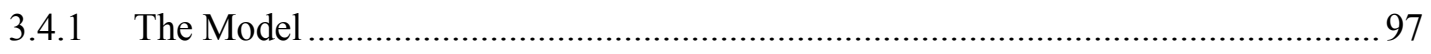

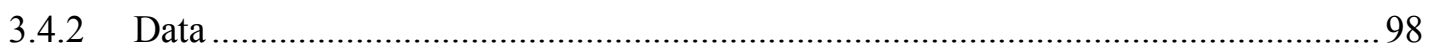

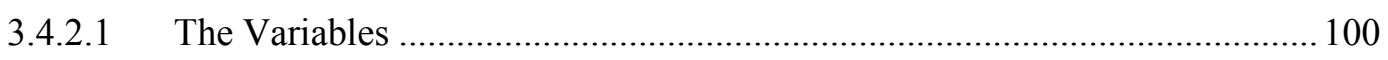

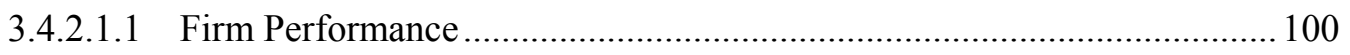

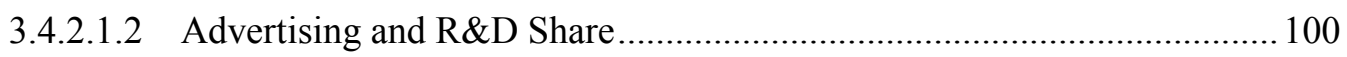

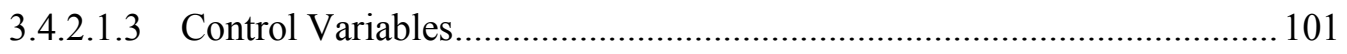

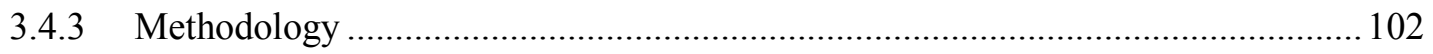

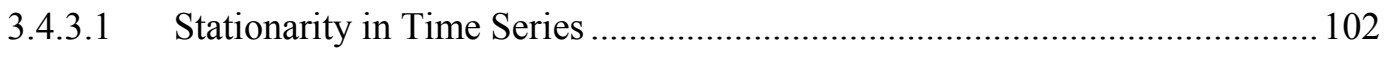

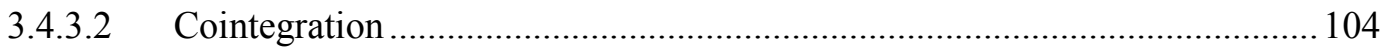

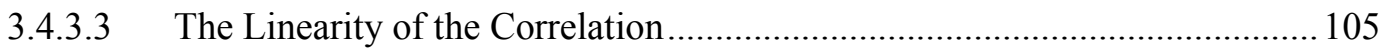

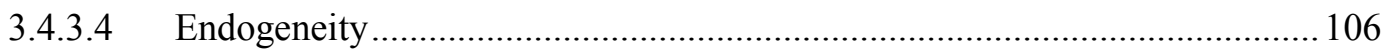

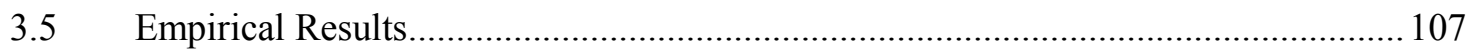

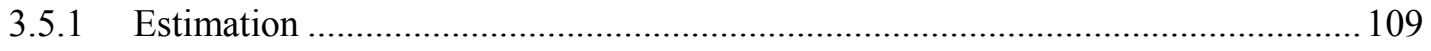

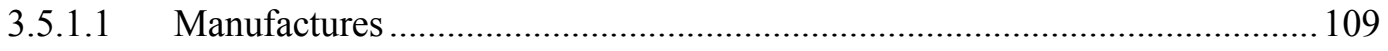

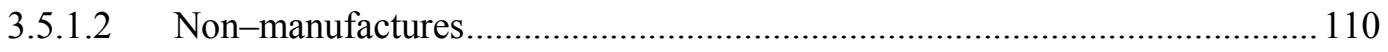

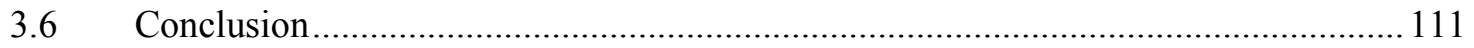


Appendices

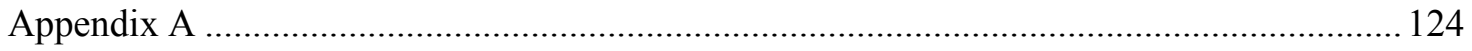

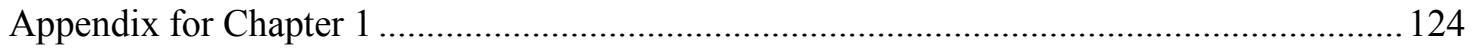

A.1 Proof of Proposition 1 ................................................................................. 124

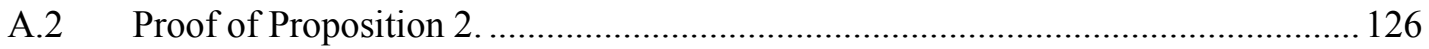

A.3 Proof of Proposition 3 ………………………………………………………..... 127

A.4 Proof of Proposition 4 .......................................................................................... 127

A.5 Proof of Proposition 5 .................................................................................... 128

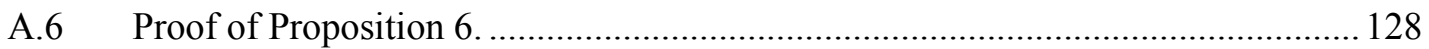

A.7 Proof of Proposition 7 ……………………………………………………. 129

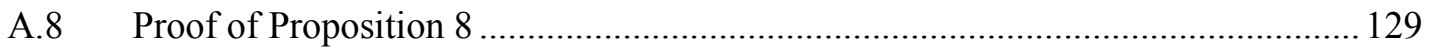

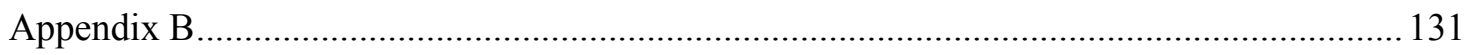

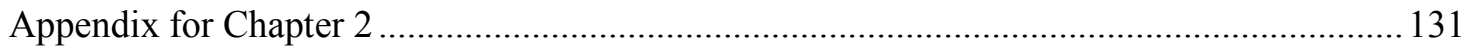

B.1 Proof of Proposition 1 ……………………………………………………….... 131

B.2 Proof of Proposition 2 …………………………………………………….... 133

B.3 Proof of Proposition 3 …………………………………………………….... 135

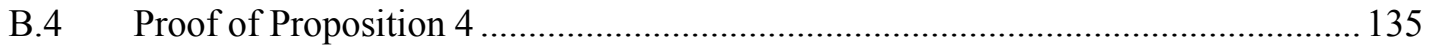

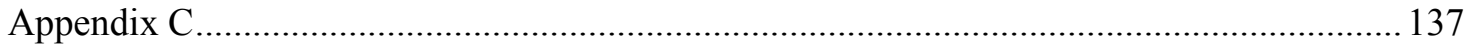

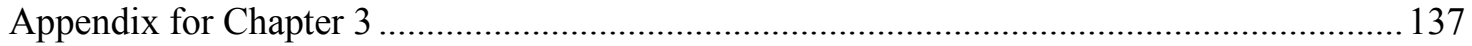

C.1 Instrument Validity and Relevance ................................................................... 137

C.2 The Sargan-Hansen Endogeneity Test for Manufactures ........................................ 139

C.3 The Sargan-Hansen Endogeneity Test for Non-manufactures …………………... 144

Bibliography or References........................................................................................... 149 


\section{List of Tables}

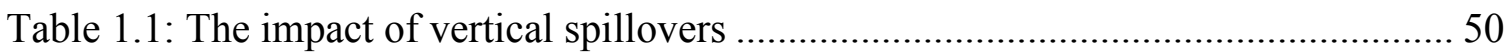

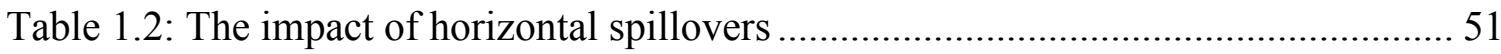

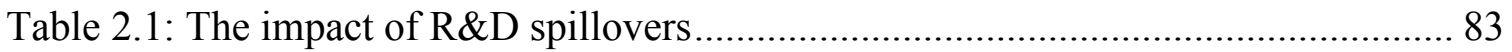

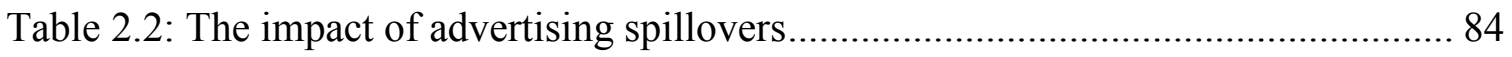

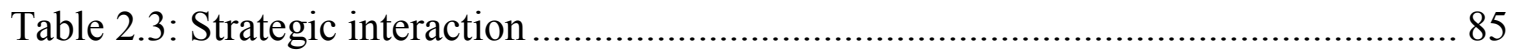

Table 3.1: The list of the U. S. manufacturing companies ......................................... 113

Table 3.2: The list of the U.S. non-manufacturing companies ................................. 114

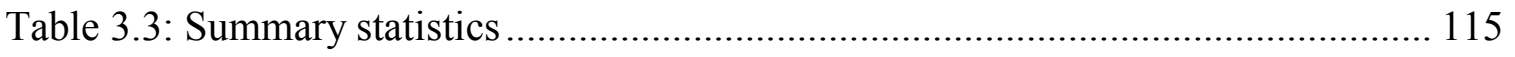

Table 3.4: The results of the Fisher unit-root test ................................................ 116

Table 3.5: The results of the Fisher unit-root test after the first difference .................. 117

Table 3.6: The results of the Kao test for cointegration .......................................... 118

Table 3.7: The results of the Pearson correlation test ................................................ 119

Table 3.8: The results of OLS estimation for manufacturing companies ..................... 120

Table 3.9: The results of OLS estimation for non-manufacturing companies .............. 121

Table C.1: The first stage of IV (2SLS) estimation, manufacturing companies............. 142

Table C.2: The results of IV (2SLS) estimation, manufacturing companies................. 143

Table C.3: The first stage of IV (2SLS) estimation, non-manufacturing companies..... 147

Table C.4: The results of IV (2SLS) estimation, non-manufacturing companies.......... 148

\section{List of Illustrations}


Illustration 3.1: Mean of variables of interest for manufacturing companies................ 122

Illustration 3.2: Mean of variables of interest for non-manufacturing companies ........ 123 


\section{List of Appendices}

Appendix A.......................................................... 125

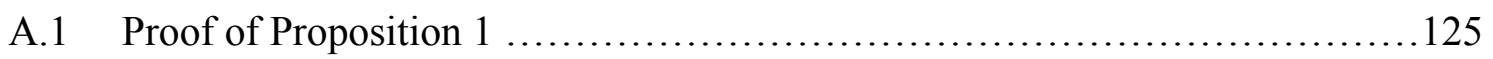

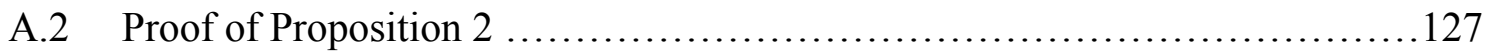

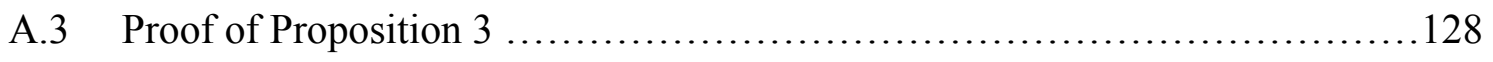

A.4 Proof of Proposition 4 ............................................. 129

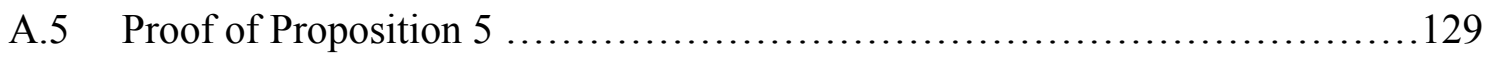

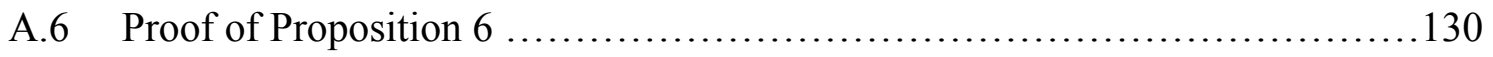

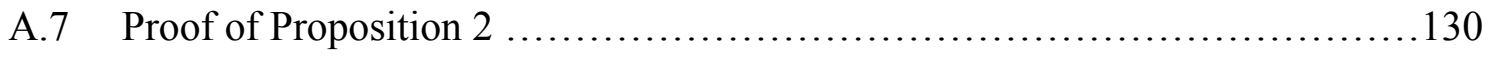

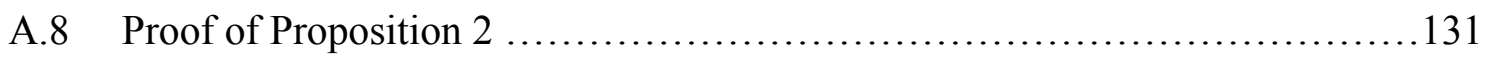

Appendix B............................................................ 132

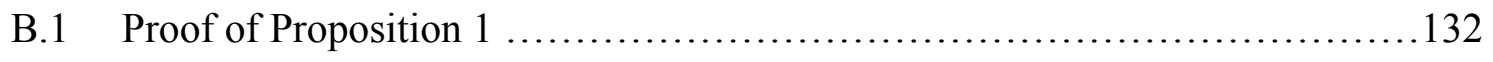

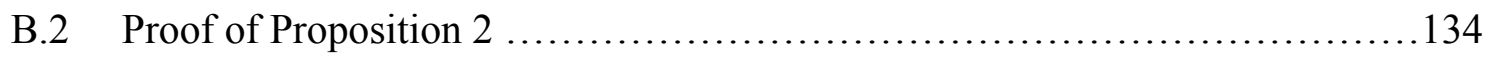

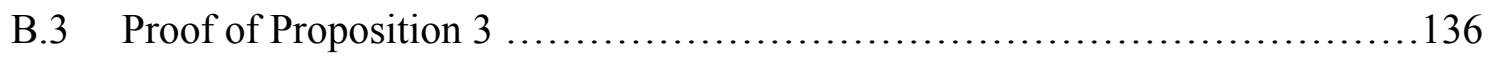

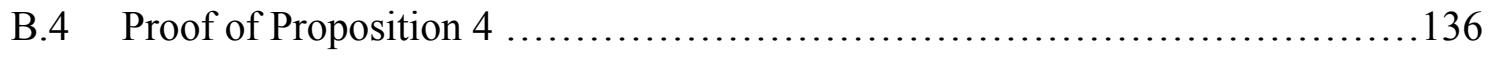

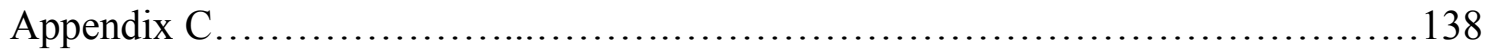

C.1 Instrument Validity and Relevance..................................138

C.2 The Sargan-Hansen Endogeneity Test for Manufactures...................140

C.3 The Sargan-Hansen Endogeneity Test for Non-manufactures................ 145 


\section{Chapter 1: Cooperative R\&D with Differentiated Products in}

\section{Vertically Related Industries}

\subsection{Introduction}

The importance of industry clustering for innovation and the economic performance of industrialized countries due to remarkable access to knowledge spillovers has been largely stressed recently by the theoretical and empirical literature (Gilbert et al. 2008). R\&D alliances have been widely promoted as a new phenomenon and an effective strategy to enhance economic returns from $\mathrm{R} \& \mathrm{D}$ activities and improve industrial competitiveness. The globalization of the economy and innovation competition trigger catching up East Asia economies like Korea and Taiwan. The growing importance of technological knowledge in the $\mathrm{R} \& \mathrm{D}$ process of companies in certain industries, such as pharma-ceuticals, is also a factor supporting R\&D alliances, particularly with universities and public research institutions (Motohashi 2005).

The results of several surveys show that small corporations tend to participate in R\&D collaborations more than the large corporations because of the lack of in-house management resources. Large companies active in the global market have been actively collaborating with foreign corporations. However, language and geographic barriers restrict the effective collaborations in such activities (Motohashi 2008).

By R\&D collaboration, firms not only coordinate their R\&D investment, but also share all the results of the research. The collaboration eliminates the wasteful duplication of $\mathrm{R} \& \mathrm{D}$ efforts, mitigates the risk, and distributes fixed costs among participants. Indeed, cooperative R\&D has a long history in the U.S. science and technology policy. Major cooperative initiatives in pharmaceuticals manufacture, petrochemicals, synthetic rubber, 
and atomic weapons were commenced during World War II, and the National Advisory Committee on Aeronautics, established in 1915 and involved NASA in 1958, made significant contributions to commercial and military aircraft design (Mowery 1998).

Although the theoretical literature implies that potential gains to firms' cooperation are higher than no cooperation when intra-industry spillovers are sufficiently high, the empirical literature signifies the importance of inter-industry technological information flows. However, knowledge spillovers affect firms differently based on the industry they belong to, their size and their absorptive capacity, their own R\&D investment, as well as their technological specialization (Kafouros and Buckley 2008). The linkages between final good manufacturers and the intermediate good producers are important for prosperous innovation (Hippel 1988; Riggs and Hippel 1994; Lee 1996). Descriptive evidence of R\&D cooperation between industries and within industries shows that inter-industry agreements are much more frequent than intra-industry agreements.

Upstream industry requires developing and producing the intermediate goods to meet the requirement of downstream which makes inter-industry spillovers inevitable. The bilateral exchanged information on new technology and materials helps $R \& D$ participating partners to adopt them quickly. Inter-industry spillovers are called vertical spillovers and usually are desirable and voluntary, whereas intra-industry spillovers known as horizontal spillovers often are undesirable and involuntary (Atallah, 2002). Peters (1995) shows that horizontal spillovers may increase or decrease R\&D, whereas vertical spillovers increase $R \& D$, profit, and welfare. According to d'Aspremont and Jacquemin (1988), Kamien et al. (1992), Suzumura (1992), and Yi (1996), if horizontal spillovers are sufficiently high, a horizontal R\&D cartel yields higher technological 
improvement and higher welfare, whereas vertical R\&D cartels yield higher welfare than horizontal R\&D cartels if horizontal spillovers between upstream firms are low.

Becker and Peters (1995) study the effect of R\&D-competition between two vertically related cooperation networks. They find that vertical spillovers not only stimulate the $R \& D$ process and competition between suppliers but also reduce the time of development and increase the probability for the retailers to be the first to introduce the new product to the market. Harhoff (1991), studies a two-industry model of R\&D where the upstream industry is a monopolist and supplies an intermediate good to oligopolistic downstream firms, which compete in quantity and quality enhancing R\&D. Downstream firms use the vertical spillovers as a substitute for their own $R \& D$. This helps them to reduce their R\&D costs, increase the quality of their products and increase their output which results in higher demand for the intermediate good. Thus, both industries benefit from vertical spillovers.

Atallah (2002) and Ishii (2006) study cooperative R\&D between vertically related industries with two suppliers and two retailers where both industries provide a homogeneous good. Atallah considers four possibilities for firms: to cooperate horizontally, vertically, generally, or not to cooperate at all. He finds that no setting uniformly dominates other settings in terms of $R \& D$, yet general cooperation yields the highest R\&D and welfare when spillovers are high. Ishii compares vertical R\&D cartels, horizontal R\&D cartels, vertical research joint ventures (RJVs) and non-cooperative R\&D. He shows that vertical RJV yields the highest technological improvement. Although they considered a homogeneous product for both industries, in the real world a large variety of differentiated products are produced using a homogeneous intermediate 
good. Indeed, product differentiation affects competition between firms and consequently affects firms' strategies of output and innovation efforts. Indeed, there is no paper to analyse in what extent product differentiation may affect firms' strategies of $R \& D$ in vertically related market.

De Bondt et al. (1992) study a symmetric two-stage setting in which n firms sequentially choose cost-reducing R\&D investment. They show that product differentiation is important in a cost-reducing game with spillovers. Product differentiation affects rivals' reactions with quantity competition, such that the knowledge spillovers of cost-reducing $\mathrm{R} \& \mathrm{D}$ are not inhibited as much as they would be, with homogeneous products. Thus, the benefit of cooperative R\&D depends not only on the information flows and the number of rivals but also on the degree of product differentiation.

This chapter completes Atallah's (2002) and Ishi's (2006) analysis by considering differentiated products where all previous studies deal with homogeneous goods in both industries. Although previous analyses studied the ranking of cooperation settings in terms of $\mathrm{R} \& \mathrm{D}$, there is no literature about the ranking of settings in terms of profitability. This chapter makes several contributions to the literature. First, this is the first paper which investigates the impact of product differentiation and $R \& D$ cooperation on innovation and welfare in vertically related industries where vertical and horizontal spillovers flow. Second, the chapter studies the impact of cooperative settings, spillovers and product differentiation on firms' behavior. Third, the chapter studies the strategic interaction of firms' decision on the R\&D investment. Lastly, the chapter studies the ranking of cooperation settings in terms of $\mathrm{R} \& \mathrm{D}$, and profitability in each industry. 
The model studied in this chapter incorporates two vertically related duopolistic industries with horizontal spillovers (within each industry) and vertical spillovers (between the two industries) in a three-stage game theoretical framework. The upstream industry provides a homogeneous intermediate good, whereas the downstream industry produces differentiated products. Firms invest in cost reducing R\&D output, under different cooperative structures and then compete in output. Three different types of cooperation are considered: no cooperation, horizontal cooperation and vertical cooperation.

The main findings of the chapter are summarized as follows. Vertical spillovers positively affect R\&D expenditures directly due to their cost reducing effect and indirectly due to their effect on horizontal spillovers and cooperative structures. Horizontal spillovers may increase or decrease $R \& D$ investments with respect to their magnitude under different cooperation settings. Comparing cooperative structures in terms of R\&D shows that vertical cooperation setting dominates the others. Horizontal and vertical cooperation settings yield the same level of R\&D if and only if horizontal spillovers are perfect. Comparing cooperative structures in terms of profitability shows that no setting dominates the others. The comparison shows that retailers and suppliers may have different types of cooperation preferences under similar circumstances. The ranking of cooperation settings grounds on the sign and magnitudes of horizontal competitive externalities, vertical competitive externalities, and product differentiation. Product differentiation influences firms' behavior and affects the ranking of cooperative structures in terms of profitability. 
The chapter is organized as follows. Section 1.2 presents a relevant literature review of empirical studies. Section 1.3 provides and solves the model. The effects of spillovers and product differentiation on R\&D and welfare are studied in section 1.4. Section 1.5 examines the strategic interaction between firms' R\&D expenditures. Section 1.6 compares cooperation settings in terms of $R \& D$ and profitability. Section 1.7 discusses some policy related issues and conclusions.

\subsection{Literature Review}

The majority of empirical models that analysed $R \& D$ cooperation found a positive impact of cooperative R\&D on innovation (Brouwer and Kleinknecht, 1999; Vanhaverbeke et al., 2002). Powell and Grodal (2005) provide an extensive analysis showing that cooperative R\&D has a positive effect on a firm's innovation activity. However, a systematic study that would evaluate various types of innovation cooperation simultaneously is lacking. Darby et al. (2003) show that there is a positive effect of R\&D cooperation on patenting by U.S. firms. Kremp and Mairesse (2004) show that cooperative $R \& D$ significantly and positively affects innovation by French firms. Lokshin et al. (2008) state that R\&D cooperation of German firms has a positive effect on innovation while engaging in diversified R\&D cooperation settings (different types of partners) affects innovation more significantly and positively. Belderbos et al. (2004) show that horizontal cooperation of Dutch firms and cooperation with universities and research institutes positively affect firm performance. Aschhoff and Schmidt (2008) analyse the annual German innovation survey. They find cooperation with competitors is profitable in terms of cost reductions. Lööf and Heshmati (2002) study the evidence of cooperative R\&D in the Swedish manufacturing industry and find that cooperation with 
competitors positively affects innovation output, while cooperation with suppliers restricts it. Winters and Stam (2007) show that R\&D cooperation has a positive relationship with product and process innovation of high technology SMEs. Arvanitis and Bolli (2009) study the determinants and the effects of R\&D cooperation on innovation at the firm level in Belgium, Germany, Norway, Portugal, and Switzerland. They find that international cooperation and cooperation with universities have a positive effect on innovation in three out of five countries.

Adams and Mircea (2004) show that research joint ventures increase innovation by U.S. firms. Röller et al. (1997) analyse the determinants of RJV formation in the U.S. and find that cost-sharing and technological similarities significantly affect firms' $R \& D$ cooperation strategies. Firms' incentive to join an RJV in vertically related industries significantly increases if innovation between upstream and downstream firms is complementarity and the technology involved in these sectors is similar. Dyer and Ouchi (1993) show that consulting and exchanging information between a downstream firm and an upstream firm have a mutual impact on improving the productivity of both firms. They show that vertical cooperation is a significant advantage of Japanese firms' style partnership, which leads them to succeed in the global marketplace. Sako (1995) shows that in the Japanese automotive industry, suppliers with superior (inferior) technological efficiencies prefer vertical (horizontal) technological cooperation.

The importance of knowledge spillovers for research success is stressed by most of the empirical models. Indeed, the effects of innovation complementarities, absorptive capacities, and technical similarities reinforce the efficiency of spillovers. Clark et al. (1987) study the impact of vertical spillovers on product development performance in the 
auto industry, where products are differentiated. They find that saving time and engineering hours are one of the most important effects of vertical cooperation on product development. Harabi (2010) finds that there is a significant impact of vertical R\&D cooperation on innovation in German manufactures. The evidence shows that the impact of informal leakage of technological knowledge on firms' innovative behaviour is stronger than formal ones such as joint venture or contractual R\&D cooperation. The study also highlights the importance of other key determinants of innovative activities, such as technological opportunities, appropriability conditions, and market demand. The evidence shows that the information produced by and transferred from upstream to downstream firms is a substitute for a downstream firm's own innovation. Cockburn and Henderson (1996) analyse the effects of spillovers on research productivity in the pharmaceutical industry and find that knowledge spillovers between research groups within and across pharmaceutical companies are important determinants of research productivity. Cassiman and Veugelers $(1998,1999)$ study the Belgian manufacturing industry and find that firms develop their R\&D strategies to maximize their benefit from the technological information flows. They find that most of the cooperative agreements are vertical or with research institutes, driven by innovation complementarities between these industries and the search for external knowledge.

Most of the empirical analyses indicate a positive effect, and a mutual reinforcing of internal R\&D activities, as well as indicating absorption capacity, and external sources of R\&D. Moreover, it is not only that R\&D cooperation stimulates a firm's innovation activity but also, the firm's innovation activity stimulates its R\&D cooperation (Powell and Grodal, 2005). Hou and Mohnen (2011) studied the complementarity of in-house 
$R \& D$ and external technology acquisition in Chinese manufacturing firms. They find that firms tend to combine internal and external sources of technology and thereby, R\&D cooperation has a significant positive effect on internal R\&D if and only if firms have sufficient absorptive capacity. Fitjar and Rodriguez-Pose (2011) study the sources of firm product and process R\&D in a large sample of Norwegian firms and find that engaging in R\&D cooperation positively affects firms' innovation. Indeed, cooperation with extraregional partners is more effective to innovation than cooperation with local partners. Becker and Dietz (2004) also study cooperative R\&D in the German manufacturing industry and show that vertical R\&D cooperation enhances the probability of developing new products. They show that firms tend to cooperate in $R \& D$ to complement the internal resources in the innovation process. Svetina and Prodan (2008) study the contribution of different knowledge sources of R\&D activities from a sample of Slovenian firms. They find that firms strengthen internal knowledge with external knowledge, mainly obtained from firms and institutions in the global environment. The process of globalization, the convergence of consumer preferences, the pace and scope of technological change, the increasing similarity of technologies across countries, and the cross-fertilisation of technology between industries boost cooperative $\mathrm{R} \& \mathrm{D}$, which mitigates costs and risks associated with R\&D investments (Narula 2003; Veugelers 1997).

Furthermore, there are studies that find no or little evidence for a positive impact of R\&D cooperation on firms' innovation. Kemp et al. (2003) study a large sample of Dutch SMEs and find no significant effect of R\&D cooperation on innovation. Janz et al. (2003) study the impact of R\&D cooperation of German and Swedish innovative firms on their innovation output. They also find no significant effect of R\&D cooperation on 
innovation. Frenz and Ietto-Gillies (2009) study a sample of U.K. enterprises. They find that although innovation is affected by intra-firm knowledge sources, own-generation, and bought-in $\mathrm{R} \& \mathrm{D}$, the benefits of joint innovation in the form of cooperation are less clear.

The results of both the theoretical and empirical studies show that the effect of product substitutability on firms' strategies of output and R\&D has not been explored which implies more theoretical analysis is required. In the next section, the proposed model is presented.

\subsection{The Model}

There are two identical upstream firms, suppliers (shown by $s_{1}, s_{2}$ ), providing a homogeneous input. There are two symmetric downstream firms, retailers (shown by $r_{1}, r_{2}$ ), transforming the homogeneous input into the final product using a (one to one) fixed coefficient technology and competing a la Cournot. The final good may be differentiated. A consumer uses both of the two goods, $r_{1}$ and $r_{2}$. Undertaking no R\&D, suppliers acquire a constant unit production cost of $s$ and sell the input to retailers at a unit price of $t$, the wholesale price. Retailers pay the suppliers $t$ for each unit purchased and incur an additional internal production cost of $r$. Lastly, retailers sell the product to consumers at price $p$. Consumers consume goods $y_{r 1}$ and $y_{r 2}$ and maximize their utility function with respect to their budget constraint $\left(M=p_{1} y_{r 1}+p_{2} y_{r 2}+y_{0}\right)$ where $y_{0}$ is a numeraire. The consumer's utility is given by 


$$
U=a\left(y_{r 1}+y_{r 2}\right)-\frac{\left(y_{r 1+}^{2} y_{r 2}^{2}\right)}{2}-b y_{r 1} y_{r 2}+y_{0}
$$

where $y_{r i}$ denotes retailer $i$ 's output and $b \in[0,1]$ is an index indicating the degree of product substitutability ${ }^{1}$ (negatively related to product differentiation). Final goods are homogeneous if $b=1$, imperfect substitutes if $0<b<1$ and independent when $b=0$. Maximizing utility over $y_{r 1}$ and $y_{r 2}$ yields the retailers' demand functions. Thus, retailers face the following linear inverse demand system.

$$
p_{i}\left(y_{r i}, y_{r j}\right)=a-y_{r i}-b y_{r j} \quad i=1,2
$$

Firms can undertake cost reducing R\&D activities. The dollar cost of $x$ units of $\mathrm{R} \& \mathrm{D}$ for firm $i$ is $u x_{i}^{2}$, where $x_{i}$ represents the R\&D output of firm $i$, and $u>0$ is a cost parameter. Assuming that $u$ is sufficiently high for the profit function to be concave, sufficiently low for firms to undertake strictly positive amounts of R\&D. The total R\&D output is denoted $X$.

$$
X=x_{r 1}+x_{r 2}+x_{s 1}+x_{s 2}
$$

Each unit of R\&D conducted by a firm reduces its own cost by one dollar, reduces the cost of its competitor by $h$ dollars (horizontal spillovers) and reduces the cost of each firm in the other industry by $v$ dollars (vertical spillovers), $h, v \in[0,1] . h$ and $v$ can be different for many factors such as different absorptive capacities, different technological similarities, the different efficiency of communication channels, etc. The unit cost for downstream firm $i$ is:

\footnotetext{
${ }^{1}$ Note that $b$ is different from the slope of the demand curve.
} 


$$
c_{r i}=t+r-x_{r i}-h x_{r j}-v\left(x_{s 1}+x_{s 2}\right) \quad i=1,2
$$

The unit cost of an upstream firm is:

$$
c_{s i}=s-x_{s i}-h x_{s j}-v\left(x_{r 1}+x_{r 2}\right) \quad i=1,2
$$

The cost functions show that the final cost of each firm depends on the R\&D choices of all firms. Suppliers and retailers mutually benefit from R\&D activities of one another through vertical spillovers, while competitors benefit from R\&D investments of each other through horizontal spillovers. Higher R\&D leads to lower cost and consequently higher output. Moreover, higher output increases the value of R\&D to a firm since more units of output benefit from the cost reduction effects.

To satisfy the following non-negativity constraints, parameters are assumed to be as follows:

$$
\begin{aligned}
& r>x_{r 1}+h x_{r 2}+v\left(x_{s 1}+x_{s 2}\right) \\
& s>x_{s 1}+h x_{s 2}+v\left(x_{r 1}+x_{r 2}\right)
\end{aligned}
$$

These constraints ensure that production costs after undertaking R\&D are strictly positive.

This game has three stages. In the first stage, each firm decides on its R\&D simultaneously. In the second stage, upstream firms choose their output competing a la Cournot, anticipating the derived demand curve of the downstream industry. In the third stage, downstream firms choose their output levels competing a la Cournot, taking the wholesale price as given. 


\subsubsection{Output Stage}

The game begins with the third stage where retailers choose their output to maximize their own profit non-cooperatively.

\subsubsection{Third Stage}

In the third stage, retailer's problem is:

$$
\max _{y_{r i}} \pi_{r i}=\left(p_{i}\left(y_{r i}, y_{r j}\right)-c_{r i}\right) y_{r i}-u x_{r i}^{2} \quad i=1,2
$$

Given that retailers are symmetric, they have symmetrical behavior. Maximizing and solving the two f.o.c. simultaneously yields:

$$
\begin{array}{ll}
y_{r i}=\frac{(2-b)\left[(a-r-t)+v\left(x_{s 1}+x_{s 2}\right)\right]+(2-b h) x_{r i}-(b-2 h) x_{r j}}{\left(4-b^{2}\right)} & i=1,2 \\
p_{i}=\frac{(2-b)\left[a+(1+b)\left(r+t-v\left(x_{s 1}+x_{S 2}\right)\right)\right]-\left[\left(2-b^{2}-b h\right) x_{r i}+\left(b+2 h-b^{2} h\right) x_{r j}\right]}{\left(4-b^{2}\right)} & i=1,2
\end{array}
$$

Total output is the sum of downstream firms' output, $Y=y_{r 1}+y_{r 2}$.

From Eq. (1.3.2), the inverse demand curve of suppliers is derived as:

$$
t\left(y_{s i}, y_{s j}\right)=\frac{(1+h)\left(x_{r 1}+x_{r 2}\right)-(2+b)\left(y_{s i}+y_{s j}\right)+2\left[(a-r)+v\left(x_{s i}+x_{s j}\right)\right]}{2} \quad i=1,2
$$

\subsubsection{Second Stage}

In the second stage, each supplier $i$ non-cooperatively chooses its own output, $y_{s i}$, to maximize its profit considering the derived inverse demand of retailers, Eq.(1.3.3). Thus, supplier $i$ solves the following problem: 


$$
\max _{y_{s i}} \pi_{s i}=\left(t\left(y_{s i}, y_{s j}\right)-c_{s i}\right) y_{s i}-u x_{s i}^{2} \quad i=1,2
$$

Since suppliers are identical and produce a homogeneous intermediate good, they will hold identical positions ex post. Maximizing and solving the two f.o.c. yields:

$$
y_{s i}=\frac{\left.2(a-r-s)+(1+h+2 v)\left(x_{r 1}+x_{r 2}\right)+2(2-h+v) x_{s i}+2(2 h+v-1) x_{s j}\right)}{3(2+b)} \quad i=1,2
$$

Considering that each unit purchased from suppliers is transformed into one unit provided by retailers, total output is the same for upstream and downstream industries. Thus, total output is:

$$
Y=\frac{2\left[2 a-2 r-2 s+(1+h+2 v)\left(x_{r 1}+x_{r 2}\right)+(1+h+2 v)\left(x_{s 1}+x_{s 2}\right)\right]}{3(2+b)}
$$

and the final price is:

$$
p=\frac{a(4+b)+2(1+b)(r+s)-(1+b)(1+h+2 v)\left(x_{r 1}+x_{r 2}\right)-(1+b)(1+h+2 v)\left(x_{s 1}+x_{s 2}\right)}{3(2+b)}
$$

where the wholesale price charged by suppliers is:

$$
t=\frac{2(a-r+2 s)+(1+h-4 v)\left(x_{r 1}+x_{r 2}\right)-2(1+h-v)\left(x_{S 1}+x_{S 2}\right)}{6}
$$

\subsubsection{R\&D Stage}

In the first stage of the game, all firms choose their R\&D investments simultaneously. To capture the variety of cooperative structures, three scenarios in the first stage is considered. The first scenario is non-cooperative $\mathrm{R} \& \mathrm{D}(N C)$, so that each firm chooses its $R \& D$ to maximize its own profit. The second scenario is horizontal cooperative $R \& D$ (HC) where firms cooperate with their competitors. The third scenario is vertical 
cooperative $\mathrm{R} \& \mathrm{D}(V C)$, in which suppliers (retailers) cooperate with retailers (suppliers).

Denote the R\&D set of all firms as $\beta \equiv\left\{x_{r 1}, x_{r 2}, x_{s 1}, x_{s 2}\right\}$. The profit of a downstream firm can be rewritten as

$$
\pi_{r i}(\beta)=\left[p_{i}(\beta)-c_{r i}(\beta)\right] y_{r i}(\beta)-u x_{r i}^{2} \quad i=1,2
$$

and the profit of an upstream firm is:

$$
\pi_{s i}(\beta)=\left[t(\beta)-c_{s i}(\beta)\right] y_{s i}(\beta)-u x_{s i}^{2} \quad i=1,2
$$

Therefore, welfare is also a function of the $\mathrm{R} \& \mathrm{D}$ set since $W(\beta)=\left(\pi_{r 1}(\beta)+\pi_{r 2}(\beta)+\right.$ $\left.\pi_{s 1}(\beta)+\pi_{s 2}(\beta)\right)+C S^{2}$

In the first stage, under $N C$ each firm determines its $\mathrm{R} \& \mathrm{D}$ to maximize its own profit. Each retailer solves the following problem:

$$
\max _{x_{r i}} \pi_{r i}(\beta) \quad i=1,2
$$

while each supplier faces the following problem:

$$
\max _{x_{s i}} \pi_{s i}(\beta) \quad i=1,2
$$

Maximizing and simultaneous solving the four f.o.c. of Eqs. (1.3.5) and (1.3.6), we obtain research efforts under $N C$ by each retailer and supplier:

$$
\begin{aligned}
& \quad x_{r i}^{N C}= \\
& \frac{(a-r-s)[2(5-h+4 v)-b(5 h+4 v-1)]}{\left(72 u-26-2 h(8-5 h)-9 b^{3} u-68 v+4 h v-32 v^{2}+b\left[(h(4+5 h)-1)+36 u+2 v+14 h v+8 v^{2}\right]-2 b^{2}\left[h^{2}+9 u+h(v-1)-\left(2+5 v+2 v^{2}\right)\right]\right.} \\
& \\
& { }^{2} \text { Consumer surplus is defined as } C S=U\left(y_{0}, y_{r 1}, y_{r 2}\right)-\left(p_{1} y_{r 1}+p_{2} y_{r 2}+y_{0}\right) .
\end{aligned}
$$




$$
x_{s i}^{N C}=
$$

$\frac{2\left(4-b^{2}\right)(a-r-s)(2-h+v)}{\left(72 u-26-2 h(8-5 h)-9 b^{3} u-68 v+4 h v-32 v^{2}+b\left[(h(4+5 h)-1)+36 u+2 v+14 h v+8 v^{2}\right]-2 b^{2}\left[h^{2}+9 u+h(v-1)-\left(2+5 v+2 v^{2}\right)\right]\right.}$

$i=1,2$

Under $H C$, competitors in each industry choose their R\&D to maximize their joint profits. Thus, in the downstream industry, retailers solve

$$
\max _{x_{r 1}, x_{r 2}}\left(\pi_{r 1}(\beta)+\pi_{r 2}(\beta)\right)
$$

and in the upstream industry, suppliers solve

$$
\max _{x_{s 1}, x_{s 2}}\left(\pi_{s 1}(\beta)+\pi_{s 2}(\beta)\right)
$$

Maximizing and simultaneous solving the four f.o.c. of Eqs. (1.3.7) and (1.3.8), we obtain research efforts under $H C$ :

$$
\begin{array}{ll}
x_{r i}^{H C}=\frac{4(a-r-s)(1+h+2 v)}{\left(9 b^{2} u-8(h+2 v)^{2}-4(2+4 h-9 u+8 v)-2 b\left(h^{2}-18 u+(1+2 v)^{2}+2 h(1+2 v)\right)\right)} & i=1,2 \\
x_{s i}^{H C}=\frac{2(a-r-s)(1+h+2 v)(2+b)}{\left(9 b^{2} u-8(h+2 v)^{2}-4(2+4 h-9 u+8 v)-2 b\left(h^{2}-18 u+(1+2 v)^{2}+2 h(1+2 v)\right)\right)} & i=1,2
\end{array}
$$

Under $V C$ each retailer cooperates with one supplier. Given that suppliers are identical and produce a homogeneous intermediate good, it is insignificant which retailer cooperates with each supplier. Without loss of generality, let $r_{i}$ cooperates with $s_{i}(i=1,2)$ undertake their R\&D to maximize their joint profits.

$$
\max _{x_{r i}, x_{s i}}\left(\pi_{r i}(\beta)+\pi_{s i}(\beta)\right) \quad i=1,2
$$


Following the maximization of Eq (9), we obtain research efforts under $V C$ :

$$
\begin{aligned}
& x_{r i}^{V C}= \\
& \frac{(a-r-s)\left[14+b-b^{2}+h\left(2-5 b-b^{2}\right)+2 v\left(8-2 b-b^{2}\right)\right]}{72 u-34-32 h-9 b^{3} u-100 v+2(h-16 v)(h+2 v)+b^{2}\left[5+4 h-h^{2}-18 u+2 v(7+h)+8 v^{2}\right]+b\left[1+h(8+7 h)+36 u+10 v+22 h v+16 v^{2}\right]} \\
& x_{s i}^{V C}=\underbrace{(a-r-s)(4-2 b)[5+2 b-h(1+b)+v(b+4)]} \quad i=1,2 \\
& \frac{\left(h u-34-32 h-9 b^{3} u-100 v+2(h-16 v)(h+2 v)+b^{2}\left[5+4 h-h^{2}-18 u+2 v(7+h)+8 v^{2}\right]+b\left[1+h(8+7 h)+36 u+10 v+22 h v+16 v^{2}\right]\right.}{i=1,2}
\end{aligned}
$$

\subsection{The Impacts of Spillovers and Product Differentiation on R\&D and Welfare}

This section addresses the effects of vertical and horizontal spillovers on innovation, output, and welfare where products are differentiated and cooperative ${ }^{3}$ structures are $^{-}$ varied.

Proposition 1. The impact of vertical spillovers on $R \& D$, output and welfare are always positive.

An increase in vertical spillovers reduces production costs of all firms under any types of cooperation. Retailers benefit from higher $v$ due to its cost reduction effect and through access to a greater quantity of input. Table 1.1 shows the results of Proposition 1.

$$
\partial c_{r i}(h, v, \beta(h, v))^{4} / \partial v<0, \text { while } \partial \pi_{r i} / \partial c_{r i}<0 \text { and } \partial \pi_{r i} / \partial y_{r i}>0
$$

\footnotetext{
${ }^{3}$ All the detailed analysis and proofs are in the appendix.
} 


$$
\begin{array}{r}
i=1,2 \\
\partial c_{s i}(h, v, \beta(h, v))^{5} / \partial v<0, \text { while } \partial \pi_{s i} / \partial c_{s i}<0 \text { and } \partial \pi_{s i} / \partial y_{s i}>0 \\
i=1,2
\end{array}
$$

This encourages them to increase their output and thereby, increase their demand for the intermediate good which benefits suppliers as well. Higher output increases the net benefit of $R \& D$, induces a further increase in $R \& D$. Higher output is also associated with higher consumer surplus and higher welfare.

Conclusively, an increase in vertical spillovers always increases innovation, output, and welfare. These findings are consistent with those of Peters (1995), Steurs (1994, 1995) and Atallah (2002); however, they only studied homogeneous goods.

Proposition 2. The impact of vertical spillovers on firms' behavior depends on the magnitudes of product substitutability and horizontal spillovers in each equilibria.

Although higher $v$ increases $R \& D$ by all firms, the results show that when final goods are substitutes, retailers increase their R\&D less than suppliers. However, firms in both industries tend to increase their R\&D equally when goods are independent.

Higher $b$ increases competition between retailers, reduces $p$ (a direct and an indirect effect, $\partial p\left(b,(\beta(b))^{6} / \partial b<0\right)$. Higher $b$ changes the position (the intercept and the slope

$$
\begin{gathered}
{ }_{4} \frac{\partial c_{r i}(h, v, \beta(h, v))}{\partial v}=\left(\frac{\partial c_{r i}(h, v, \beta(v))}{\partial v}+\frac{\partial c_{r i}(h, v, \beta(h, v))}{\partial t(h, v, \beta(v))} \frac{\partial t(h, v, \beta(h, v))}{\partial v}+\sum_{i=1,2} \frac{\partial c_{r i}(h, v, \beta(v))}{\partial x_{r i}(h, v)} \frac{\partial x_{r i}(h, v)}{\partial v}+\right. \\
\left.\sum_{i=1,2} \frac{\partial c_{r i}(h, v, \beta(v))}{\partial x_{s i}(h, v)} \frac{\partial x_{s i}(h, v)}{\partial v}\right) \\
5 \frac{\partial c_{s i}(h, v, \beta(h, v))}{\partial v}=\left(\frac{\partial c_{s i}(h, v, \beta(h, v))}{\partial v}+\sum_{i=1,2} \frac{\partial c_{s i}(h, v, \beta(h, v))}{\partial x_{r i}(h, v)} \frac{\partial x_{r i}(h, v)}{\partial v}+\sum_{i=1,2} \frac{\partial c_{s i}(h, v, \beta(h, v))}{\partial x_{s i}(h, v)} \frac{\partial x_{s i}(h, v)}{\partial v}\right)
\end{gathered}
$$


through $x_{r i}$ and $x_{s i}$ ) of the demand curve of the retailers. Indeed, the convexity of the profit function induces retailers to produce less output when the price is low. Thus, retailers reduce their output, their $\mathrm{R} \& \mathrm{D}$ and their demand for the intermediate good. Although higher product substitutability reduces the demand of the intermediate good, it increases the wholesale price $\left(\partial t(\beta(b))^{7} / \partial b>0\right)$ which mitigates the negative effect of $b$ on suppliers' profit. This reflects the power of suppliers. Indeed, retailers suffer from an increase in $b$ more than suppliers. Finally, the sum of the positive effects of higher $v$ and the negative effects of $b$ on the firms' profits induces retailers to increase their R\&D less than suppliers.

Under $N C$ and $V C$ firms are worried about the information leakage to their competitor. When products are independent, retailers may be neglected to $h$, whereas suppliers providing a homogeneous intermediate good are concerned about the flow of the technological information to their competitors. Conclusively, when $h$ is sufficiently high and goods are independent an increase in $v$ induces retailers and suppliers to increase their R\&D equally.

Although under $H C$ firms internalize $h$, an increase in $v$ induces suppliers and retailers to increase their R\&D equally when goods are independent. Suppliers increase their R\&D more than retailers when goods are substitutes since $b$ has a significant negative effect on retailers' net benefit of R\&D.

$$
\begin{aligned}
& { }_{6} \frac{\partial p(b,(\beta(b))}{\partial b}=\left(\frac{\partial p(b,(\beta(b))}{\partial b}+\sum_{i=1,2} \frac{\partial p(b,(\beta(b))}{\partial x_{r i}(b)} \frac{\partial x_{r i}(b)}{\partial b}+\sum_{i=1,2} \frac{\partial p(b,(\beta(b))}{\partial x_{s i}(b)} \frac{\partial x_{s i}(b)}{\partial b}\right) \\
& { }^{7} \frac{\partial t(\beta(b))}{\partial b}=\left(\sum_{i=1,2} \frac{\partial t(\beta(b))}{\partial x_{r i}(b)} \frac{\partial x_{r i}(b)}{\partial b}+\sum_{i=1,2} \frac{\partial t(\beta(b))}{\partial x_{s i}(b)} \frac{\partial x_{s i}(b)}{\partial b}\right)
\end{aligned}
$$


(1) Under any type of cooperation, $\frac{\partial x_{r i}}{\partial v}<\frac{\partial x_{s i}}{\partial v}$ if $0<b \leq 1$

(2) Under NC and VC, $\frac{\partial x_{r i}}{\partial v}=\frac{\partial x_{s i}}{\partial v}$ if $b=0$ and $h=1$

(3) Under HC, $\frac{\partial x_{r i}}{\partial v}=\frac{\partial x_{s i}}{\partial v}$ if $b=0$

(4) Under VC, $\frac{\partial x_{r i}}{\partial v}=\frac{\partial x_{s i}}{\partial v}$ if $b=1$

Moreover, under $V C$ inter-industry partners internalize $v$ which boosts the benefit of its cost reduction effects, induces suppliers to increase their R\&D more than retailers when goods are independent or imperfect substitutes. When both industries produce a homogeneous product, their marginal gain of $R \& D$ is equal. Thus, they increase their R\&D equally.

\section{Proposition 3.}

(i) An increase in horizontal spillovers reduces $R \& D$ by all firms under $N C$, increases $R \& D$ by all firms under $H C$, and may increase or decrease $R \& D$ under $V C$.

(ii) An increase in horizontal spillovers increases welfare and output under HC and VC. However, it has an ambiguous effect on welfare and output under NC.

Under $N C$, an increase in $h$ has a negative impact on R\&D of all firms. Higher $h$ reduces the net benefit of $R \& D$ since it reduces the rival's cost which is not in favor of any non-cooperative chain. Thus, firms in both industries reduce their R\&D. The 
reduction in R\&D increases firms' production costs ${ }^{8}$ and consequently affects firms' output and prices ${ }^{9}$. Additionally, higher $b$ boosts competition between retailers, reduces the price and induces them to reduce their output due to the convexity of the profit function which requires firms to decrease (increase) their output when the price decreases (increases). Ultimately, the sum of these two effects determines the level of output. Higher output is associated with higher consumer surplus and higher welfare. Thus, consumer surplus and welfare are reduced when the sum of effects of $h$ and $b$ on output is negative; otherwise, they are increased. Table 1.2 summarizes the results of Proposition 3.

Under $H C$, firms within each industry decide on their R\&D cooperatively and maximize their joint profits. Thus, intra-industry firms, internalizing $h$, may not worry about the information leakage to the rival, benefit from higher $h$ and increase their R\&D. Higher R\&D is associated with lower production cost which induces firms to increase

$$
\begin{aligned}
& 8 \frac{\partial c_{r i}(h, \mathrm{v}, \beta(h, \mathrm{v}))}{\partial h}=\left(\frac{\partial c_{r i}(h, \mathrm{v}, \beta(h, v))}{\partial h}+\frac{\partial c_{r i}(h, v, \beta(h, v))}{\partial t(h, v, \beta(h, v))} \frac{\partial t(h, v, \beta(h, v))}{\partial h}+\sum_{i=1,2} \frac{\partial c_{r i}(h, v, \beta(h, v))}{\partial x_{r i}(h, v)} \frac{\partial x_{r i}(h, v)}{\partial h}+\right. \\
& \left.\quad \sum_{i=1,2} \frac{\partial c_{r i}(h, v, \beta(h, v))}{\partial x_{s i}(h, v)} \frac{\partial x_{s i}(h, v)}{\partial h}\right) \\
& \text { and } \frac{\partial c_{s i}(h, v, \beta(h, v))}{\partial h}= \\
& \qquad\left(\frac{\partial c_{s i}(h, v, \beta(h, v))}{\partial h}+\sum_{i=1,2} \frac{\partial c_{s i}(h, v, \beta(h, v))}{\partial x_{r i}(h, v)} \frac{\partial x_{r i}(h, v)}{\partial h}+\sum_{i=1,2} \frac{\partial c_{s i}(h, v, \beta(h, v))}{\partial x_{s i}(h, v)} \frac{\partial x_{s i}(h, v)}{\partial h}\right) \\
& 9 \frac{\partial p(h, v, \beta(h, v))}{\partial h}=\left(\frac{\partial p(h, v,(\beta(h, v))}{\partial h}+\sum_{i=1,2} \frac{\partial p(h, v,(\beta(h, v))}{\partial x_{r i}(h, v)} \frac{\partial x_{r i}(h, v)}{\partial h}+\sum_{i=1,2} \frac{\partial p(h, v,(\beta(h, v))}{\partial x_{s i}(h, v)} \frac{\partial x_{s i}(h, v)}{\partial h}\right) \\
& \text { and } \frac{\partial t(h, v, \beta(h, v))}{\partial h}=\left(\frac{\partial t(h, v,(\beta(h, v))}{\partial h}+\sum_{i=1,2} \frac{\partial t(h, v,(\beta(h, v))}{\partial x_{r i}(h, v)} \frac{\partial x_{r i}(h, v)}{\partial h}+\sum_{i=1,2} \frac{\partial t(h, v(\beta(h, v))}{\partial x_{s i}(h, v)} \frac{\partial x_{s i}(h, v)}{\partial h}\right)
\end{aligned}
$$


their output. Higher output is associated with higher consumer surplus and higher welfare.

Under $V C$, higher $h$ reduces the production cost of the rival and thereby, reduces the net benefit of R\&D to the firm. From the retailers' perspective, when goods are independent, the information leakage is negligible. Thus, retailers increase their R\&D since the private gains from R\&D offset the negative effects of higher $h$. As $b$ increases, competition between retailers becomes intense, the negative effect of outgoing information to the rival dominates the positive effect of incoming knowledge spillovers which induces retailers to reduce their $\mathrm{R} \& \mathrm{D}$ when $h$ is high and $v$ is low. However, retailers increase their R\&D when $v$ is high enough to mitigate the negative impact of $h$. An increase in $h$ affects suppliers significantly since they produce a homogeneous input and are concerned about the information leakage to their competitor. Thus, suppliers increase their R\&D when $v$ is high enough to mitigate the negative effects of $h$; otherwise, they reduce their R\&D. $V C$ internalizes $v$ which boosts its cost reduction effects, offsets the sum of the effects of higher $h$ and $b$ on output, and thereby induces firms to increase their output. Higher output is associated with higher consumer surplus and higher welfare.

Proposition 4. The impact of horizontal spillovers on firms' behavior depends on the magnitudes of horizontal spillovers and product substitutability in each equilibria.

Although higher $h$ decreases R\&D in both industries under $N C$, the results show that when final goods are independent, retailers decrease their R\&D less than suppliers. This result shows that suppliers producing a homogeneous good are worried about the information leakage to their competitors, while retailers providing independent products 
are neglected about higher $h$. Although firms' profits are negatively affected by $b$, the effects on retailers' profits (through lower output and higher $t$ ) are more than the effects on suppliers' profits (through lower demand, but higher $t$ ). Thus, higher $h$ reduces retailers' profit more than suppliers' and induces retailers to reduce their R\&D more than suppliers when goods are substitutes.

(1) Under $N C$, $\left|\frac{\partial x_{r i}}{\partial h}\right|<\left|\frac{\partial x_{s i}}{\partial h}\right|$ if $b=0$

(2) Under $N C,\left|\frac{\partial x_{r i}}{\partial h}\right|>\left|\frac{\partial x_{s i}}{\partial h}\right|$ if $b>0$

Under $H C$, higher $h$ increases R\&D by all firms. Competitors internalize $h$ and benefit from higher $h$. The results show that when final goods are independent suppliers and retailers increase their $R \& D$ equally since their marginal benefit from $R \& D$ is equal. However, as $b$ increases, suppliers increase their R\&D more than retailers. This result reflects the sum of effects of $b$ and $h$ along with the effects of cooperative structures on firms' behavior. Although higher $h$ increases firms' benefit through its cost reduction effect (under $H C$ ), higher $b$ reduces firms' net benefit of R\&D. Although the sum of the effects of $h$ and $b$ on firms' benefit is positive, the effects on suppliers' are more than retailers'. Thus, when goods are substitutes, suppliers increase their R\&D more than retailers.

(1) Under $H C, \frac{\partial x_{r i}}{\partial h}=\frac{\partial x_{s i}}{\partial h}$ if $b=0$

(2) Under $H C, \frac{\partial x_{r i}}{\partial h}<\frac{\partial x_{s i}}{\partial h}$ if $b>0$

Under $V C$, retailers and suppliers internalize $v$. Internalizing $v$ mitigates the negative effects of $h$ on firms' marginal profit of R\&D. When goods are independent, retailers are neglected to $h$. Thus, an increase in $h$ induces retailers to increase their R\&D. 
Suppliers providing a homogeneous input, are worried about the information leakage to their competitors. Therefore, suppliers increase their R\&D only if $h$ is sufficiently low and $v$ is high enough; otherwise, they reduce their R\&D. When goods are imperfect substitutes, competition between retailers is severe which affects retailers' strategies of output, and thereby affects suppliers. Suppliers providing a homogeneous input are worried about the flow of knowledge spillovers to their competitors. Indeed, an increase in $h$ reinforces these effects, such that suppliers reduce their R\&D when $v$ is not high enough to mitigate the negative effects of $h$. Conclusively, an increase in $h$ induces retailers to increase their R\&D more than suppliers when goods are imperfect substitutes. When goods are homogenous, inter-industry firms' net benefit of R\&D is equal, and thereby higher $h$ induces them to increase (decrease) their R\&D equally when $h$ is low (high) and $v$ is high enough (low).

(1) Under $V C, \frac{\partial x_{r i}}{\partial h}>\frac{\partial x_{s i}}{\partial h}$ if $b=0, h$ is sufficiently low and $v$ is high enough; otherwise, $\frac{\partial x_{s i}}{\partial h}<0$

(2) Under $V C, \frac{\partial x_{r i}}{\partial h}>\frac{\partial x_{s i}}{\partial h}$ if $b>0$

(3) Under $V C, \frac{\partial x_{r i}}{\partial h}=\frac{\partial x_{s i}}{\partial h}$ if $b=1$

\subsection{Strategic Interaction}

This section analyzes when R\&D expenditures are strategic complements or substitutes. As will be shown, the magnitudes of product substitutability, horizontal and vertical spillover affect R\&D and strategic interaction. 


\section{Proposition 5.}

(i) $x_{r i}$ and $x_{r j}$ are strategic complements if spillovers are high enough; otherwise, they are strategic substitutes.

(ii) $x_{s i}$ and $x_{s j}$ are strategic complements if spillovers are high enough; otherwise, they are strategic substitutes.

(iii) $x_{r i}$ and $x_{s i}$ are always strategic complements.

The result of Proposition 5 shows that R\&D expenditures by intra-industry firms are strategic complements when spillovers are high enough (parts $i$ and $i i)$. An increase in $\mathrm{R} \& \mathrm{D}$ by a retailer (supplier) reduces production costs of the rival, increases the marginal gain of $R \& D$ within the industry and induces the firm to increase its $R \& D$ $\left(\partial^{2} \pi_{r i} / \partial x_{r i} \partial x_{r j}>0\right.$ and $\left.\partial^{2} \pi_{s i} / \partial x_{s i} \partial x_{s j}>0\right)$. However, R\&D expenditures by intraindustry firms are strategic substitutes when spillovers are sufficiently low $\left(\partial^{2} \pi_{r i} / \partial x_{r i} \partial x_{r j}<0\right.$ and $\left.\partial^{2} \pi_{s i} / \partial x_{s i} \partial x_{s j}<0\right)$. In this case, higher R\&D expenditures of a retailer (supplier) have no significant impact on production costs of the rival, reduce the marginal benefit of R\&D within the industry and induce the firm to reduce its R\&D.

R\&D expenditures by inter-industry firms are always strategic complements (part iii). An increase in $\mathrm{R} \& \mathrm{D}$ expenditures by a retailer (supplier) reduces production costs of its input provider (its customer), increases the marginal profit of $R \& D$ and induces firms in both industries to increase their $\operatorname{R} \& \mathrm{D}\left(\partial^{2} \pi_{r i} / \partial x_{r i} \partial x_{s i}>0\right.$ and $\left.\partial^{2} \pi_{s i} / \partial x_{s i} \partial x_{r i}>0\right)$. 


\subsection{Comparison of Cooperative Structures}

In this section, cooperation settings are compared in terms of $R \& D$ and profitability. This comparison is essential to determine the appropriate choices of $R \& D$ cooperation with respect to associated technological improvement, profit, and welfare. This comparison helps firms to decide to cooperate with whom if they tend to engage in the cooperative R\&D. This also helps the regulator to introduce policies to encourage firms participating in a cooperative type associated with higher innovation and welfare.

Proposition 6. The ranking of cooperation settings in terms of $R \& D$ depends on the magnitudes of product substitutability and spillovers.

(i) $\quad\left(X_{V C}=X_{H C}\right)>X_{N C}$ iff $h=1$.

(ii) $X_{V C}>X_{N C}>X_{H C}$; otherwise $X_{V C}>X_{H C}>X_{N C}$.

Although ranking the cooperation settings in terms of $\mathrm{R} \& \mathrm{D}$ requires a numerical method for parameter values, the same results are attainable by an analytical study of the sign and magnitudes of competitive externalities internalized by each cooperative structure. Internalizing the effect of a firm's R\&D expenditures on the profit of other firms is the key for this analysis.

Horizontal competitive externalities $(H C E s)^{10}$ represent the marginal effect of a firm's $\mathrm{R} \& \mathrm{D}$ on the profit of its competitor $\left(H C E_{r i}{ }^{11}=\partial \pi_{r i}(\beta) / \partial x_{r j}\right.$ and $H C E_{s i}{ }^{12}=$

\footnotetext{
${ }^{10}$ HCEri (HCEsi) refers to horizontal competitive externalities of retailers (suppliers).
} 
$\partial \pi_{s i}(\beta) / \partial x_{s j}$ where $\left.i=1,2\right)$. HCEs are positive (negative) when an increase in R\&D by a firm increases (decreases) the profit of the competitor. Moreover, an increase in R\&D by a firm increases (decreases) the profit of its competitor when $h$ is high (low). $H C E_{r i}$ is negative if $(10+b) h+(8-4 b) v-(2+5 b)<0$ and $H C E_{s i}$ is negative if $(2 h+v-$ $1)<0$. Although $h$ and $v$ have positive effects on $H C E s$, product substitutability has a negative effect on them. The effect of $b$ on $H C E_{r i}$ is stronger than its effect on $H C E_{s i}$. Comparing industries' $H C E s$ shows that $H C E_{s i}>H C E_{r i}$, the difference decreases with $b$. $H C$ internalizes HCEs.

Vertical competitive externalities $(V C E s)^{13}$ represent the marginal effect of a firm's $\mathrm{R} \& \mathrm{D}$ on the profits of firms in the other industry $\left(V C E_{r i}{ }^{14}=\partial \pi_{r i}(\beta) / \partial x_{s i}\right.$ and $V C E_{s i}{ }^{15}=$ $\begin{aligned} 11 \frac{\partial \pi_{r i}(\beta)}{\partial x_{r j}}= & \frac{\partial \pi_{r i}(\beta)}{\partial y_{r i}(\beta)} \frac{\partial y_{r i}(\beta)}{\partial x_{r j}}+\frac{\partial \pi_{r i}(\beta)}{\partial p(\beta)} \frac{\partial p(\beta)}{\partial x_{r j}}-\frac{\partial \pi_{r i}(\beta)}{\partial c_{r i}(\beta)} \frac{\partial c_{r i}(\beta)}{\partial x_{r j}}= \\ & \frac{(10 h+8 v-2-b(5-h+4 v))\left(a-r-s+(1+h+2 v)\left(x_{r 1}+x_{r 2}\right)+(1+h+2 v)\left(x_{s 1}+x_{s 2}\right)\right.}{9(2-b)(2+b)^{2}}\end{aligned}$

$$
\begin{aligned}
12 \frac{\partial \pi_{s i}(\beta)}{\partial x_{s j}}= & \frac{\partial \pi_{s i}(\beta)}{\partial y_{s i}(\beta)} \frac{\partial y_{s i}(\beta)}{\partial x_{s j}}+\frac{\partial \pi_{s i}(\beta)}{\partial t(\beta)} \frac{\partial t(\beta)}{\partial x_{s j}}-\frac{\partial \pi_{s i}(\beta)}{\partial c_{s i}(\beta)} \frac{\partial c_{s i}(\beta)}{\partial x_{s j}}= \\
& \frac{2(2 h+v-1)\left(a-r-s+(1+h+2 v)\left(x_{r 1}+x_{r 2}\right)+(1+h+2 v)\left(x_{s 1}+x_{s 2}\right)\right)}{9(2+b)}
\end{aligned}
$$

${ }^{13}$ VCEri (VCEsi) refers to vertical competitive externalities of retailers (suppliers).

$$
\begin{aligned}
14 \frac{\partial \pi_{r i}(\beta)}{\partial x_{s i}}= & \frac{\partial \pi_{r i}(\beta)}{\partial y_{r i}(\beta)} \frac{\partial y_{r i}(\beta)}{\partial x_{s i}}+\frac{\partial \pi_{r i}(\beta)}{\partial p(\beta)} \frac{\partial p(\beta)}{\partial x_{s i}}-\frac{\partial \pi_{r i}(\beta)}{\partial c_{r i}(\beta)} \frac{\partial c_{r i}(\beta)}{\partial x_{s i}}= \\
& \frac{2(1+h+2 v)\left(a-r-s+(1+h+2 v)\left(x_{r 1}+x_{r 2}\right)+(1+h+2 v)\left(x_{s 1}+x_{s 2}\right)\right.}{9(2+b)^{2}}
\end{aligned}
$$


$\partial \pi_{s i}(\beta) / \partial x_{r i}$ where $\left.i=1,2\right)$. This externality is always positive, provided that higher R\&D of a firm always increases the benefits of its supplier (customer). Product substitutability has a negative effect on $V C E s$. The effect on $V C E_{r i}$ is stronger than it is on $V C E s_{i}$. Comparing industries' $V C E s$ shows that $V C E_{s i}=V C E_{r i}$ when goods are independent; otherwise $V C E_{s i}>V C E_{r i}$. Comparing HCEs and VCEs, shows that $V C E s \geq$ $H C E s$, such that they are equal when $h=1$.

Conclusively, internalizing a positive externality boosts $R \& D$, whereas internalizing a negative externality reduces R\&D. Thus, the cooperation setting which internalizes greater positive competitive externalities yields higher R\&D.

The first part of Proposition 6 states that $\left(X_{V C}=X_{H C}\right)>X_{N C}$ iff $h=1 . \quad V C$ intern-alizes $V C E s$ which are always positive and increase R\&D. No externality is internalized by $N C$. Thus, for any parameter values, $V C$ always yields higher $\mathrm{R} \& \mathrm{D}$ than $N C$ does. $H C$ internalizes $H C E s$ which may be positive or negative. If and only if $h$ is perfect $(h=1), V C E s=H C E s$ and thereby, $V C$ and $H C$ yield the same level of R\&D. However, $V C$ yields higher R\&D than $H C$ if $h<1$. Ultimately, comparing these settings shows that $\left(X_{V C}=X_{H C}\right)>X_{N C}$ when $h=1$.

Part $i i$ of Proposition 6 state that $X_{V C}>X_{N C}>X_{H C}$ when spillovers are low. Obviously, $V C$ yields the highest $\mathrm{R} \& \mathrm{D}$ by internalizing the positive $V C E s$ for any values of $h$ and $v$. Compare $N C$ and $H C$, in which $N C$ internalizes no externalities and $H C$

$$
\begin{aligned}
15 \frac{\partial \pi_{s i}(\beta)}{\partial x_{r i}}= & \frac{\partial \pi_{s i}(\beta)}{\partial y_{s i}(\beta)} \frac{\partial y_{s i}(\beta)}{\partial x_{r i}}+\frac{\partial \pi_{s i}(\beta)}{\partial t(\beta)} \frac{\partial t(\beta)}{\partial x_{r i}}-\frac{\partial \pi_{s i}(\beta)}{\partial c_{s i}(\beta)} \frac{\partial c_{s i}(\beta)}{\partial x_{r i}}= \\
& \frac{(1+h+2 v)\left(a-r-s+(1+h+2 v)\left(x_{r 1}+x_{r 2}\right)+(1+h+2 v)\left(x_{s 1}+x_{s 2}\right)\right)}{9(2+b)}
\end{aligned}
$$


internalizes $H C E s$ which can be positive or negative. When $h$ is sufficiently low, HCEs are negative. Internalizing these negative externalities reduces the joint profits and induces firms to decrease their R\&D. Therefore, when $h$ is sufficiently low $N C$ yields higher R\&D and $X_{V C}>X_{N C}>X_{H C}$ is observed. When $h$ is high, its externalities are positive. These positive HCEs are still less than the positive $V C E s$ for any value of the parameters. Internalizing the positive HCEs induces competitors to increase their R\&D and yields $X_{V C}>X_{H C}>X_{N C}$. Higher R\&D is associated with a higher output which reflects a higher value of cost reduction. Thus, we can conclude that the same ranking is observed for welfare.

Moreover, higher $b$ reduces competitive externalities, increases the required threshold of spillovers ${ }^{16}$ to turn $H C E s$ positive. Note that $V C E s$ are always positive and greater than HCEs. Thus, higher $b$ has no significant effect on the ranking of cooperation settings in terms of R\&D and just influences the required threshold of $h$ and $v$ to keep the ranking unchanged. Now, this question arises that whether firms tend to form a vertical cooperation voluntarily? Is $V C$ associated with the highest profit for all firms? To answer these questions we study the ranking of cooperation settings in terms of profitability. The following Proposition summarizes the ranking of cooperation settings in terms of profitability in each industry.

\section{Proposition 7.}

\footnotetext{
${ }^{16}$ For example: If $b=0,(13 h+8 v<5)$ then $X_{V C}>X_{N C}>X_{H C}$; otherwise $X_{V C}>X_{H C}>$ $X_{N C}$; if $b=0.5,(h+0.53 v<0.47)$ then $X_{V C}>X_{N C}>X_{H C}$; otherwise $X_{V C}>X_{H C}>X_{N C}$ and if $b=1,(23 h+10 v<13)$ then $X_{V C}>X_{N C}>X_{H C}$; otherwise $X_{V C}>X_{H C}>X_{N C}$.
} 
(i) If products are independent: $\pi_{r i}^{V C}>\pi_{r i}^{N C}>\pi_{r i}^{H C}$ when $h=0$ and $v=0 ; \pi_{r i}^{V C}>$ $\pi_{r i}^{H C}>\pi_{r i}^{N C}$ when $0 \leq h<1$ and $v>0 ;\left(\pi_{r i}^{V C}=\pi_{r i}^{H C}\right)>\pi_{r i}^{N C}$ when $h=1$.

(ii) If products are imperfect substitutes: $\pi_{r i}^{N C}>\pi_{r i}^{V C}>\pi_{r i}^{H C}$ when $h=0$ and $v=0$; $\pi_{r i}^{V C}>\pi_{r i}^{H C}>\pi_{r i}^{N C}$ when $h=0$ and $v=1 ; \pi_{r i}^{H C}>\pi_{r i}^{V C}>\pi_{r i}^{N C}$ when $h=1$ and $v=0$.

(iii) If products are homogenous: $\pi_{r i}^{H C}>\pi_{r i}^{N C}>\pi_{r i}^{V C}$ when $h=0$ and $v=0 ; \pi_{r i}^{V C}>$ $\pi_{r i}^{H C}>\pi_{r i}^{N C}$ when $h=0$ and $v=1 ; \pi_{r i}^{H C}>\pi_{r i}^{V C}>\pi_{r i}^{N C}$ when $h=1$ and $v=0$.

The analytic results to rank the cooperation settings in terms of profitability are attained by focusing on the impact of $h, v$, and $b$ on firms' R\&D strategies along with the effects of internalized competitive externalities on the profit. The comparison rests on the sign and magnitudes of $h, v$, and $b$ as well as HCEs and VCEs. Although firms benefit from knowledge spillovers through their cost reduction effects, the benefit is substantial when they are large, such that the incoming knowledge spillovers dominate the outgoing technological information. Additionally, higher $b$ boosts competition between retailers, negatively affects the market demand and reduces retailers' profits.

Part $i$ of Proposition 7 states that retailers' profit producing independent goods is ranked as $\pi_{r i}^{V C}>\pi_{r i}^{N C}>\pi_{r i}^{H C}$ if $h=0$ and $v=0$. When products are independent, retailers are neglected to the information leakage to their competitors and increase their $\mathrm{R} \& \mathrm{D}$ to benefit from its cost reduction effect. Note that $V C E_{r i}$ is positive, whereas $H C E_{r i}$ is negative when $h=0$ and $v=0$. Indeed, suppliers providing a homogeneous input are strongly sensitive to the knowledge spillovers to their rivals. When $h=0$, suppliers 
increase their R\&D which benefits retailers through the positive $V C E_{r i}$. Thus, retailers benefit from $V C$, whereas they suffer from $H C$ internalizing the negative $H C E_{r i} . N C$ internalizes no externality. Thus, $\pi_{r i}^{V C}>\pi_{r i}^{N C}>\pi_{r i}^{H C}$ is concluded. As spillovers increase, $H C E_{r i}$ turns positive, yet $V C E_{r i}>H C E_{r i}$. Thus, $\pi_{r i}^{V C}>\pi_{r i}^{H C}>\pi_{r i}^{N C}$ is attained. Moreover, $H C E_{r i}=V C E_{r i}$ when $h=1$ which results in $\left(\pi_{r i}^{V C}=\pi_{r i}^{H C}\right)>\pi_{r i}^{N C}$.

Part $i i$ of Proposition 7 states that $\pi_{r i}^{N C}>\pi_{r i}^{V C}>\pi_{r i}^{H C}$ when products are imperfect substitutes, $h=0$ and $v=0$. When products are substitutes, competition between retailers is strong. Thus, retailers reduce their output and demand of the intermediate good which negatively affects suppliers' profit and thereby, influences suppliers' R\&D strategies. Thus, $V C$ may lead firms to over-invest in R\&D. Indeed, $H C E_{r i}$ is negative when spillovers are low, and thereby leads firms to under-investing in R\&D. Although $V C$ yields higher profit than $H C$, the highest profit is attained by $N C$ internalizing no externality since $N C$ prevents retailers from over-investing in R\&D which may occur by $V C$. Thus, $\pi_{r i}^{N C}>\pi_{r i}^{V C}>\pi_{r i}^{H C}$ is concluded. Higher $v$ benefits firms and mitigates the negative effects of $b$ on the profit. When $v=1$, firms benefit from R\&D activities of one another and increase their R\&D which turns $H C E_{r i}$ positive, such that $V C E_{r i}>H C E_{r i}$. Moreover, $H C E_{r i}$ is positive up to the point that $b \leq 2 / 3$ if $h=0$ and thereby, $\pi_{r i}^{V C}>$ $\pi_{r i}^{H C}>\pi_{r i}^{N C}$ is attained. When $h=1$ and $v$ is sufficiently low, retailers gain higher profit by internalizing $H C E_{r i}$ than they do by internalizing $V C E_{r i}$ since $H C E_{r i}>V C E_{r i}$ up to the point that $b \leq 2 / 3$, and thereby, $\pi_{r i}^{H C}>\pi_{r i}^{V C}>\pi_{r i}^{N C}$ is observed.

Part iii of Proposition 7 states that $\pi_{r i}^{H C}>\pi_{r i}^{N C}>\pi_{r i}^{V C}$ when goods are homogenous, $h=0$ and $v=0$. When goods are homogenous, competition between 
retailers is intense which induces retailers to reduce their output and demand for the intermediate good which negatively affects suppliers' profit and influences their R\&D strategies. In this context, $V C$ may lead firms to over-invest in R\&D. $N C$ also may lead them to over-invest in $\mathrm{R} \& \mathrm{D}$ due to the strong competition; however, $V C$ is associated with a greater over-investing in $\mathrm{R} \& \mathrm{D}$ which reduces retailers' profits. $H C$ internalizes the negative $H C E_{r i}$ which is mitigated by $b$ when products are homogenous. Thus, retailers benefit from $H C$ since it prevents them from over-investing in R\&D by other settings. Comparing the settings shows that $\pi_{r i}^{H C}>\pi_{r i}^{N C}>\pi_{r i}^{V C}$. When $v=1$, internalizing $v$ reinforces its positive effects, increases the net benefit of R\&D to all firms. Thus, $V C$ is more profitable to both industries since $V C E_{r i}>H C E_{r i}$ and $\pi_{r i}^{V C}>$ $\pi_{r i}^{H C}>\pi_{r i}^{N C}$ is attained.

Proposition 7 shows that retailers attain the highest profit under $V C$ when goods are independent and spillovers are sufficiently low. Higher $b$ affects firms' strategies of R\&D due to its effects on output. Higher $b$ mitigates the effects of horizontal competitive externalities. $N C$ is associated with higher profits by preventing retailers from overinvesting in $R \& D$ when goods are imperfect substitutes and spillovers are sufficiently low. Furthermore, $N C$ and $V C$ may induce retailers to over-invest in $\mathrm{R} \& \mathrm{D}$ when products are homogeneous and spillovers are sufficiently low. In this case, retailers gain higher profit under $H C$. The results show that the negative effects of over-investing in R\&D on retailers' profit more than offset the gains associated with the cost reduction effects of the R\&D. $V C$ leads retailers to the highest profit when $v$ is high enough.

Now, consider the profit of suppliers providing a homogeneous intermediate good where their output level is affected by retailers' strategies of output. Although higher $b$ reduces 
the demand of the intermediate good, higher $b$ increases the wholesale price which reflects the power of suppliers.

\section{Proposition 8.}

(i) If goods are independent: $\pi_{s i}^{H C}>\pi_{s i}^{N C}>\pi_{s i}^{V C}$ when $h=0$ and $v=0 ; \pi_{s i}^{V C}>\pi_{s i}^{H C}>$ $\pi_{s i}^{N C}$ when $h=0$ and $v=1 ;\left(\pi_{s i}^{V C}=\pi_{s i}^{H C}\right)>\pi_{s i}^{N C}$ when $h=1$.

(ii) If goods are imperfect substitutes: $\pi_{s i}^{N C}>\pi_{s i}^{V C}>\pi_{s i}^{H C}$ when $h=0$ and $v=0$; otherwise, $\pi_{s i}^{V C}>\pi_{s i}^{H C}>\pi_{s i}^{N C}$.

(iii) If goods are homogenous: $\pi_{s i}^{V C}>\pi_{s i}^{N C}>\pi_{s i}^{H C}$ when $h=0$ and $v=0$; otherwise, $\pi_{s i}^{V C}>\pi_{s i}^{H C}>\pi_{s i}^{N C}$.

Part $i$ of Proposition 8 states that $\pi_{s i}^{H C}>\pi_{s i}^{N C}>\pi_{s i}^{V C}$ when final products are independent and spillovers are sufficiently low. In this case, suppliers benefit from higher demand and have enough incentive to increase their R\&D and benefit from its cost reduction effects when $h$ is sufficiently low. Retailers also increase their R\&D to benefit from its cost reduction effects. Although $H C E_{s i}$ is negative when $h=0$, suppliers benefit from internalizing these negative $H C E_{s i}$ since it mitigates suppliers' concerns about the flow of the knowledge spillovers to the competitor, prevents them from over-investing in R\&D by other settings. This result shows that $V C$ may induce suppliers to over-invest in R\&D which reduces the profits. Although $N C$ internalizes no externality, suppliers benefit from $N C$ since it also prevents them from over-investing in $\mathrm{R} \& \mathrm{D}$. The overinvestment under $V C$ is stronger than it is under $N C$. Thus, $\pi_{s i}^{H C}>\pi_{s i}^{N C}>\pi_{s i}^{V C}$ is achieved. As $v$ increases, yet $h$ is sufficiently low, firms increase their R\&D further. 
Additionally, when $v=1$, inter-industry firms benefit from internalizing $V C E_{s i}$ which reinforces the cost reduction effects of $v$. Vertical spillovers also mitigate the negative $H C E_{s i}$, such that $\pi_{s i}^{V C}>\pi_{s i}^{H C}>\pi_{s i}^{N C}$ is attained. Ultimately, $H C E_{s i}=V C E_{s i}$ when $h=$ 1 which results in $\left(\pi_{s i}^{V C}=\pi_{s i}^{H C}\right)>\pi_{s i}^{N C}$.

Part $i i$ of Proposition 8 states that $\pi_{s i}^{N C}>\pi_{s i}^{V C}>\pi_{s i}^{H C}$ when products are imperfect substitutes, $h=0$ and $v=0$. When products are substitutes, competition between retailers is strong. Thus, retailers reduce their output which affects suppliers' strategies of output as well. These effects reduce firms' incentive to increase their R\&D and thereby, $V C$ leads inter-industry firms to over-investing in R\&D. Furthermore, $H C E_{s i}$ is negative due to the low levels of spillovers. Internalizing these negative competitive externalities leads suppliers to under-invest in R\&D which reduces suppliers' profit. In this case, $V C$ yields higher profit than $H C$, while $N C$ internalizing no externality yields the highest profit to the suppliers since $N C$ prevents them from over-investing and (or) underinvesting in R\&D. Thus, $\pi_{s i}^{N C}>\pi_{s i}^{V C}>\pi_{s i}^{H C}$ is concluded. Higher $h$ and $v$ increase the net benefit of R\&D, more than offset the effects of $b$ on firms' profit, and positively affect firms' incentive to increase their R\&D. Thus, $\pi_{s i}^{V C}>\pi_{s i}^{H C}>\pi_{s i}^{N C}$ is concluded when spillovers are high enough.

Part iii of Proposition 8 states that $\pi_{s i}^{V C}>\pi_{s i}^{N C}>\pi_{s i}^{H C}$ when products are homogenous, $h=0$ and $v=0$. When products in both industries are homogenous, competition between firms in both industries is intense. This reduces firms' incentive to increase their R\&D. $N C$ internalizes no externality, yet boosts competition and induces suppliers to over-invest in R\&D. $H C$ internalizes the negative $H C E_{s i}$, induces suppliers to 
under-invest in $\mathrm{R} \& \mathrm{D}$. $H C$ reduces suppliers' profit (by under-investing in $\mathrm{R} \& \mathrm{D}$ ) more than $N C$ does (by over-investing in $\mathrm{R} \& \mathrm{D}$ ). In this case, $V C$ prevents suppliers from over-investing in R\&D associated with $N C$ and thereby, suppliers attain the highest profit under $V C$. Thus, $\pi_{s i}^{V C}>\pi_{s i}^{N C}>\pi_{s i}^{H C}$ is concluded. As spillovers increase, firms have enough incentive to increase their R\&D, $H C E_{s i}$ turns positive and $\pi_{s i}^{V C}>\pi_{s i}^{H C}>\pi_{s i}^{N C}$ is concluded.

Proposition 8 shows that when goods are independent and spillovers are sufficiently low, $V C$ leads suppliers to over-invest in R\&D. To avoid over-investing in $\mathrm{R} \& \mathrm{D}$, suppliers tend to $H C$. However, $H C$ leads suppliers to under-invest in $\mathrm{R} \& \mathrm{D}$ when products are imperfect substitutes, yet spillovers are sufficiently low. These results reflect the effects of $b$ on firms' strategies of R\&D. $V C$ yields the highest profit of suppliers when products are homogenous. The results show that forming an appropriate cooperative setting under different levels of spillovers and product substitutability is critical to profit maximizing firms to choose the adequate innovation efforts.

\subsection{Conclusion}

This chapter aims to study the impact of cooperative R\&D on innovation, welfare, and profitability in vertically related industries where products are differentiated, horizontal and vertical spillovers are present. A two industry framework under a symmetric scenario is considered, where upstream firms produce a homogeneous intermediate good and sell it to downstream firms. Downstream firms produce differentiated products.

Although vertical spillovers always increase $R \& D$ expenditures, horizontal spillovers may increase or decrease them. Vertical spillovers have a multiplied positive 
impact on R\&D by stimulating horizontal spillovers and through the cooperative structure. Inter-industry firms always benefit from higher innovation efforts of one another. The impact of horizontal spillovers on $R \& D$ depends on the cooperative structure, the level of horizontal and vertical spillovers and product substitutability. Firms' behavior is affected by cooperative structure and the magnitudes of spillovers and product substitutability. Retailers and suppliers have different responses to a change in the level of spillovers and product substitutability. Although higher product differentiation mitigates retailers' concerns about horizontal spillovers, it has no significant effect on suppliers' stress.

Higher product substitutability always increases competition between retailers, affects the position of the demand curve, induces retailers to reduce their output and the demand of the intermediate good. Although the reduction in demand affects suppliers' net benefit of $R \& D$, the power of suppliers mitigates the effect by increasing the wholesale price.

Comparing cooperative settings in terms of $\mathrm{R} \& \mathrm{D}$, shows that vertical cooperation always dominates the others. When horizontal spillovers are perfect, horizontal cooperation and vertical cooperation yield the same level of R\&D. The second best cooperation setting in terms of $R \& D$ and welfare is non-cooperative $R \& D$ if spillovers are sufficiently low; otherwise, horizontal cooperation leads to the second best. Horizontal cooperation decreases R\&D and welfare when spillovers are sufficiently low. This result does not necessarily hold when one of the spillovers is high. The ranking of cooperation settings rests on the sign and magnitudes of competitive externalities, spillovers and product substitutability. Product substitutability affects the required 
threshold of spillovers. Higher product differentiation yields higher output and R\&D by all firms under any type of cooperation setting.

An important question that arises in the study of the productive cooperation settings is its relative importance to firms' decisions. Cooperation settings were compared in terms of profitability in each industry. It was shown that profitability is affected by the sign and magnitudes of competitive externalities, product substitutability, as well as horizontal and vertical spillovers. The result indicates that retailers and suppliers have no common interest to voluntarily form vertical cooperation under similar circumstances. Although suppliers always gain the highest profit under vertical cooperation when final goods are homogenous, retailers attain the highest profit under vertical cooperation only if vertical spillovers are sufficiently high. Moreover, vertical cooperation may induce firms to over-invest in R\&D. Over-investing in R\&D reduces firms' profits.

The study of cooperative $R \& D$ and of protecting innovation certainly increases substantial science and technology policy issues. Drawing policy recommendations requires prudence since it deals with many practical issues like asymmetric information between firms and regulators. However, the model suggests some considerations on R\&D policy with respect to the incentives of cooperation settings' perspective.

The model suggests that the selection of cooperation settings and of incentives to cooperation is imperative to the conclusion of $R \& D$ levels. The model indicates that vertical cooperation is associated with the highest innovation and welfare. The regulator requires introducing policies to direct inter-industry firms to this goal. The optimal policy varies based on the magnitudes of spillovers and product substitutability. To 
encourage innovation efforts, a series of legislative actions to strengthen industrial technological capabilities should be strongly supported. The regulator should introduce policies to make the profits for each firm to be at least as large as the profits of the firm in the non-cooperative scenario to encourage them to cooperate in R\&D activities. In this way, firms would vertically cooperate since it is profitable to them.

The model has many possible extensions. A critical determinant of cooperative $\mathrm{R} \& \mathrm{D}$ is the level of knowledge spillovers. The importance of differentiating between outgoing technical knowledge and incoming technological information has not been addressed by the paper. It was assumed that the flow of horizontal (vertical) spillovers between firms in both industries is the same. In the real world, absorptive capacity, the pace and scope of technological change, and communication channels are different among firms (industries) which leads to different levels of knowledge spillovers. Moreover, downstream firms dealing with the final consumer may bear more vertical spillovers, whereas upstream firms providing a homogenous intermediate good may develop more horizontal spillovers. This, in turn, may affect the symmetry of horizontal and vertical spillovers. 
Table 1.1: The impact of vertical spillovers

\begin{tabular}{cccc}
\hline & $\begin{array}{c}\text { No } \\
\text { Cooperation }\end{array}$ & $\begin{array}{c}\text { Horizontal } \\
\text { Cooperation }\end{array}$ & $\begin{array}{c}\text { Vertical } \\
\text { Cooperation }\end{array}$ \\
\hline$\partial x_{r i} / \partial v$ & + & + & + \\
$\partial x_{s i} / \partial v$ & + & + & + \\
$\partial X / \partial v$ & + & + & + \\
$\partial Y / \partial v$ & + & + & + \\
$\partial W / \partial v$ & + & + & + \\
\hline
\end{tabular}


Table 1.2: The impact of horizontal spillovers

\begin{tabular}{cccc}
\hline & $\begin{array}{c}\text { No } \\
\text { Cooperation }\end{array}$ & $\begin{array}{c}\text { Horizontal } \\
\text { Cooperation }\end{array}$ & $\begin{array}{l}\text { Vertical } \\
\text { Cooperation }\end{array}$ \\
\hline$x_{\text {ri }} / \partial h$ & - & + & + if $b=0$ \\
& & & \pm if $b>0$ \\
$\partial x_{s i} / \partial h$ & - & + & \pm \\
$\partial X / \partial h$ & - & + & \pm \\
$\partial Y / \partial h$ & \pm & + & + \\
$\partial W / \partial h$ & \pm & + & + \\
\hline
\end{tabular}




\section{Chapter 2: The Impact of Cooperative R\&D and Advertising on}

\section{Innovation}

\subsection{Introduction}

Advertising and innovation are two major instruments for firms to beat the competition, improve their future returns effectively and earn extraordinary profits (Askenazy et al. 2015; Hirschey and Weygandt 1985; Drucker 1954). The recent studies show that the strategic interaction between advertising and $R \& D$ depends on the returns associated with these activities (Kaiser 2005). Advertising and R\&D can be strategic substitutes; firms may substitute advertising for $R \& D$ when the returns associated with advertising are higher than the returns on $R \& D$. However, advertising and $R \& D$ can also be strategic complements. The literature has taken the view that cooperative $R \& D$ and advertising have positive effects on firm value.

Advertising enables firms to introduce their products to potential consumers, to encourage consumers to purchase the products, to distinguish their products from competitors' and conclusively to increase profits. Advertising cooperation between two competitors increases advertising expenditures and profits. Horizontal advertising cooperation between companies that operate at the same level of supply chain identifies and develops successful strategies to improve a variety of metrics of performance. Competitors share certain common interests and objectives like the joint development of new products, the evolution of advanced technology and the achievement of high levels of R\&D. The cooperation leverages the strengths of each partner to open up new consumer markets or enhance common target markets (Gou et al. 2014). 
Additionally, cost reducing R\&D increases firms' efficiency and profits. Cost reducing R\&D investments reduce firms' production costs, induce firms to increase their output and R\&D further. Horizontal cooperative R\&D yields higher innovation efforts and profits when the information leakage to the rivals (horizontal R\&D spillovers) is high enough. Cooperative R\&D affects innovation efforts and profitability through cost sharing effects (Atallah 2002).

Although R\&D activities are always associated with positive spillovers, which are desirable to the rivals, advertising may generate positive or negative spillovers. Advertising spillovers are positive (negative) if they increase (decrease) the demand for the rivals' products. Sahni (2015) shows that online advertising positively affects competitors' markets. In particular, he finds that the effects are more severe when product differentiation is low. An instance of positive advertising spillovers can be considered by the impact of advertising of Pepsi on the demand of its rival, Coca-Cola due to their positive correlation and the strong substitutability. Shapiro (2018) shows that there are positive spillovers from television advertising of prescription psychicenergizers. Advertising activities have positive externalities on the market size of all rivals if all firms invest in advertising activities and compete a la Cournot (Cellini and Lambertini 2002).

Friedman (1983) incorporates positive and negative advertising spillovers in an oligopolistic model. He shows that when advertising spillovers are negative, the cost of advertising is increased and profit is reduced. An illustration of negative advertising spillovers can be modified by providing specific information, counterfeiting a wellknown prestigious brand (sub-brand), and recalling products. For example, advertising a 
product as $\mathrm{GMO}^{17}$ free brings new information to light about health risks associated with GMO products. This advertising not only decreases the demand of the competitors', but also it influences the demand for other products (imperfect substitutes or independent products), which may contain GMOs in their ingredients. Another example of negative advertising spillovers is advertising counterfeit products as genuine ones which negatively affects the market of the premium brand. Premium brands attract consumers with their associated exclusive prestige. However, counterfeiting a premium brand enables a variety of consumers to take advantage of the brand name. Thus, the selfrespect and aristocracy of the consumers of genuine items induce them to either abandon the premium brand, or cheapening and degrading the items (Commuri 2009). Although marketers create a bridge between relevant brands in their brand portfolios to increase marketing efficiency through positive spillovers of brand equity, negative spillovers may occur and affect relative brands that are not directly involved (Lie et. al. 2008). For example, prompting a recall of Nescafé products due to a severe quality problem encourages the consumers to update their evaluations not just for Nescafé but also for other Nestlé's sub-brands.

To succeed in the marketplace, corporations require engaging in cooperative R\&D and marketing activities (Griffin and Hauser 1996). Firms hire scientists to maintain and develop technology, hire marketing experts to sell the products, speak to consumers, and promote products. If there is no connection between these groups, their ability to synthesize skills, develop and produce successful products decreases which

17 Genetically modified Organisms (GMOs) are living organisms whose genetic material has been artificially manipulated in a laboratory through genetic engineering. 
cause firms to suffer. Marketing and $R \& D$ activities in new innovative products are neither independent nor static and they should not be analyzed separately.

Previous theoretical studies focused on the effects of cooperative advertising and cooperative R\&D on firms' value. There are many analyses investigating the effects of $R \& D$ spillovers and cooperative $R \& D$ strategies on innovation. However, there is no analysis to address the impact of cooperating in $\mathrm{R} \& \mathrm{D}$ and advertising on innovation and welfare. However, investigating these effects is essential and helps the regulator to introduce required policies to protect innovation and welfare notably, where horizontal mergers are prohibited. This chapter makes several contributions to the existing literature. First, it is the first paper to model the simultaneous presence of R\&D and advertising spillovers, by allowing each firm to participate in cost reducing R\&D and advertising activities simultaneously. The advertising spillovers may be positive or negative. Second, the chapter studies the effect of cooperative R\&D or (and) cooperative advertising by allowing firms to choose their $R \& D$ and advertising expenditures to maximize their joint profits (where firms cooperate which is not the same as noncooperative equilibria). Third, the strategic interaction between $R \& D$ and advertising activities of competitors is analyzed. Finally, this chapter studies the ranking of cooperative structures in terms of $R \& D$.

In a two-stage game, two symmetric duopolists producing differentiated products invest in R\&D and advertising in the first stage and then compete in output in the second stage. The cost reducing $\mathrm{R} \& \mathrm{D}$ decreases the production cost of the participating firm and its competitor through R\&D spillovers. Advertising increases own demand and increases (reduces) the demand of the rival through positive (negative) advertising spillovers. 
It is found that higher R\&D and advertising spillovers always increase innovation, output and welfare when goods are independent. When goods are imperfect substitutes or homogeneous, the effects of R\&D and (or) advertising spillovers on innovation, output, and welfare depend on the sign and magnitude of advertising spillovers, R\&D spillovers, product differentiation and cooperative structures. The study of the ranking of cooperation settings in terms of $\mathrm{R} \& \mathrm{D}$ shows that cooperative advertising always reduces innovation when advertising spillovers are negative. Indeed, internalizing positive externalities always promotes innovation and thereby, the type of cooperation which internalizes larger positive externalities yields higher innovation efforts. The study of the strategic interaction between competitors' decisions on R\&D and advertising shows that the advertising of a firm complements its competitor's investment in R\&D and advertising when advertising spillovers are positive and large enough. Although R\&D of a firm always complements its competitor's investments in R\&D and advertising when goods are independent, that complements the competitor's R\&D and advertising expenditures solely if R\&D spillovers are high enough when goods are substitutes.

The chapter is organized as follows. A relative literature review of empirical studies is provided in section 2.2. The model is presented in section 2.3. The impact of spillovers ${ }^{18}$ on innovation, output and welfare are studied in section 2.4. Section 2.5 examines the strategic interaction between competitors' advertising and R\&D expenditures. The four scenarios (no cooperation, R\&D cooperation, advertising

\footnotetext{
${ }^{18}$ Spillovers refer to R\&D and advertising spillovers.
} 
cooperation, $\mathrm{R} \& \mathrm{D}$ and advertising cooperation) in terms of $\mathrm{R} \& \mathrm{D}$ are compared in section 2.6. Section 2.7 provides a brief summary and conclusion.

\subsection{Literature Review}

The majority of empirical analyses study the cost sharing effects of advertising and R\&D cooperation and find a positive impact of cooperative advertising and $R \& D$ on profits (Gasmi et al. 1992; Vanhaverbeke et al. 2002). Sridhar et al. (2014) study data of a sample of the U.S. high technology manufacturing firms. They find that, firms' investments in R\&D, advertising, and inventory affect firms' performance as well as their future expenditures in each of these three areas. Focusing on the long-term effects, they find that investments in advertising and inventory holding increase sales, whereas investment in R\&D does not. Advertising and R\&D increase a firm's value, whereas inventory holding does not. Furthermore, investments in all three functions are positively affected by sales, yet negatively affected by firm value.

Most of the $R \& D$ intensive industries, like the pharmaceutical industry and automotive industry have large advertising expenditures (Matraves 1999; Kwong and Norton 2007; Kaiser 2005). Focusing on the competitive roles of advertising and R\&D expenditures, evidence shows that advertising and R\&D expenditures are critical to the price competition and the formation of market structure in the global pharmaceutical industry (Matraves 1999).

A large volume of literature in economic management has been produced that argues various motives that encourage firms to collaborate on R\&D (Nielsen 2002; Nooteboom 1999). A number of empirical studies explore the determinants of $R \& D$ 
cooperation (Kleinknecht and Reijnen 1992; Fritsch and Lukas 2001; Tether 2002; Belderbos et al. 2004). A major finding of recent contributions is that the goals and, the determinants of $R \& D$ cooperation differ depending on the type of $R \& D$ and cooperation partner. Fritsch and Lukas (2001) study a sample of the German manufacturing firms and find that innovative effort directed at process improvement is associated with cooperation with suppliers; however, product innovations are associated with customer cooperation. Tether (2002), studies a sample of innovating firms from the UK. He finds that R\&D cooperation is followed by firms pursuing disruptive innovations rather than incremental innovations.

Siebert (1996) studies the effect of R\&D alliances on firm economic performance using the data of a sample of the U.S. joint ventures. He shows that cooperation has no direct impact on profit margin. Indeed, the effect of R\&D investment on the profit margin is larger for cooperating than for non-cooperating firms. Aschhoff and Schmidt (2008), from the study of firm level data of the annual German innovation survey, find that cooperative $\mathrm{R} \& \mathrm{D}$ strengthens cost reductions, which are determinant to the innovation processes. Cooperative R\&D has a positive impact on a firm's economic success with market novelties. The positive effects of cooperative $R \& D$ are reinforced if firms cooperate in the introduction and marketing of innovative products, which are still at the beginning of their life cycle.

Kwoka (1993) studies the data of a sample of the U.S, auto industry and finds that advertising in the auto industry positively affects a car's model sales; however, the effect is temporary and limited. Seldon and Doroodian (1989) study the impact of advertising on the cigarette industry. They find that although advertising positively affects the 
demand for the cigarette in the U.S., the health warnings mitigates the effect. They show that the industry responds to the health warnings by increasing the advertising activities. Nerlove and Waugh (1961) find a positive impact of advertising on the U.S. orange industry.

Despite the importance of the effectiveness of advertising alliances, few empirical studies address the effectiveness of alternative strategies for cooperative advertising. Gasmi et al (1992) study potential marketing coordination in the Cola market (Nash behaviour, Stackelberg leadership and several potential coordination of collusion) using data for two decades. They find evidence which confirms joint marketing alliances. In similar studies, Wang et al. (2004) find a similar conclusion for the U.S. butter and margarine industry. Kadiyali (1996) studies the U.S. photographic film industry where evidence shows cooperation on both advertising and price. Roberts and Samuelson (1988) address the joint profit maximizing choice of advertising in the U.S. cigarette market.

Cooperative advertising enhances target markets when advertising spillovers are positive and (or) advertising is not comparative. Anderson et al. (2016), from the study of the data of all TV advertising expenditures from the U.S. over-the-counter analgesics, find that there are negative effects of comparative advertising on the competitors. Engaging in comparative advertising negatively affects the market of the rival and reduces the joint profits where firms cooperate in advertising. The comparative advertising causes more damage to the targeted competitor than benefit to the advertiser. 
Matraves (1999) and Kwong and Norton (2007) find that industry specifications, $R \& D$ intensity of the industry, returns on $R \& D$ and marketing activities determine how the strategic interaction of advertising and R\&D between firms may vary. Advertising and R\&D expenditures may be either strategic substitutes or strategic complements. If the returns associated with advertising are higher than returns on $R \& D$, firms may substitute advertising for R\&D investment. This mechanism is more significant when firms face credit constraints or have to pursue short-run objectives. However, evidence shows that advertising and $R \& D$ can also be complements, such that some $R \& D$ intensive industries like pharmaceuticals also have high advertising expenditures. Askenazy et al. (2015) study the data of a sample of firms from the French manufacturing industry. They employed a model including both static and dynamic interactions between $\mathrm{R} \& \mathrm{D}$, advertising, and competitive environment. They find that for a given competitive environment, quality leaders invest more in advertising to extract more rents. Additionally, the inverted- $U$ relation between competition and $R \& D$ remains with the introduction of advertising. Indeed, more competition is associated with more advertising expenditures.

Although there is a large theoretical and empirical literature analyzing the importance of R\&D and marketing along with the effects of cooperative R\&D and advertising on firms' value, firms' performance, and firms' strategies, there is no theoretical or empirical literature to study the impact of R\&D and advertising cooperation on innovation, output, and welfare. This paper contributes to the literature by its unique approach. 


\subsection{The Model}

There are two symmetric firms producing differentiated products and competing a la Cournot. Firms interact in two stages. In the first stage, they choose their expenditures on $\mathrm{R} \& \mathrm{D}(x)$ and advertising $(a)$. In the second stage, they decide on their output $(y)$. Good $i$ is produced by firm $i$, where $i=1,2$. In this model, advertising increases the market demand for the good, has some feature of "complementary"19 advertising (Bagwell, 2007), may or may not provide information. The considered advertising in this chapter does not provide hard information on price or product characteristics, it also does not affect product differentiation. This model shares some features with the model by Becker and Murphy (1993). A consumer consumes two goods, 1 and 2. Consumers have a stable set of preferences and advertising is complementary to consumption. The consumer's utility function is given by

$$
\mathrm{U}\left(y_{0}, y_{1}, y_{2}\right)=k\left(y_{1}+y_{2}\right)-\frac{\left(y_{1}^{2} y_{2}^{2}\right)}{2}-b y_{1} y_{2}+\left(a_{1}+\theta a_{2}\right) y_{1}+\left(\theta a_{1}+a_{2}\right) y_{2}+y_{0}
$$

where $y$ is output, $a$ denotes advertising, $\theta \in[-1,1]$ is a parameter measuring the advertising spillover, $b \in[0,1]$ is a parameter indicating the degree of product substitutability (negatively related to product differentiation). Final goods are homogeneous if $b=1$, imperfect substitutes if $0<b<1$ and independent if $b=0 . y_{0}$ is the numeraire, given by the budget constraint as $y_{0}=M-p_{1} y_{1}-p_{2} y_{2}$, where $M$ is

\footnotetext{
${ }^{19}$ The complementary view admits that the advertising may contain information and influence consumer behaviour accordingly. However, the consumer may value "social prestige," and advertising by a firm may be an input that contributes toward the prestige that increases satisfaction when the firm's product is consumed.
} 
income and $p$ is the price. Advertising by a firm generates a positive (negative) spillover $(\theta)$ for the value of the other product to the consumer.

Maximizing the utility over $y_{1}$ and $y_{2}$ yields the following demand functions:

$$
p_{i}\left(y_{i}, y_{j}, a_{i}, a_{j}\right)=k-y_{i}-b y_{j}+a_{i}+\theta a_{j} \quad i=1,2
$$

The inverse demand function shows that the demand of each firm depends on the advertising choices of all firms. In this setting, advertising causes a parallel shift in the demand curve, no slope effect. Advertising improves value (by increasing the vertical demand intercept of the inverse demand curve). The demand of the rival is negatively affected by a firm's advertising when $\theta<0$ and it is positively affected when $\theta>0$.

Each firm participates in advertising and cost reducing R\&D activities. The dollar cost of $x$ units of R\&D for firm $i$ is $\gamma x_{i}^{2} / 2$, where $x_{i}$ represents the R\&D output by firm $i$, and $\gamma>0$ is a cost parameter. The dollar cost of $a$ units of advertising for firm $i$ is $\lambda a_{i}^{2} / 2$, where $a_{i}$ represents the advertising by firm $i$, and $\lambda>0$ is a cost parameter. Assuming that $\gamma$ and $\lambda$ are sufficiently high for the profit function to be concave, sufficiently low for firms to undertake strictly positive amount of R\&D and advertising. The total R\&D output is denoted by $X$ and total advertising is denoted by $a$.

$$
\begin{aligned}
& X=x_{1}+x_{2} \\
& a=a_{1}+a_{2}
\end{aligned}
$$

Each unit of R\&D conducted by a firm reduces its own cost by one dollar, reduces the cost of its competitor by $\beta$ dollars, $\beta \in[0,1]$. The magnitude of $\beta$ depends on different factors such as different absorptive capacities, different technological 
similarities, the different efficiency of communication channels, etc. Undertaking no $\mathrm{R} \& \mathrm{D}$, firms acquire a constant unit production cost of $\alpha$. The unit cost for firm $i$ is:

$$
c_{i}=\alpha-x_{i}-\beta x_{j} \quad i=1,2
$$

The cost function shows that the final cost of each firm depends on the R\&D choices of all firms. This game has two stages. In the first stage, each firm decides on its R\&D and advertising simultaneously. In the second stage, firms choose their output competing a la Cournot, anticipating the market demand.

\subsubsection{Output stage}

The game begins with the second stage where firms choose their output to maximize their own profit non-cooperatively.

In the second stage, firms' problem is:

$$
\max _{y_{i}} \pi_{i}=\left(p_{i}\left(y_{i}, y_{j}, a_{i}, a_{j}\right)-c_{i}\right) y_{i}-\gamma \frac{x_{i}^{2}}{2}-\lambda \frac{a_{i}^{2}}{2} \quad i=1,2
$$

Given that firms are symmetric, they follow a symmetric behavior. Maximizing and solving the two f.o.c. simultaneously yields:

$$
\begin{array}{rr}
y_{i}=\frac{2\left(k-\alpha+a_{i}+\theta a_{j}+x_{i}+\beta x_{j}\right)-b\left(k-\alpha+\theta a_{i}+a_{j}+\beta x_{i}+x_{j}\right)}{4-b^{2}} & i=1,2 \\
p_{i}=\frac{(2-b) k+2\left(\alpha+a_{i}-x_{i}\right)+2 \theta a_{j}-2 \beta x_{j}+b\left(\alpha-\theta a_{i}-a_{j}-\beta x_{i}-x_{j}\right)-b^{2}\left(\alpha-x_{i}-\beta x_{j}\right)}{4-b^{2}} & i=1,2
\end{array}
$$

\subsubsection{Advertising and R\&D Stage}

In the first stage of the game, firms choose their $R \& D$ and advertising expenditures simultaneously. One noticeable feature of cooperative $R \& D$ and advertising is the great 
variety of possible linkages between firms. Firms may participate in R\&D cooperation on one project, while in advertising cooperation on another project. To capture the variety of cooperative structures, four scenarios for firms' behavior in the first stage are considered. The first scenario is non-cooperative $\mathrm{R} \& \mathrm{D}$ and advertising $(N N)$ so that each firm chooses its own R\&D and advertising to maximize its own profit. The second scenario is cooperative $\mathrm{R} \& \mathrm{D}(R N)$ where firms choose their R\&D cooperatively, but each firm chooses its own advertising non-cooperatively. The third scenario is cooperative advertising $(N A)$, in which firms choose their advertising cooperatively, but each firm chooses its R\&D non-cooperatively. The fourth scenario is cooperative R\&D and advertising $(R A)$, where firms determine their $\mathrm{R} \& \mathrm{D}$ and advertising cooperatively. Define the $\mathrm{R} \& \mathrm{D}$ and advertising set of all firms as $\varphi \equiv\left\{x_{1}, x_{2}, a_{1}, a_{2}\right\}$. Therefore, the profit of each firm can be rewritten as:

$$
\pi_{i}(\varphi)=\left(p_{i}(\varphi)-c_{i}(\varphi)\right) y_{i}(\varphi)-\gamma \frac{x_{i}^{2}}{2}-\lambda \frac{a_{i}^{2}}{2}
$$

Thus, welfare is also a function of $R \& D$ and advertising set, defined as:

$$
W(\varphi)=\left(\pi_{1}(\varphi)+\pi_{2}(\varphi)\right)+C S^{20}
$$

In the first stage, under $N N$ each firm determines its $\mathrm{R} \& \mathrm{D}$ and advertising to maximize its own profit. Each firm solves the following problem:

$$
\max _{x_{i}, a_{i}} \pi_{i}(\varphi) \quad i=1,2
$$

\footnotetext{
${ }^{20}$ Consumer surplus is defined as $C S=U\left(y_{0}, y_{1}, y_{2}\right)-\left(p_{1} y_{1}+p_{2} y_{2}+y_{0}\right)$.
} 
Simultaneously solving the four first order conditions of Eq. (2), shows research and advertising efforts that each firm chooses under $N N$ :

$$
\begin{array}{lr}
x_{i}^{N N}=\frac{2 \lambda(k-\alpha)(2-b \beta)}{2 \gamma(1+\theta)(2-b \theta)+2 \lambda(1+\beta)(2-b \beta)-\gamma \lambda(2-b)(b+2)^{2}} & i=1,2 \\
a_{i}^{N N}=\frac{2 \gamma(k-\alpha)(2-b \beta)}{2 \gamma(1+\theta)(2-b \theta)+2 \lambda(1+\beta)(2-b \beta)-\gamma \lambda(2-b)(b+2)^{2}} & i=1,2
\end{array}
$$

Under $R N$, firms choose their R\&D to maximize their joint profits, but each firm chooses its own advertising level to maximize its profit.

$$
\begin{array}{ll}
\max _{x_{1}, x_{2}} \pi_{1}(\varphi)+\pi_{2}(\varphi) & \\
\max _{a_{i}} \pi_{i}(\varphi) & i=1,2
\end{array}
$$

Simultaneously solving the four f.o.c. of Eqs. (3) and (4), shows research and advertising efforts that each firm undertakes under $R N$ :

$$
\begin{array}{lr}
x_{i}^{R N}=\frac{2 \lambda(k-\alpha)(\beta+1)(2-b)}{\lambda(2-b)\left[\gamma(b+2)^{2}-2(1+\beta)^{2}\right]-2 \gamma(1+\theta)(2-b \theta)} & i=1,2 \\
a_{i}^{R N}=\frac{2 \gamma(k-\alpha)(2-b \theta)}{\lambda(2-b)\left[\gamma(b+2)^{2}-2(1+\beta)^{2}\right]-2 \gamma(1+\theta)(2-b \theta)} & i=1,2
\end{array}
$$

Under $N A$, firms decide on their advertising level to maximize their joint profits, but each firm chooses its R\&D investment to maximize its own profit.

$$
\begin{array}{lr}
\max _{a_{1}, a_{2}} \pi_{1}(\varphi)+\pi_{2}(\varphi) & \\
\max _{x_{i}} \pi_{i}(\varphi) & i=1,2
\end{array}
$$


Simultaneously solving the four f.o.c. of Eqs. (5) and (6), shows research and advertising efforts that each firm undertakes under $N A$ :

$$
\begin{array}{lr}
x_{i}^{N A}=\frac{2 \lambda(k-\alpha)(2-b \beta)}{\gamma(2-b)\left[\lambda(b+2)^{2}-2(1+\theta)^{2}\right]-2 \lambda(1+\beta)(2-b \beta)} & i=1,2 \\
a_{i}^{N A}=\frac{2 \gamma(k-\alpha)(2-b)(1+\theta)}{\gamma(2-b)\left[\lambda(b+2)^{2}-2(1+\theta)^{2}\right]-2 \lambda(1+\beta)(2-b \beta)} & i=1,2
\end{array}
$$

Under $R A$, firms determine their $\mathrm{R} \& \mathrm{D}$ and advertising cooperatively to maximize their joint profits.

$$
\max _{x_{1}, x_{2}, a_{1}, a_{2}} \pi_{1}(\varphi)+\pi_{2}(\varphi)
$$

Simultaneously solving the four f.o.c. of Eq. (7), determines the research and advertising efforts that each firm undertakes under $R A$ :

$$
\begin{array}{lr}
x_{i}^{R A}=\frac{2 \lambda(k-\alpha)(\beta+1)}{2 \gamma(1+\theta)^{2}+2 \lambda(1+\beta)^{2}-\lambda \gamma(b+2)^{2}} & i=1,2 \\
a_{i}^{R A}=\frac{2 \gamma(k-\alpha)(\theta+1)}{2 \gamma(1+\theta)^{2}+2 \lambda(1+\beta)^{2}-\lambda \gamma(b+2)^{2}} & i=1,2
\end{array}
$$

\subsection{The Impact of Spillovers on $R \& D$ and Welfare}

This section addresses ${ }^{21}$ the effects of $R \& D$ and advertising spillovers on innovation, output, and welfare where products are differentiated and cooperative structures are varied.

${ }^{21}$ All the detailed analysis and proofs are provided in the appendix. 


\section{Proposition 1.}

(i) Under $N N$ and $N A$, an increase in $R \& D$ spillovers increases innovation, output, and welfare if they are low enough.

(ii) Under $R N$ and $R A$, an increase in $R \& D$ spillovers always increases innovation, output, and welfare.

An increase in $\beta$ reduces production costs of the rival and is not desirable. Under $N N$ and $N A$, higher $\beta$ increases innovation when the benefit from incoming technological knowledge dominates the negative effects of outgoing information. In this context, higher $\beta$ increases the net benefit of $R \& D$, yields higher innovation and output. Higher output increases the net benefit of advertising and induces firms to increase their advertising expenditures. Higher advertising increases the demand and thereby yields a higher profit. Higher output also increases consumer satisfaction and welfare. As product substitutability increases, competition becomes intense which requires firms' carefulness about the effect of their innovation efforts on their rival. Indeed, firms reduce their innovation efforts when the sum of the effects of $\beta$ and $b$ on the profit is negative. Table 2.1 summarizes the results of Proposition 1.

Under $R N$ and $R A$, firms decide on their R\&D cooperatively to maximize their joint profits. In this case, firms may not worry about the leakage of the technical information to the competitor. Higher $\beta$ increases innovation. Higher innovation reduces production costs and induces firms to increase their output. Higher $b$ increases competition, imposes some pressure on the demand, and induces firms to reduce their output which is more than offset by higher $\beta$, and thereby firms increase their output. Higher output increases 
the net benefit of advertising and induces firms to increase their advertising. Consumers benefit from higher output and welfare increases as the result.

Under $R N$, an increase in $\beta$ increases profit if $\theta$ is low $(\theta \leq b / 2)$ such that the benefit from incoming advertising spillovers dominates the negative effect of the outgoing advertising spillovers. $R N$ does not internalize $\theta$. Thus, under $R N$ competitors suffer from $\theta$ when it is high, whereas they benefit from $\theta$ under $R A$, where they decide on their R\&D and advertising expenditures cooperatively.

\section{Proposition 2.}

(i) Under $N N$ and $R N$, an increase in advertising spillovers increases innovation, output, and welfare when advertising spillovers are low enough; otherwise, that decreases them.

(ii) Under NA and RA, an increase in advertising spillovers always increases innovation, output, and welfare.

Table 2.2 summarizes the results of Proposition 2.

An increase in $\theta$ increases the demand of the competitor's products which is not desirable. $N N$ and $R N$ do not internalize $\theta$. Higher $\theta$ increases the profit if the gains from incoming advertising spillovers dominate the negative effects of outgoing advertising spillovers on the demand. Indeed, firms may worry about the effect of higher $\theta$ on the demand of the competitor's products. This reduces the net benefit of advertising. Indeed, higher $b$ boosts competition, induces firms to reduce their output, and thereby increases firms' concerns about the impact of $\theta$ on the demand of the rival. Thus, higher $\theta$ benefits firms and induces them to increase their output and innovation when products are highly 
differentiated and $\theta$ is sufficiently low. In this context, higher innovation reduces production cost and benefits firms (this effect is significant when firms also cooperate in $R \& D$ ) and induces firms to increase their output further. Higher output increases the net benefit of advertising and induces firms to increase their advertising expenditures. Conclusively, higher output increases consumer surplus and welfare.

Under $N A$ and $R A$, firms choose their advertising expenditures cooperatively to maximize their joint profits. An increase in $\theta$ provokes the demand of the rival, benefits the rival. This enhances the competitor's incentive to increase its output and advertising efforts. Higher advertising boosts the market size, benefits both of the firms, and induces them to increase their output further. Higher output highlights the value of cost reducing $R \& D$ and induces firms to increase their R\&D. Higher R\&D benefits both of the firms and induces them to develop their innovation further to benefit from the value of its cost reduction effects (this effect is significant when firms cooperate in R\&D). Higher $b$ increases competition, induces firms to reduce their output which increases firms' concerns about the effects of $\theta$ on the demand. However, cooperating in advertising and internalizing the effects of $\theta$ mitigate these concerns, offset the negative effects of $b$ on output and profits specifically when firms also cooperate in R\&D. Ultimately, higher $\theta$ induces firms to increase their output and innovation. Consumers benefit from higher output and welfare improves.

Note that under $N A$, where firms choose their own R\&D non-cooperatively, an increase in $\theta$ increases the profit if $\beta$ is low $(\beta \leq b / 2)$; otherwise, it reduces the firm's profit. 


\subsection{Strategic Interaction of R\&D and Advertising}

This section studies when R\&D and advertising expenditures are strategic complements or strategic substitutes.

\section{Proposition 3.}

(i) $x_{j}$ and $x_{i}$ are strategic complements when $R \& D$ spillovers are high enough and (or) product substitutability is low enough; otherwise, they are strategic substitutes.

(ii) $x_{j}$ and $a_{i}$ are strategic complements when $R \& D$ spillovers are high enough and (or) product substitutability is low enough; otherwise, they are strategic substitutes.

(iii) $a_{j}$ and $x_{i}$ are strategic complements when advertising spillovers are high enough and (or) product substitutability is low enough; otherwise, they are strategic substitutes.

(iv) $a_{j}$ and $a_{i}$ are strategic complements when advertising spillovers are high enough and (or) product substitutability is low enough; otherwise, they are strategic substitutes

Table 2.3 shows a summary of the results.

Part $i$ of Proposition 3 states that when $\beta$ is high enough and products are highly differentiated, an increase in $R \& D$ by a firm always increases the marginal profit of R\&D to its rival. Higher R\&D of a firm reduces the firm's production cost as well as the rival's (through $\beta$ ), benefits both, induces them to increase their output and $\mathrm{R} \& \mathrm{D}$ further. Thus, $\mathrm{R} \& \mathrm{D}$ expenditures are strategic complements when $\beta$ is high enough and (or) $b$ is 
low. Higher product substitutability increases competition between firms, increases firms' concerns about the cost reduction effects of their $R \& D$ on the rival. Thus, firms increase their $\mathrm{R} \& \mathrm{D}$ when the benefit of incoming technological information dominates the negative effects of outgoing knowledge spillovers. The gain is significant when $\beta$ is high enough and $b$ is low. When $\beta$ is low and (or) $b$ is sufficiently high, an increase in $R \& D$ by a firm reduces the net benefit of $R \& D$ to the rival due to the intense competition, induces the rival to reduce its $R \& D$. In this case, $R \& D$ activities of the competitors are strategic substitutes.

Part $i$ of Proposition 3 states that an increase in R\&D by a firm always increases the marginal profit of advertising to the rival when $\beta$ is high enough and products are highly differentiated. A firm benefits from $\mathrm{R} \& \mathrm{D}$ of the rival through $\beta$. When products are highly differentiated, firms may not worry about the cost reduction effects of their R\&D activities on the rival. Thus, the firm increases its R\&D. This benefits the rival, reduces its production costs, and induces that to increase its output. Indeed, higher output increases the net benefit of advertising and induces the rival to increase its advertising. When goods are substitutes, competition is intense which requires firms' carefulness about the effects of their activities on the rival. Thus, $x_{j}$ and $a_{i}$ are strategic substitutes when $\beta$ is low and (or) $b$ is high.

Part iii of Proposition 3 states that an increase in advertising expenditures by a firm increases the marginal benefit of $\mathrm{R} \& \mathrm{D}$ to the rival when $\theta$ is high enough and products are highly differentiated. Higher advertising increases the demand of the competitor's products through $\theta$, benefits the competitor, and induces the competitor to increase its 
output. Higher output increases the net benefit of $R \& D$ and induces the competitor to increase its R\&D. Thus, $a_{j}$ and $x_{i}$ are strategic complements when $\theta$ is high enough and (or) $b$ is low enough. Moreover, when $\theta$ is sufficiently low (negative) and (or) $b$ is sufficiently high, a firm suffers from higher advertising of the competitor, reduces its output and R\&D. Thus, in this case, $a_{j}$ and $x_{i}$ are strategic substitutes.

Part $i v$ of Proposition 3 states that an increase in advertising expenditures by a firm increases the net benefit of advertising to the rival when goods are highly differentiated and $\theta$ is high enough. In this context, firms benefit from the advertising activities of one another due to its positive effect on the demand. Indeed, higher advertising of a firm reduces the demand of the competitor if $\theta$ is negative. When products are substitutes, firms are worried about the effects of their advertising on the demand of the rival. Thus, firms increase their advertising activities when $b$ is low and $\theta$ is high enough such that the gains from incoming advertising spillovers more than offset the negative effects of outgoing spillovers on the demand. Otherwise, firms reduce their advertising.

\subsection{Comparison of Cooperative Structures}

In this section, the different types of cooperation are compared in terms of R\&D. This comparison is important given that in the literature, there is no study focused on comparing these types of cooperation in terms of R\&D. Certainly, the choices that firms face with respect to cooperative structures are more complex than this binary decision. Firms require deciding not only whether to cooperate or not, but also to cooperate in which activities. The four types of cooperation are studied: no cooperation, R\&D 
cooperation, advertising cooperation, $\mathrm{R} \& \mathrm{D}$ and advertising cooperation. They have been explained in detail in Section 2.3.

Before proceeding with the analysis, it will be helpful to restate that the advertising spillovers may be positive or negative in this chapter. The negative advertising spillovers have a negative impact on the demand of the rival. Consequently, the cooperation setting which internalizes this negative effect yields lower $R \& D$. However, internalizing the positive advertising spillovers may increase (decrease) the innovation efforts with respect to the sign and magnitudes of spillovers and product substitutability. Moreover, when R\&D and advertising spillovers are low, the private gain from R\&D and advertising is substantial and boosts firms' incentive to increase their investment in them. This may induce firms to overinvest in $R \& D$ when firms decide on their R\&D and advertising non-cooperatively due to the strong competition. Additionally, under no cooperation, the importance of outgoing spillovers may induce firms to underinvest in R\&D when spillovers are sufficiently high.

The following Proposition summarizes the ranking of cooperation settings.

\section{Proposition 4.}

(i) If $\theta<0, \beta=0$ and $b=0$, then $X_{N N}=X_{R N}>X_{N A}=X_{R A}$

(ii) If $\theta<0,0<\beta<0.1$ and $b=0$, then $X_{R N}>X_{N N}>X_{R A}>X_{N A}$

(iii) If $\theta<0, \beta>0.1$ and $b=0$, then $X_{R N}>X_{R A}>X_{N N}>X_{N A}$

(iv) If $\theta<-b / 2, \beta<b / 2$ and $b>0$, then $X_{N N}>X_{R N}>X_{N A}>X_{R A}$

(v) If $\theta<-b / 2, \beta>b / 2$ and $b>0$, then $X_{R N}>X_{R A}>X_{N N}>X_{N A}$

(vi) If $\theta<b / 2$ and $\beta<b / 2$ where $\theta<\beta$, then $X_{N N}>X_{R N}>X_{N A}>X_{R A}$ 
(vii) If $\theta<b / 2$ and $\beta<b / 2$ where $\theta>\beta$, then $X_{N N}>X_{N A}>X_{R N}>X_{R A}$

(viii) If $\theta>b / 2$ and $\beta>b / 2$ where $\theta<\beta$, then $X_{R A}>X_{R N}>X_{N A}>X_{N N}$

(ix) If $\theta>b / 2$ and $\beta>b / 2$ where $\theta>\beta$, then $X_{R A}>X_{N A}>X_{R N}>X_{N N}$

To better understand the ranking of cooperation settings, it is helpful to review the competitive externalities and the effects of internalizing them. Cooperative R\&D induces firms to internalize the effect of the R\&D investment on the profits of the competitor. In other words, the competitive externality associated with R\&D reflects the marginal impact of the R\&D of a firm on the profits of other firms. In this model there are two types of competitive externalities: the advertising externality $(A E)^{22}$ and the R\&D externality $(R E)^{23} . A E$ represents the marginal effects of a firm's advertising on the profit of its competitor. This externality is internalized under $N A$ and $R A$. $A E$ can be positive or negative; depending on whether an increase in the advertising of a firm increases or decreases the profit of the other firms. $A E$ increases with spillovers, advertising and R\&D activities of the competitor and reduces with product substitutability. $R E$ represents the marginal effects of a firm's R\&D on the profit of the other firm. This externality is internalized under $R N$ and $R A^{24} . R E$ can be positive or negative; depending on whether an increase in R\&D by a firm increases or decreases the profit of the other firm. $R E$ increases with spillovers, advertising and R\&D

$$
\begin{aligned}
& { }^{22} A E=\frac{\partial \pi_{1}}{\partial a_{2}}=\frac{2(2 \theta-b)\left[(k-\alpha)+(1+\theta) a_{2}+(1+\beta) x_{2}\right]}{(2-b)(2+b)^{2}} \\
& { }^{23} R E=\frac{\partial \pi_{1}}{\partial x_{2}}=\frac{2(2 \beta-b)\left[(k-\alpha)+(1+\theta) a_{2}+(1+\beta) x_{2}\right]}{(2-b)(2+b)^{2}} \\
& { }^{24} R A \text { internalizes the sum of } A E \text { and } R E, \text { such that } \frac{\partial \pi_{1}}{\partial x_{2}}+\frac{\partial \pi_{1}}{\partial a_{2}}=\frac{4(\theta+\beta-b)\left[(k-\alpha)+(1+\theta) a_{2}+(1+\beta) x_{2}\right]}{(2-b)(2+b)^{2}}
\end{aligned}
$$


investments of the competitor and reduces with product substitutability. No competitive externalities are internalized under $N C$.

Part $i$ of Proposition 4 states that $X_{N N}=X_{R N}>X_{N A}=X_{R A}$ if $\theta$ is negative, $\beta$ reaches zero and goods are independent. Competition between firms is affected by advertising and cost reducing R\&D activities. When $\theta$ is negative, $A E$ is negative. Internalizing the negative advertising externality reduces the net benefit of advertising, reduces firms' incentive to increase their output and R\&D. $N A$ internalizes the negative $A E$. Additionally, when $\beta=0$, internalizing $R E$ is not effective since $R E$ also reaches zero. $R N$ internalizes $R E$ which is not effective (since $\beta=0$ and $b=0$ ), while $R A$ internalizes the sum of $A E$ and $R E$ which is negative. Under $N N$, no competitive externality is internalized. Thus, $N N$ and $R N$ yield the highest level of R\&D. $N A$ and $R A$ yield the same level of $\mathrm{R} \& \mathrm{D}$ which is lower than the $\mathrm{R} \& \mathrm{D}$ under $R N$ and $N N$.

Part $i i$ of Proposition 4 states that $X_{R N}>X_{N N}>X_{R A}>X_{N A}$ when $\theta$ is negative, $\beta$ is sufficiently low, and goods are independent. The negative $\theta$ is associated with negative externalities. When $\beta$ is sufficiently low, its externality is low yet positive since $\beta>0 . R N$ internalizes $R E$, whereas $R A$ internalizes the sum of $R E$ and $A E$. Although firms may weakly benefit from internalizing $R E$, internalizing the negative advertising externalities $(R E+A E<0)$ may more than offset the benefits. Thus, the highest innovation is achieved under $R N$. $N N$ internalizes no externality and takes second place of the ranking. $N A$ just internalizes $A E$ which is negative and yields lower $\mathrm{R} \& \mathrm{D}$ than $R A$ does. 
Part iii of Proposition 4 states that $X_{R N}>X_{R A}>X_{N N}>X_{N A}$ when $\theta$ is negative, $\beta$ is intermediate, and goods are independent. The negative $\theta$ is associated with negative $A E$, whereas $\beta$ is associated with positive $R E . \quad R N$ internalizes the positive $R E$. Thus, the highest $\mathrm{R} \& \mathrm{D}$ is achieved under $R N . R A$ internalizes the sum of $R E$ and $A E$ which is positive $(R E+A E>0)$, yet it is less than $R E$. In fact, the effects of negative $A E$ mitigate the effects of the positive $R E$ and thereby, $R A$ takes the second place in the ranking. Compare $N N$ and $N A$, where $N A$ internalizes the negative $A E$ which reduces firms' incentive to increase their R\&D, while $N N$ internalizes no externality. Conclusively, $N N$ yields higher R\&D than $N A$ does.

Part $i v$ of Proposition 4 states that $X_{N N}>X_{R N}>X_{N A}>X_{R A}$ when $\theta$ is negative, $\beta$ is sufficiently low, and goods are substitutes. When goods are substitutes, competition is intense. Thus, firms are worried about the effects of their R\&D and advertising on the rival through spillovers. The negative $\theta$ and the sufficiently low $\beta$ are both associated with negative competitive externalities when $b>0$. However, the negative effects of $A E$ are stronger than the effects of $R E . N N$ internalizes no externality, yields the highest innovation efforts. $R N$ takes the second place of the ranking by internalizing the weakly negative $R E$. NA internalizes the negative externality of advertising $(A E>R E)$ and takes the third place. $R A$ internalizes the sum of the negative competitive externalities and yields the least R\&D.

Part $v$ of Proposition 4 states that $X_{R N}>X_{R A}>X_{N N}>X_{N A}$ when $\theta$ is negative, $\beta$ is high and goods are substitutes. Although the negative $\theta$ is associated with negative competitive externalities, $\beta$ is associated with positive externality if it is high enough. Thus, internalizing $R E$ benefits firms and induces them to increase their R\&D. $R N$ 
internalizes the positive competitive externality of $R \& D$ and increases the net benefit of R\&D to the firms. $R A$ internalizes the sum of $A E$ and $R E$ where the negative effects of $A E$ partially offset the positive effect of $R E$. Thus, the highest innovation efforts are achieved under $R N$, whereas the second best is achieved under $R A$. Comparing $N N$ and $N A$ shows that $N N$ which internalizes no externality yields a higher R\&D investment than $N A$ which internalizes the negative competitive externalities of advertising.

Part $v i$ of Proposition 4 states that $X_{N N}>X_{R N}>X_{N A}>X_{R A}$ when $\theta$ and $\beta$ are positive and sufficiently low, yet $\beta>\theta$. When $\theta$ and $\beta$ are sufficiently low, they are associated with negative competitive externalities. Since $\theta$ is less than $\beta$, the negative effects of internalizing $\theta$ are more than the effects of internalizing $\beta$. Thus, $R A$ yields the least innovation efforts by internalizing the sum of these negative externalities. However, the highest innovation effort is achievable under $N N$ since $N N$ internalizes no externality. Comparing $R N$ and $N A$ where $\beta>\theta$ shows that $R N$ yields higher innovation efforts than $N A$ does.

Part vii of Proposition 4 states that $X_{N N}>X_{N A}>X_{R N}>X_{R A}$ when $\theta$ and $\beta$ are positive and sufficiently low yet $\theta>\beta$. Note that $\theta$ and $\beta$ are associated with negative competitive externalities when they are sufficiently low. Internalizing any negative externality reduces the net benefit of $R \& D$ and induces firms to reduce their $R \& D$ efforts. The negative competitive externality of advertising is less than the negative competitive externality of $\mathrm{R} \& \mathrm{D}$ when $\theta>\beta$. Therefore, $N A$ yields higher innovation efforts by internalizing $\theta$ than $R N$ internalizing $\beta$. Indeed, $R A$ yields the least innovation efforts by internalizing the sum of these negative externalities. However, the highest innovation effort is achieved by $N N$, which does not internalize any externality. 
Part viii of Proposition 4 states that $X_{R A}>X_{R N}>X_{N A}>X_{N N}$ when $\theta$ and $\beta$ are positive and high yet $\beta>\theta$. When $\theta$ and $\beta$ are high enough, they are associated with positive competitive externalities. Internalizing the positive competitive externalities benefits firms, increases the net benefit of $R \& D$, and induces firms to increase their output and R\&D. $R A$ internalizes the sum of positive competitive externalities of advertising and R\&D. Thus, $R A$ yields the highest innovation efforts. Comparing $R N$ and $N A$ shows that although both internalize a positive competitive externality, $R N$ yields higher innovation efforts than $N A$ does since $R E>A E$. Moreover, $N N$ yields the least innovation effort by internalizing no externality.

Part $i x$ of Proposition 4 states that $X_{R A}>X_{N A}>X_{R N}>X_{N N}$ when $\theta$ and $\beta$ are positive and high, yet $\theta>\beta$. Internalizing positive externalities increases the net benefit of $\mathrm{R} \& \mathrm{D}$ and induces firms to increase their innovation effort. Thus, $R A$ yields the highest innovation efforts by internalizing the sum of positive competitive externalities. Indeed, $N A$ internalizes a larger positive competitive externality than $R N$ does, since $A E>R E$. Thus, $N A$ takes the second place of the ranking and $R N$ takes the third place of that. Finally, $N N$ internalizes no externality and yields the least innovation efforts.

Considering the fact that higher cost reducing $\mathrm{R} \& \mathrm{D}$ reduces firms' production cost and yields a higher output. Ultimately, higher output yields higher consumer surplus and higher welfare. Thus, the same ranking is concluded for cooperative settings in terms of welfare. 


\subsection{Conclusion}

This chapter aims to study the impact of cooperative R\&D and advertising on innovation and welfare by duopolists, producing differentiated products in the presence of R\&D and advertising spillovers. Firms choose R\&D and advertising expenditures in the first stage and compete in output in the second stage. Four types of cooperation are considered: no cooperation, R\&D cooperation, advertising cooperation, $R \& D$ and advertising cooperation. The effects of cooperation strategies, product differentiation, and spillovers on innovation, advertising, output, welfare, and profit are considered. Additionally, strategic interaction between R\&D and advertising is studied. Finally, cooperation settings in terms of R\&D are classified. It is shown that no type of cooperation uniformly dominates the others. The type of cooperation yielding more innovation efforts depends on R\&D spillovers, advertising spillovers, and product differentiation. The ranking of cooperative structures rests on the sign and magnitude of $\mathrm{R} \& \mathrm{D}$ and advertising externalities which capture the effect of the R\&D or (and) advertising activities of a firm on the profit of the other firm. The cooperative structure inducing firms to internalize higher positive competitive externalities yields higher innovation efforts.

The impact of R\&D spillovers on innovation efforts, output, profit, and welfare are positive when firms cooperate in R\&D. However, the impact on innovation, output, profit, and welfare depends on the sign and magnitudes of spillovers and product substitutability when firms do not cooperate in R\&D. Additionally, the effects of advertising spillovers on innovation efforts, output and welfare are always positive when firms cooperate in advertising. However, the effect on innovation, output, profit, and 
welfare depends on the sign and magnitudes of spillovers and product substitutability when firms do not cooperate in advertising.

Strategic interaction among firms shows that firms' innovation efforts and advertising activities are strategic complements when spillovers are high enough and (or) product substitutability is low enough. Firms' innovation and advertising expenditures are strategic substitutes when spillovers are low and (or) product substitutability is sufficiently high.

The ranking of cooperative structures in terms of $R \& D$ rests on the sign and magnitudes of spillovers, product differentiation, and the prevailed cooperative structure. No cooperation setting dominates the other settings when spillovers are sufficiently low. However, cooperative R\&D and advertising yield the highest level of innovation when spillovers are sufficiently high. The same ranking is concluded for cooperative settings in terms of welfare since a larger cost reducing R\&D reduces firms' production cost and yields a higher output and thereby, higher consumer surplus and higher welfare are attained.

One of the basic results of the strategic cooperative R\&D and (or) advertising is the effects of cost sharing between competitors which enables firms to invest in more advertising and R\&D activities, positively affects innovation efforts and (or) the market size through internalizing spillovers when they are high enough. However, the model shows that these results do not necessarily hold when advertising and (or) R\&D spillovers are sufficiently low. In particular, cooperative advertising between competitors decreases R\&D when advertising spillovers are negative. Moreover, when R\&D 
spillovers are high enough, yet advertising spillovers are negative (sufficiently low), R\&D cooperation still benefits competitors.

The results of this chapter can be tested empirically. Effects of spillovers and product substitutability on innovation efforts, output, profit and welfare, the effect of collusion on innovation and advertising expenditures, and how firms respond to different R\&D and advertising strategies of their competitors can be addressed by empirical studies.

To protect innovation, the study of cooperative $R \& D$ and of cooperative advertising raises important science, technology, and marketing policy issues. Since this model abstracts from many real world issues, especially asymmetric information between the regulators and firms, drawing policy recommendations from the model requires carefulness. The model provides some considerations of R\&D policy and advertising regulation from the point of view of the incentives of cooperation and mergers.

The model points to an interaction between $\mathrm{R} \& \mathrm{D}$ cooperation policy, patent policy, and advertising cooperation procedures. To take advantage of internalizing the beneficial advertising and (or) technological spillovers where firms are allowed to cooperate, a slack patent and (or) advertising policy is recommended. However, innovation should be protected where cooperation is prohibited.

The model shows that the optimal R\&D and advertising policy varies according to R\&D spillovers, advertising spillovers, product substitutability and the prevailing cooperative structure. The model suggests that $R \& D$ cooperation is more often socially beneficial than advertising cooperation when advertising spillovers are negative. If, 
however, advertising spillovers are positive the cooperative structure which internalizes the most positive competitive externalities is more socially beneficial.

The results have suggestions for merger analysis. To maximize joint profits, mergers usually require the use of $R \& D$ and marketing. Economists usually focus on the output and efficiency effects of mergers, nevertheless, the innovation effects of mergers require more attention. The results show that the innovation effects of mergers in duopolistic industries depend on the level of R\&D and advertising spillovers. The appropriability conditions, technology absorptive capacities, the prevailed cooperative structure, the levels of spillovers, product substitutability, and market structure before the merger, are the key elements that lead the merger to reinforce or mitigate the negative effect of output reduction by increasing or decreasing in $R \& D$ and (or) advertising. In other words, this analysis points toward strict merger policy where output decisions are joint, yet R\&D decisions and (or) advertising decisions remain separate.

Ultimately, to support innovation the regulator should introduce policies to protect and access intellectual properties through a comprehensive strategy. Higher innovation translates to higher output and higher welfare and should be one of the most important focuses of the government. Although companies, businesses, and entrepreneurs should be supported, creators and inventors also should have enough incentive to continue. Cooperative R\&D allows companies to share the cost of the $R \& D$ and have access to the technological information of one another which may be encouraged through subsidizing or tax cut upon cooperative R\&D specifically where products are substitutes and competition is strong. This is a key step to solidify encouraging innovation. 
Table 2.1: The impact of R\&D spillovers

\begin{tabular}{|c|c|c|c|c|}
\hline & $\begin{array}{c}\text { No } \\
\text { Cooperation }\end{array}$ & $\begin{array}{c}\mathrm{R} \& \mathrm{D} \\
\text { Cooperation }\end{array}$ & $\begin{array}{l}\text { Advertising } \\
\text { cooperation }\end{array}$ & $\begin{array}{l}\text { R\&D and } \\
\text { Advertising } \\
\text { Cooperation }\end{array}$ \\
\hline$\partial X / \partial \beta$ & $\begin{array}{l}+ \text { if } b<2 /(1+2 \beta) \\
- \text { if } b>2 /(1+2 \beta)\end{array}$ & + & $\begin{array}{l}+ \text { if } b<2 /(1+2 \beta) \\
- \text { if } b>2 /(1+2 \beta)\end{array}$ & + \\
\hline$\partial a / \partial \beta$ & $\begin{array}{l}+ \text { if } b<2 /(1+2 \beta) \\
- \text { if } b>2 /(1+2 \beta)\end{array}$ & + & $\begin{array}{l}+ \text { if } b<2 /(1+2 \beta) \\
-i f b>2 /(1+2 \beta)\end{array}$ & + \\
\hline$\partial Y / \partial \beta$ & $\begin{array}{l}+ \text { if } b<2 /(1+2 \beta) \\
- \text { if } b>2 /(1+2 \beta)\end{array}$ & + & $\begin{array}{l}+ \text { if } b<2 /(1+2 \beta) \\
- \text { if } b>2 /(1+2 \beta)\end{array}$ & + \\
\hline$\partial \pi_{i} / \partial \beta$ & $\begin{array}{l}+ \text { if } \theta \leq b / 2 \& \beta \leq b / 2 \\
- \text { if } \theta>b / 2 \& \beta>b / 2\end{array}$ & $\begin{array}{l}+ \text { if } \theta \leq b / 2 \\
\pm \text { if } \theta>b / 2\end{array}$ & $\begin{array}{l}+ \text { if } \beta \leq b / 2 \\
\pm \text { if } \beta>b / 2\end{array}$ & + \\
\hline$\partial W / \partial \beta$ & $\begin{array}{l}+ \text { if } b<2 /(1+2 \beta) \\
- \text { if } b>2 /(1+2 \beta)\end{array}$ & + & $\begin{array}{l}+ \text { if } b<2 /(1+2 \beta) \\
- \text { if } b>2 /(1+2 \beta)\end{array}$ & + \\
\hline
\end{tabular}


Table 2.2: The impact of advertising spillovers

\begin{tabular}{|c|c|c|c|c|}
\hline & $\begin{array}{c}\text { No } \\
\text { Cooperation }\end{array}$ & $\begin{array}{c}\text { R\&D } \\
\text { Cooperation }\end{array}$ & $\begin{array}{l}\text { Advertising } \\
\text { cooperation }\end{array}$ & $\begin{array}{l}\text { R\&D and } \\
\text { Advertising } \\
\text { Cooperation }\end{array}$ \\
\hline$\partial X / \partial \theta$ & $\begin{array}{l}+ \text { if } b<2 /(1+2 \theta) \\
-i f b>2 /(1+2 \theta)\end{array}$ & $\begin{array}{l}+ \text { if } b<2 /(1+2 \theta) \\
- \text { if } b>2 /(1+2 \theta)\end{array}$ & + & + \\
\hline$\partial a / \partial \theta$ & $\begin{array}{l}+ \text { if } b<2 /(1+2 \theta) \\
- \text { if } b>2 /(1+2 \theta)\end{array}$ & $\begin{array}{l}+ \text { if } b<2 /(1+2 \theta) \\
- \text { if } b>2 /(1+2 \theta)\end{array}$ & + & + \\
\hline$\partial Y / \partial \theta$ & $\begin{array}{l}+ \text { if } b<2 /(1+2 \theta) \\
- \text { if } b>2 /(1+2 \theta)\end{array}$ & $\begin{array}{l}+ \text { if } b<2 /(1+2 \theta) \\
- \text { if } b>2 /(1+2 \theta)\end{array}$ & + & + \\
\hline$\partial \pi_{i} / \partial \theta$ & $\begin{array}{l}+ \text { if } \theta \leq b / 2 \& \beta \leq b / 2 \\
- \text { if } \theta>b / 2 \& \beta>b / 2\end{array}$ & $\begin{array}{l}+ \text { if } \theta \leq b / 2 \\
- \text { if } \theta>b / 2\end{array}$ & $\begin{array}{l}+ \text { if } \beta \leq b / 2 \\
- \text { if } \beta>b / 2\end{array}$ & + \\
\hline$\partial W / \partial \theta$ & $\begin{array}{l}+ \text { if } b<2 /(1+2 \theta) \\
- \text { if } b>2 /(1+2 \theta)\end{array}$ & $\begin{array}{l}+ \text { if } b<2 /(1+2 \theta) \\
- \text { if } b>2 /(1+2 \theta)\end{array}$ & + & + \\
\hline
\end{tabular}


Table 2.3: Strategic interaction

\begin{tabular}{ccc}
\hline & $b=0$ & $b>0$ \\
\hline$\partial^{2} \pi_{i} / \partial x_{i} \partial x_{j}$ & + & $+i f \beta>b / 2$ \\
& + & $-i f \beta<b / 2$ \\
$\partial^{2} \pi_{i} / \partial a_{i} \partial x_{j}$ & & $-i f \beta>b / 2$ \\
& $+i f \theta>0$ & $+i f \theta>b / 2$ \\
$\partial^{2} \pi_{i} / \partial x_{i} \partial a_{j}$ & $-i f \theta<0$ & $-i f \theta< \pm b / 2$ \\
\hline$\partial^{2} \pi_{i} / \partial a_{i} \partial a_{j}$ & $+i f \theta>0$ & $+i f \theta>b / 2$ \\
& $-i f \theta<0$ & $-i f \theta< \pm b / 2$ \\
\hline
\end{tabular}




\section{Chapter 3: The Impact of R\&D and Advertising on Firm Performance}

\subsection{Introduction}

Research and development (R\&D) and advertising are the most important marketing strategy elements (Mizik and Jacobson 2003). Marketing and innovation are the two fundamental functions of a business enterprise where they are translated to investment in two major aspects, R\&D as part of the company's innovation activities and advertising as part of its marketing mix (Drucker 1954). Firms' R\&D strategies seek to generate knowledge assets that allow a firm to develop either superior products or more efficient methods of production, while advertising attempts to differentiate the firm's product from competitors' products (Erickson and Jacobson 1992). Recent studies show that R\&D expenditures have grown faster than advertising expenditures. Although R\&D expenditures have grown among all types of firms, advertising expenditures have become more concentrated among larger firms (Hirschey et al. 2012).

Wernerfelt (1984) states that in advanced technology industries, R\&D investment offers benefits (p. 174) -"similar to a high tree in a small forest; because it obtains more sun, it will grow faster and remain taller". The technology intense industries are characterized by the continuous introduction of new innovative generation of products. Although potential return rewards motivate investment in R\&D and (or) marketing activities, the returns are significantly affected by the industry characteristics. For example, over the past three decades, the Information and Communications Technology industry (ICT) has witnessed several distinct developed generations, each pushing the technological frontier further. Given that bringing new products to market involves various elements of the marketing mix, how does management allocate resources to $R \& D$ 
when investment in advertising also carries over to affect future success? What significantly governs the choice of a company to invest in R\&D and (or) advertising when the main focus is on strategic advantages in instruments that affect the success of new products?

Firms decide on R\&D and advertising investment with respect to their resource constraints. The intensities of investment in R\&D and (or) marketing activities are strongly affected by the future returns of these activities. Additionally, industry competition drives profitability and therefore competitive strategy (Porter 1979). Previous analyses have shown that a company's specifications, R\&D intensity of the industry, returns on $\mathrm{R} \& \mathrm{D}$ and marketing activities determine how the strategic interaction of advertising and R\&D between firms may vary (Matraves 1999, Kwong and Norton 2007). Motivated by these findings, industry research scientists are becoming increasingly interested in the linkage between industry characteristics and marketing strategy instruments. R\&D and advertising expenditures are the important concern for industry analysts, who use them as proxies for innovation inputs and consider them to be a determinant of growth, productivity, and competitiveness. Moreover, a growing volume of empirical work shows that, in many instances, these strategy differences are related to the company's specifications or the industry characteristics.

This chapter examines the effectiveness of R\&D and advertising investments on market share for a panel of 150 manufacturing and non-manufacturing companies (Tables 3.1 and 3.2 show the list of them) concentrated in the U.S. information and communications technology industry. The focus on the set of active companies in an advanced technology industry rather than companies in a few different industries with 
different characteristics is a significant contribution to the existing literature on R\&D and advertising investment. The goal of the empirical analysis is to measure the impact of R\&D share and advertising share on market share of high tech companies. In the literature, the choice of the empirical model applied has relied on whether one focuses on firms' value or firms' performance. For studies incorporating a few companies, authors have looked at the impact of $R \& D$ and (or) advertising expenditures on the stock market performance. However, this chapter looks at the impact of R\&D and advertising expenditures on the revenue share of high tech companies. Additionally, the use of more recent (up to 2016) data makes this study different from others. Moreover, this chapter adopts a key marketing metric (market share). The focus on revenue share rather than firms' value is deliberate. Firstly, this is in line with most of the literature. Secondly, firms' revenue share is more interesting from a policy perspective, given the focus on the most advanced technology companies (manufacturers and non-manufacturers), results from this chapter may be able to indicate the potential role for R\&D policy in stimulating R\&D investment by high tech companies.

The following section contains the existing literature on the topic. Section 3.3 presents the conceptual framework of the analysis. The proposed model, data, methodology and other estimation issues are presented in section 3.4. Empirical results are presented in Section 3.5. Section 3.6 concludes the study.

\subsection{Literature Review}

The empirical studies show that although R\&D intensive industries are associated with large advertising expenditures, advertising intensive industries also require new 
innovative products. R\&D and advertising are costly and highly risky activities and require the participating companies to have strong financial stability. To have the required incentive to participate in $R \& D$, a firm must be able to set aside enough returns to make the investment profitable (Levin et al. 1987). Productive investment in R\&D results in an innovative product or service which enables a firm to differentiate its products from the competitors and to capture a greater market share. Indeed, firms require engaging in marketing activities to promote innovative products. Thus, there is a positive relationship between R\&D investment, advertising expenditures, and firm performance (Chauvin and Hirschey 1993). Additionally, taking full advantage of advertising requires a firm to have innovative and attractive products to take full advantage of advertising (Dugal and Morbey 1995; Morbey 1988). In other words, advertising investment is considered as an appropriation mechanism for investment in R\&D.

Conclusively, the result of $R \& D$ and advertising investment is reflected in the firm value (Chauvin and Hirschey 1993). Indeed, there is a bilateral relationship between firm value and firm performance. An improvement in the firm performance will push the company's stock price up, while the higher stock market price (firm value) establishes the higher reputation and makes the products more attractive which yields higher profits (Sudiyatno et al. 2012). R\&D and advertising increase firm performance due to the comparative advantage they create when used as a differentiation strategy which develops new products or processes and enhances the reputation of the brand name for the firm while its competitors cannot easily imitate them (Erickson and Jacobson 1992). 
Previous analysis shows that when an industry leader possesses higher research and development $(\mathrm{R} \& \mathrm{D})$ competence, it tends to invest more in $\mathrm{R} \& \mathrm{D}$ than competitors to maintain its leadership position. The leader's investment in R\&D displays an inverse- $U$ pattern as this advantage increases. However, the leader invests less than its followers when it benefits from the persistence of reputation. Market uncertainty and consumers' incomplete information provide more attention to the market leader because of its innovative reputation. Followers and competitors require spending millions of dollars to obtain attention in asymmetrically informed consumer markets (Ofek and Sarvary 2003). The value of the investment that must be spent on advertising to overcome the established brand loyalty of the incumbent may discourage the potential competitors from entering an advertising intensive market (Dugal and Morbey 1995; Morbey 1988).

Furthermore, there is a positive correlation between industry accounting profits and advertising intensity. An alternative interpretation of the relationship is that advertising allows firms to make monopoly profits which can be a cause of allocative inefficiency and thereby, should be considered as a potential area for legislation. The other alternative, explaining the relationship, is that the large advertising activities are the results of profitability through productive efficiency. Firms with high quality products (making higher profits per unit than they would make with low quality products) advertise more to signal this quality differentiation. Thus, high advertising expenditures are a quality premium rather than indicative of any monopoly power (Paton and Vaughan Williams 1999).

Iansiti and West (1997) state that although firms in high technology markets emphasize the role of R\&D and marketing in enhancing a firm's performance, the role of 
marketing is rarely acknowledged. This view of high technology industries is insufficient since a firm may have a strong R\&D ability but, due to its poor marketing ability, be incapable of exploiting it through commercially feasible products (Dutta et al. 1999). This argument highlights the importance of considering advertising, $R \& D$ and operational capabilities together to understand the significant role of inter-firm differences in performance. The main issue in observing the effect of innovation on firm performance is that it may require a firm a long time to convert economically valuable research and development growth into economic performance. Even after an important invention has been discovered, a firm is required to invest heavily in product development. In fact, converting a product idea into a set of successful manufacturing procedures and routines is often costly and difficult. Even after a valuable discovery has been patented, a firm in an uncertain market environment may treat the patent as a future option and postpone required investment and development costs (Bloom and Van Reenen 2002).

In high tech sectors, innovation is associated with sales growth for incumbent firms. A firm, on average, experiences a limited growth and may grow for a number of reasons that may or may not be related to R\&D activity. However, innovation is of crucial importance for a few of 'superstar' fast-growth firms (Coad and Rao 2008). It can be reasonable to expect that successful innovators grow more than other firms. Mansfield (1962) studies the data of a sample of the steel and petroleum sectors over a 40-year period and finds that successful innovators grow faster than other firms, especially if they were initially small. He states that the higher growth rate cannot be referred to their preinnovation behavior. 
There are many ambiguous theoretical and empirical results about the effectiveness of R\&D and advertising on firm value and (or) firm performance. Hirschey and Weygandt (1989) state that a firm's marketing efforts and R\&D expenditures have a positive impact on the market value of the firm. However, Jose et al. (1986) state that marketing intensity as well as deviations of R\&D intensity from industry norms, above or below, reduce firm value. Demir (2005) states that the main goal of management is to increase the market value of the firm, not just profit, which is accomplished via the sales revenue of firms. Osinga et al. (2011) state that firm value represents the expected future value that is mostly based on the marketing activities of the firm. Marketing and advertising expenditures are the instruments which affect the profitability negatively in the short-run, whereas they add value in the long-run.

Chan et al. (2001) state that investment in R\&D is considered an investment in intangible assets that contributes to the company's long-term growth and firm performance. Indeed, firm performance reflects the contribution of intangibles as well as tangible assets-in-place. However, Hall (1993) states that intangible assets are the important products of advertising investments. Intangible assets consist of the value of brand names, product differentiation, and goodwill arising from product differentiation. There is a positive relationship between advertising expenditures and stock returns such that the annual percentage changes in advertising expenditures are consistent with changes in stock prices (Reilly et al. 1977).

Scherer (1965) analyzes a small set of the largest U.S. industrial corporations and observes that inventions have a positive effect on company profits via sales growth. Interestingly, he shows that innovations typically do not increase profit margins but 
instead increase companies' profits via increased sales at constant profit margins. This suggests that sales growth is a meaningful indicator of post-innovation firm performance. Mowery (1983) considers the dynamics of the U.S. manufacturing companies over a 25year period and observes that $\mathrm{R} \& \mathrm{D}$ employment has a significantly positive impact on firm value (in terms of assets) regardless of firm size.

Geroski and Machin (1992) study a sample of large U.K. firms over an 11-year period, of which 18 percent of these firms produced an innovation during the period of study. They notice that innovating firms (i.e. firms that produced at least one 'major' innovation) not only are more profitable, but also grow faster than non-innovators. The effect of specific innovations on sales growth, however, does not last for long (p. 81) "the full effects of innovation on corporate growth are realized very soon after an innovation is introduced, generating a short, sharp one-off increase in sales turnover." They find that innovativeness has a more significant effect on profit margins than on sales growth; these findings are in contrast to Scherer's. Geroski and Toker (1996) study a sample of leading U.K. firms in different manufacturing industries and find that innovation has a significant positive effect on sales growth. Roper (1997) analyzes survey data of a large sample of small businesses in the U.K., Ireland, and Germany and finds that innovative products introduced by firms have a positive effect on sales growth. Freel (2000) studies the data of a sample of small U.K. manufacturing companies categorized by level of innovation and finds that although it is not necessarily true that innovators have experienced some form of sales or employment growth (i.e. sales per employee the measure of productivity used), yet innovators are likely to grow more. Finally, Bottazzi et al. (2001) study the dynamics of the worldwide pharmaceutical sector where 
there is no significant effect of a firm's innovation (i.e. the discovery of new chemical entities and (or) the proportion of patented products in a firm's product portfolio) on sales growth.

The ambiguity in both the theoretical and empirical results supports the requirement for more empirical analysis. It is within this context that I explore the effect of R\&D and advertising on market share in the advanced technology companies. In the next section, the proposed conceptual framework and hypotheses are presented.

\subsection{Conceptual Framework and Hypotheses}

The effectiveness valuation of $R \& D$ and advertising comes with a number of caveats including uncertainty about the type and strategies of $R \& D$ and advertising expenditures. The focus is on aggregate ( $R \& D$ and advertising) spending. There is no information on the type of advertising applied by firms (for example, price-oriented or differentiationfocused advertising). Additionally, there is no information on the type of R\&D projects (for example, process or product innovation). This information is not available for a large number of firms across the time period of study.

In the approach and evaluation of advertising and $\mathrm{R} \& \mathrm{D}$, the analysis is guided by Reibstein and Wittink (2005), who propose the use of measures relative to that of competitors. This paper uses "advertising share" and "R\&D share" rather than using absolute dollar expenditure. Reibstein and Wittink (2005) state that relative marketing metrics are more useful than absolute measures. They argue that the important question to ask is, "How are we doing relative to our competitors who operate under the same economic conditions" (Reibstein and Wittink 2005, p.8). Tubbs (2007, p.23) states that "a 
company that under-invests in $\mathrm{R} \& \mathrm{D}$ relative to its principal sector competitors will see a decline in the relative competitiveness of its products and services and this will soon be reflected in its business performance."

\subsubsection{R\&D and Advertising Expenditures}

There is an extensive agreement that the duration of the effects of advertising tends to be relatively short. Most analyses of advertising effects show that the primary effects of advertising do not last more than one year (Erickson and Jacobson 1992). The short length of advertising effects indicates that advertising has no significant effect on firm

performance. Wiggins and Lane (1983) show that high advertising efforts reduce quality risk to customers. They state that risk-averse consumers purchase highly advertised products. Thus, firms with higher advertising efforts relative to their competitors should attract more customers. However, a normal population group consists of all types of behavior groups (risk-averse, risk-neutral, and risk-lover). Moreover, the proportion of the risk-averse population is insignificant when the economy is doing well. On the other hand, higher advertising may increase the cost and thereby reduces marginal profits. Therefore, the following hypothesis is examined.

Hypothesis 1 (H1): Increasing advertising share has no significant effect on market share.

There is also a general agreement that the duration of effects of $R \& D$ is considerably longer than the duration of advertising's effects. However, there is a minor agreement on the length of the R\&D lag structure (Boulding and Staelin 1995; Ravenscraft and Scherer 1982). This paper follows Erickson and Jacobson (1992), who 
state that a three-year lagged structure captures nearly $80 \%$ of the total effect of R\&D. The long lasting R\&D effects show that $R \& D$ may have a significant effect on the profit, revenue, market share, and sales growth (Rubera and Kirca 2012).

Considering R\&D activities requires distinguishing between process and product innovations. Process innovations are revelations of new cost reducing methods for producing existing products, whereas product innovation focuses on the production of new goods and services (Pepall et al. 2008). Process innovations can contribute to the profit (the net revenue) by reducing firms' production costs as well as to market share by maintaining price competitive. Product innovations also contribute to market share and revenue by satisfying existing demand and (or) launching new demand. Conclusively, a strategy of increasing R\&D is associated with higher firm performance. Following the logic, the following is posited.

Hypothesis 2 (H2): Increasing $R \& D$ share has a positive effect on market share and revenue.

Since the effect of R\&D can last over time, competitors are willing to copy successful innovations. The duplication process may be faster and more accessible for non-manufacturers. Thus, R\&D activities by non-manufacturing companies come into operation faster than they do by manufacturing companies. Indeed, R\&D investments by non-manufacturers can be more effective on their market share. Regarding the comparison between the impacts of $\mathrm{R} \& \mathrm{D}$ on market share by manufacturers and nonmanufacturers, the following is posited: 
Hypothesis 3 (H3): Increasing $R \& D$ share has a greater effect on market share and revenue of non-manufacturing companies.

\subsection{The Model, Data, and Methodology}

This section is divided into three parts. The first part describes the model. The second one defines the data and the variables in the research model. The estimation preparation and research method which is used to test the formulated hypothesis will be described in the third part.

\subsubsection{The Model}

The model follows some features of Boulding's and Staelin (1995), who provide an approach for assessing generalizable effects of strategic actions on firm performance and theorize a multiplicative performance model:

$$
\begin{gathered}
Y_{i, t}=\prod_{a=0}^{1}\left(A D V_{i, t-a}\right) \times \prod_{b=0}^{3}\left(R \& D_{i, t-b}\right) \times e^{\theta_{i, t}} \\
\theta_{i, t}=\theta_{0}+\theta_{1} \text { Size }_{i, t}+\theta_{2} \text { Concen }_{i, t}+\varepsilon_{i, t}
\end{gathered}
$$

where $i$ indicates firm $i$ and $t$ indicates year $t$. Firm performance (market share or revenue share) is $Y$, advertising ( $R \& D)$ share is $A D V(R \& D)$, Size is (log) firm size, and Concen shows the degree of concentration in the primary industry where the firm is active.

Equation (3.4.1) shows contemporary and carryover effects applying the wellknown finite distributed lag (FDL $\left.\left[K_{A D V}, K_{R \& D}\right]\right)$ model of Hanssens et al. (2001), where $K$ implies the number of lags. The literature review led the analysis to indicate $K_{A D V}=1$ and $K_{R \& D}=3$. 
Coefficients $\theta_{1}$ and $\theta_{2}$ (Eq. 3.4.2) indicate the effects of the control variables (firm size and concentration based on the firm's primary industry). Ultimately, the error term, $\varepsilon$, controls for random contemporaneous unobserved factors.

Substituting Equation (3.4.2) in Equation (3.4.1) and taking logs, the following theoretical model is obtained which will be examined in this empirical analysis:

$$
\ln Y_{i, t}=\theta_{0}+\sum_{a=0}^{1} \ln \left(A D V_{i, t-a}\right)+\sum_{b=0}^{3} \ln \left(R \& D_{i, t-b}\right)+\theta_{1} \text { Size }_{i, t}+\theta_{2} \text { Concen }_{i, t}+\varepsilon_{i, t}
$$

\subsubsection{Data}

Rather than focusing on a large set of companies in different industries with different characteristics over a long time horizon like the bulk of the literature, this chapter uses data for a panel of advanced technology companies concentrated in an industry over a number of years. The panel is "short and wide" in that there are many industry specific companies (150 companies ${ }^{25}$ including 62 manufacturers and 88 non-manufacturers) but fewer years. The focus on companies operating in the high tech industry is deliberate. First, it allows access to a sample with similar R\&D and advertising intensity. More importantly, while previous studies have focused on the stock market value of companies across industries the estimation procedure employed in this paper focuses on the market share (revenue share) of the companies.

\footnotetext{
${ }^{25}$ Most of the manufacturing companies provide equipment for different businesses in the information and communications industry (B2B). However, most of the non-manufacturing companies provide services to the final consumers (B2C).
} 
The panel setting is publicly traded U.S. companies which are active in the information and communications technology industry for the period of 2007-2016. The data were obtained from the Electronic Data Gathering, Analysis, and Retrieval system (EDGAR) that compiles datasets from company filings maintained by the U.S. Securities and Exchange Commission and Mergent Online industry annual database. Since some key variables such as advertising expenditures are just available on an annual basis, the Mergent annual database is used. The summary of statistics is given in Table 3.3.

The data shows that in average the manufacturers spend more on advertising activities than they do on R\&D. Mostly, their share in advertising and R\&D is more than their revenue share. However, the non-manufacturers almost spend equal amount on advertising and R\&D activities, which is sufficiently lower than their revenue share.

Moreover, for the period of 2007-2010 (the recent recession) the manufacturers show a constant investment in R\&D. Since 2011 (when the economy starts recovering), the manufacturers' expenditures on advertising and R\&D increase sharply. The manufacturers reduce their spending on R\&D in 2012. In average, they uniformly increase their expenditures on R\&D and advertising in later years. Illustration 3.1 shows the result.

The data shows that from 2007 to 2009 the non-manufactures reduce their expenditures on $R \& D$ and advertising. However, since 2010 when the economy starts recovering the non-manufacturers slightly increase their spending on advertising and R\&D. In 2014, their average expenditures on $R \& D$ and advertising increase sharply. However, their investments on $R \& D$ are larger than those on advertising. This might be 
due to introducing the new generation of technologies and applications in telecommunications such as Broadband technologies, Telegram, IMO, or other new apps. The non-manufacturing companies reduce their $\mathrm{R} \& \mathrm{D}$ and advertising expenditures in 2015. However, they increase their investments in later years. Illustration 3.2 shows the result.

\subsubsection{The Variables}

This section explains the measurement and variables of interest in the research model.

\subsection{Firm Performance}

The firm revenue data, expressed in dollars, are obtained from industrial annual income from Mergent online. Market share is expressed as a fraction and is calculated as the firm's revenue divided by the revenue of all firms in the ICT industry (the same six-digit standardized industry classification (NAICS) code), gathered from Mergent segment database. For a firm that engages in multiple industries, its revenue in all the industries where it is active using the corresponding six-digit NAICS codes is considered. To derive the industry revenue, the revenue of all firms in these six-digit NAICS codes is aggregated. Ultimately, a firm's overall market share is calculated using the revenue weighted average of its market share across its different business segments.

\subsection{Advertising and R\&D Share}

Companies' advertising and R\&D data are obtained from EDGAR advertising expenses and R\&D expenses, respectively. Advertising (R\&D) share is denoted as a fraction and is computed as the firm's advertising (R\&D) expenditure divided by those of all firms in the 
ICT industry (with the same six-digit NAICS code). For a firm that operates in multiple industries, advertising and R\&D expenditures in all the industries, where it is active using the corresponding six-digit NAISC codes, are gathered. To derive the overall advertising and $R \& D$ expenditures in the industry, the advertising and $R \& D$ of all firms in these sixdigit NAICS codes are aggregated. Finally, a firm's overall advertising and R\&D share as the revenue-weighted average of its advertising and $\mathrm{R} \& \mathrm{D}$ share across different business segments are calculated.

\subsection{Control Variables}

The model includes several control variables to allow for a more precise test of hypotheses. Firm size is an important element in any analysis of firm performance. Larger firms are associated with higher market power, which reflects their market share and revenue (Boulding and Staelin 1990). The model also controls for the degree of concentration in the primary industry where the firm is performing (Lipczynski et al. 2005). Ultimately, the model controls for the positive effect of market share on profit ${ }^{26}$ (Szymanski et al. 1993).

The natural $\log$ of firm total assets measured in dollars operates as firm size. The primary six-digit NAISC code in Mergent database identifies the firm's primary industry. The degree of concentration of the firm's primary industry (based on its primary six-digit

\footnotetext{
${ }^{26}$ The theoretical model has been designed to capture the impact of R\&D and advertising on market share and (or) profit; however, due to the lack of data and information about the companies' profit for the duration of study, the empirical model estimates only the impact of $\mathrm{R} \& \mathrm{D}$ and advertising on market share.
} 
NAISC code in the Mergent database) is measured by the Herfindahl index, such that larger values imply higher concentration.

\subsubsection{Methodology}

Before proceeding to estimate the theoretical model, the following aspects are checked.

(1) Stationarity in the time series

(2) Cointegration

(3) The linearity of the correlation

(4) Endogeneity

\subsubsection{Stationarity in Time Series}

Although panel data sets are useful in analyzing cross section phenomena over time, the time series component is associated with the potential non-stationarity in the variables. A nonstationary panel data may produce spurious results, and inferences based on $t$-values may be strongly misleading (Hanssens et al. 2001). To determine whether there is a long run relationship between the variables in the presence of nonstationary panel data, panel cointegration tests are required. The majority of the panel unit-root tests require a strongly balanced data set, meaning each panel has the same number of observations covering the same time span. However, this analysis deals with an unbalanced panel data. Therefore, two panel unit-root tests are employed, the Hadri (2003) Lagrange Multiplier and Fisher-type (Choi 2001) tests. Although all the tests require no gaps in any panel's series except for the Fisher tests. Using the four methods introduced by Choi (2001), the Fisher test combines the $p$-values from the panel specific unit-root tests. Three of the 
methods are different in using the inverse-chi-squared, inverse-normal, or inverse-logit transformation of $p$-values, and the fourth modifies the inverse-chi-squared transformation which is suitable when $N \rightarrow \infty$. The inverse-normal and inverse-logit transformations can be used regardless of $N$ being finite or infinite. Moreover, Fisher performs by two options, based on either Augmented Dickey-Fuller unit-root tests or Phillips-Perron unit-root tests, on each panel depending on how the choice of the options is specified. The null hypothesis being tested by Fisher is that all panels contain a unitroot.

Thus, the Fisher panel unit-root test, based on Augmented Dickey-Fuller tests, specified for the unbalanced panel is applied. Table 3.4 in the Appendix shows the results of the Fisher test. The Fisher panel unit-root test on the undifferenced data indicates that the null hypothesis of the presence of a unit-root cannot be strongly rejected (lasset: inverse-normal $z=0.0882$, industry concentration: Inverse-chi-squared $=298.4940$ ), lasset and industry concentration are likely non-stationary in the level. However, after first differencing, the data are stationary (lasset: inverse-normal $z=-14.6643, p=0$; industry concentration: Inverse-chi-squared $=523.4452, p=0$ ). Thus, no panel contains a unit-root in first differences (table 3.5).

The null hypothesis of the Hadri Lagrange Multiplier test states that all series are stationary which is against an alternative hypothesis which states that at least one series contains a unit-root. Despite most panel unit-root tests, the Hadri Lagrange Multiplier test reverses the null and alternative hypotheses in respect, such that strong evidence is needed to reject the null hypothesis, and thereby plays as an additional alternative to check for stationarity. The major disadvantage of this test is that it is better suited for 
panels with $T$ tending to infinity and more moderate $N$, which is clearly not the case in this analysis. Indeed, this test requires a strongly balanced panel set, and thus it could be only applied to a balanced subset of the data. Given these limitations, Hadri Lagrange Multiplier test is not suitable for the considered dataset in this study.

Additionally, it is necessary to interpret the unit-root tests with caution. Karlsson and Lothgren (2000) show that when the time dimension of the panel is relatively small, the unit-root tests have low power. Thus, in this context, there is a greater possibility of incorrect conclusion that the entire panel is non-stationary in the level. Results from this test should therefore also be interpreted with caution.

\subsubsection{Cointegration}

To determine whether there is a stable, long-run relationship between variables where time series are nonstationary, the cointegration test is applied. Panel methods for cointegration are based on methods developed for single time series assuming that $T \rightarrow \infty$ and $N$ is sufficiently large. The cointegration tests are required when time series are nonstationary to determine whether they have a stable, long-run relationship. However, applying the first difference method to nonstationary time series may yield a stationary time series. One type of cointegration tests, introduced by Kao (1999) is the Engle-Granger (1987) two-step residual-based test. Kao cointegration tests (1999) describe two tests under the null hypothesis of no cointegration for panel data. One is based on a Dickey-Fuller test and another is based on an Augmented Dickey-Fuller test. For the Dickey-Fuller type test, Kao presents two sets of specifications. 
Applying the Kao test for cointegration, based on Dickey-Fuller tests, the null hypothesis of no cointegration for all test statistics and specifications is accepted (Dickey-Fuller $t=-1.097, p>0.05$ ). Given the relatively short time dimension of the panel, it is expected that no cointegrating relationship is found. Existing studies that have found a long-run relationship between firm performance, R\&D and advertising have much longer time dimensions in their analysis. Indeed, the time period in this analysis is too short to capture a long-run relationship. Table 3.6 in the Appendix presents results from the Kao's panel cointegration tests.

\subsubsection{The Linearity of the Correlation}

The Pearson correlation coefficients are a measure of the linear correlation between the variables (Pearson 1896) with a value between +1 and -1 , where 1 indicates a perfect positive linear correlation, 0 indicates no linear correlation, and -1 shows a perfect negative linear correlation. To examine whether there is a causal link between the independent and dependent variables, the linear correlation between the variables is studied. Table 3.7 shows the results. The results show that there is a moderate correlation between the dependent variable (revenue share) and the independent variables (the first lag of advertising share and the third lag of $R \& D$ share). The results show a weak correlation between the dependent variables (the first lag of advertising share and the third lag of R\&D share). In the presence of multicollinearity in the variables, the results are not reliable since the predictor variables are already predicted by the other independent variables. However, the weak correlation between the explanatory variables should not be a problem. 


\subsubsection{Endogeneity}

The variables are suspected to present a potential endogeneity problem inherent in the basic research question. The companies that influence their revenue share by promoting new innovative products in the industry may follow steps to promote innovation and advertising further. This may lead to bias in coefficient estimates, particularly in OLS regressions.

The Durbin-Wu-Hausman test (Durbin, 1954; Hausman, 1978; Wu, 1973), DWH test, is widely used to test for the endogeneity problem. However, the DWH test and the Sargan-Hansen test (Sargan 1958; Hansen et al. 1996) are identical and are just tests of orthogonality conditions (Baum et al. 2003). Thus, this analysis proceeds using the Sargan-Hansen $\operatorname{test}^{27}$ for the endogeneity problem with the null hypothesis that the regressor is exogenous. Starting with an IV estimation in which two regressors (the first lag of advertising share and the third lag of $\mathrm{R} \& \mathrm{D}$ share) are treated as endogenous variables requires performing the Sargan-Hansen endogeneity test to clarify whether the regressors need to be instrumented. The results show that the null hypothesis is rejected and there is no need for the regressors to be instrumented ${ }^{28}$. In other words, the first lag of the advertising share and the third lag of R\&D share have no correlation with the current error term, and thereby there is no endogeneity issue with respect to the lag (s) of the variables of interest. Finally, the results suggest that an Ordinary Least Square (OLS) method is required to estimate the model consistently.

\footnotetext{
${ }^{27}$ The Sargan-Hansen test is provided in the second stage of IV estimation.

${ }^{28}$ Tables C.1, C.2, C.3, and C.4 in the Appendix show the results.
} 


\subsection{Empirical Results}

The analysis uses OLS with the fixed effect option to eliminate the Fixed Effects. In the Fixed Effects (FE) model, the individual specific effect is treated as non-stochastic and is suitable for unbalanced data, which is characteristic of the dataset used in this chapter. The following considerations lead the analysis to choose a fixed effects model (Allison 2009).

There may be omitted variables, which are correlated with the variables of interest in the model. In a fixed effects model, subjects serve as their own controls and may provide a means controlling for omitted variable bias. The idea is that the effects of the omitted variables on the subject remain constant or fixed over time. Thus, the omitted variables must have time-invariant values with time-invariant effects.

(1) Time-invariant values mean that the value of the variable does not change across time. Industry characteristics (i.e. R\&D intensity of the industry) of the participating companies are an example.

(2) Time-invariant effects mean the variable has the same effect across time. For instance, the effect of the industry characteristics on the outcome at the first year is the same as the effect of that at the fifth year.

(3) If either of these assumptions is violated, the model requires having explicit measurements of the variables in question. In the case of time-varying effects, things like the interaction of the industry characteristics with time can be included. Explicit measurements of time-invariant variables are also required if 
they are thought to interact with other variables in the model (i.e. the effect of financial allocations differs by industry characteristics).

Fixed effects models, control for the average differences across groups (companies) in any observable (such as differences in R\&D investments and advertising expenditures) or unobservable (such as the companies strategies of marketing, $R \& D$, and output) predictors. In other words, instead of focusing on each year's observation in terms of how much it differs from the prior year for the same company it is efficient to think about how much each observation differs from the average for that company. With three key variables, $R \& D$ investments, advertising expenditures, and revenue share the analysis is concerned with the following:

(1) Variations in $R \& D$ investments around the mean $R \& D$ investment for each company.

(2) Variations in advertising expenditures around the mean advertising expenditures for each company.

(3) Variations in revenue share around the mean revenue share for each company.

The analysis is eager to know whether variations in the R\&D investments and advertising expenditures (around their means) are related to variations in revenue share (around their means).

Note that by subtracting the means, all of the action in the regression to withingroup (company) action is restricted. Thus, the key source of omitted variable bias, namely, unobservable across-companies differences are eliminated. This is known as a 
"fixed effects" regression because it holds constant (fixes) the average effects of each company.

Ultimately, the model uses the first lag of advertising expenditures and the third lag of $R \& D$ investments as variables of interest. Indeed, the model uses the first difference of the natural logarithm of asset and the first difference of the industry concentration as control variables since the results show that no panel contains a unitroot in first differences.

\subsubsection{Estimation}

\subsubsection{Manufacturers}

The model is estimated by OLS with the FE option. Indeed, the first differences are used for the control variables (lasset and concen) to deal with the unit-root. Table 3.8 provides the results.

The results show that advertising, surprisingly, has a negative effect on manufacturers' revenue share $\left(\beta_{0}=-.021, p<0.12\right)$. The estimates imply that revenue share decreases by $2.1 \%$ for each additional dollar investment in advertising share. Although the statistical result is insignificant, the negative sign shows that advertising activities do not benefit manufacturers. However, the R\&D has a positive effect on market share $\left(\beta_{1}=0.08, p<0.032\right)$. In fact, revenue share increases by $8 \%$ for each additional dollar invested in R\&D. The statistics show that firm size has a positive effect on revenue share $\left(\theta_{1}=.013, p<0.61\right)$. Although the statistical result is not significant, it shows that if a firm's asset value increases by a dollar the firm's revenue share increases by $1.3 \%$. Industry concentration has a negative effect on manufacturers' 
revenue share $\left(\theta_{2}=-.0013, p<0.76\right)$. The statistical result shows that if market concentration increases by a unit, the revenue share of a firm is reduces by $0.13 \%$ (higher market concentration means most of the total market share is captured by a small number of firms). However, the statistic of $p$-value shows that the effect of industry concentration on revenue share is not significant.

The results support the first and second hypotheses of the chapter that advertising has no significant effect on market share and revenue among manufacturers; also R\&D has a positive effect on market share and revenue.

\subsubsection{Non-manufacturers}

The model is estimated by OLS with the FE option. To defeat the unit-root problem, the first differences are used for the control variables (lasset and concen). Table 3.9 provides the results.

According to the results, similar to the manufacturing companies, advertising has a negative effect on non-manufacturers' revenue share $\left(\beta_{0}=-.01, p<0.075\right)$. The result shows that for each additional dollar investment in advertising, revenue share decreases by $1 \%$. However, the statistical result is not significant; the negative sign shows that advertising activities reduces profits of non-manufacturers. Despite the effects of advertising, $\mathrm{R} \& \mathrm{D}$ has a positive effect on market share $\left(\beta_{1}=0.21, p=0\right)$. The results show that revenue share increases by $21 \%$ for each additional dollar invested in R\&D. The impact of firm size on revenue share is negative $\left(\theta_{1}=-.00004, p<0.9\right)$. It shows that if a firm's asset value increases by a dollar the firm's revenue share decreases by $0.004 \%$, yet the statistical result is insignificant. The results also show that for each unit 
increasing in industry concentration, revenue share of non-manufacturing companies decreases by $4 \%\left(\theta_{2}=-.004, p<0.81\right)$. However, the effect is insignificant.

The results prove the first, second, and third hypotheses of the chapter that advertising has no significant effect on market share; R\&D has a positive effect on market share and revenue; also $R \& D$ has a greater effect on market share and revenue of non-manufacturing companies.

\subsection{Conclusion}

The crucial role of $R \& D$ and advertising activities in the marketing strategy of a company is clear. These factors have been the focus of extensive research attention. However, it is surprising that little analysis has been conducted on their effectiveness in relation to the industry specification and the R\&D intensity of the industry where the firm operates. This chapter aims to contribute to filling this gap.

This chapter proposes a conceptual framework to explain how the effectiveness of marketing instruments in the advanced technology industries is significant. Using this framework, the hypotheses concerning the effectiveness of $R \& D$ and advertising activities are developed. The hypotheses are tested using a sample of 150 U.S. companies in the ICT industry across a time span of a decade. The companies operate in the manufacturing and non-manufacturing sectors of the industry. This selection allows the analysis for a more precise test of the firm specification; also allows the analysis to study the effectiveness of the marketing instruments in both sectors. The analysis shows that investments in R\&D pay off in both sectors of manufacturing and non-manufacturing 
high tech companies in the ICT sector. R\&D investments benefit non-manufacturing companies more. Advertising share has no significant effect on market share.

This chapter explains the importance of the industry specification and the R\&D intensity of the industry in the effectiveness of marketing strategies. However, most highly R\&D intensive industries also have high advertising expenditures to introduce the new innovative products to the market or develop the market size like the pharmaceutical industry. This chapter argues that even different $R \& D$ intensive industries are not equally affected by marketing instruments. The nature of the ICT industry is based on technology and innovation. These companies participate in process R\&D to reduce the production costs along with participation in product R\&D to develop new products. Additionally, the dynamic competition in the market in which new innovative products and lower production costs are the focus of marketing strategy considerably affects the ability of a company to achieve future success. Although advertising activities help the companies to introduce the products that are new to the market as well as improve the market size, investing in advertising requires carefulness. $\mathrm{R} \& \mathrm{D}$ and innovation to advanced technology companies are more than a marketing instrument, but that is an important input. The results of this chapter help the management to decide on marketing strategy to guide the firm to success. 
Table 3.1: The list of the U. S. manufacturing companies

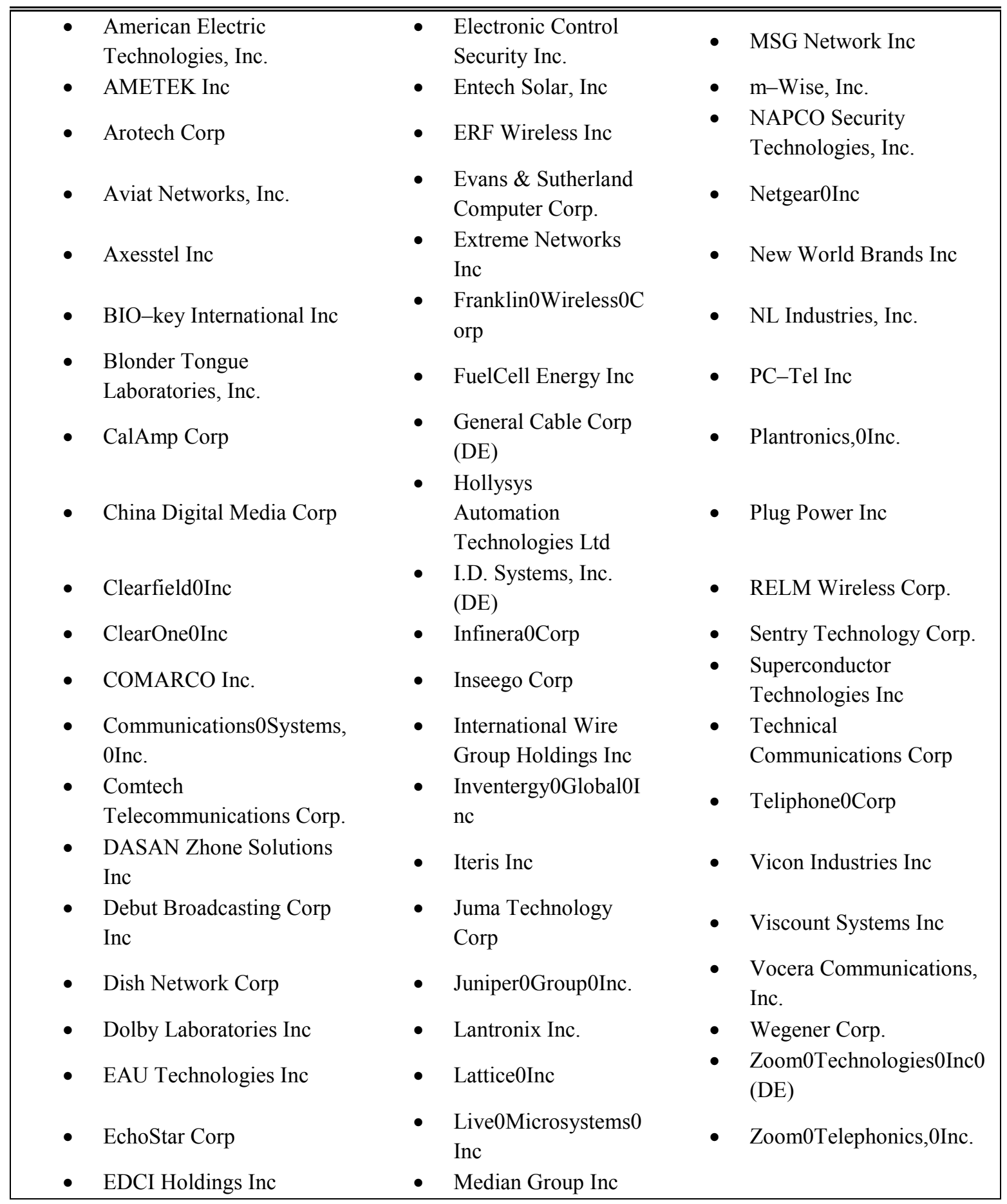


Table 3.2: The list of the U.S. non-manufacturing companies

\begin{tabular}{|c|c|c|}
\hline 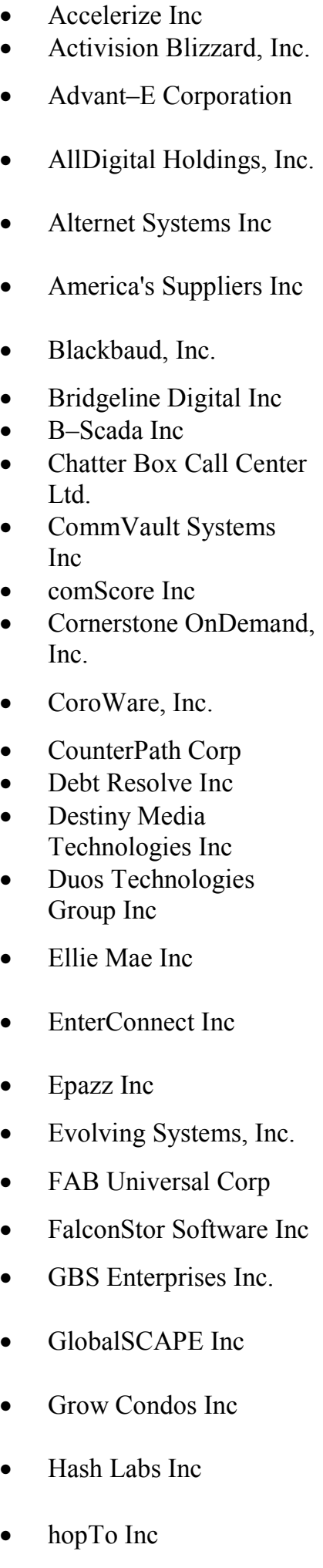 & 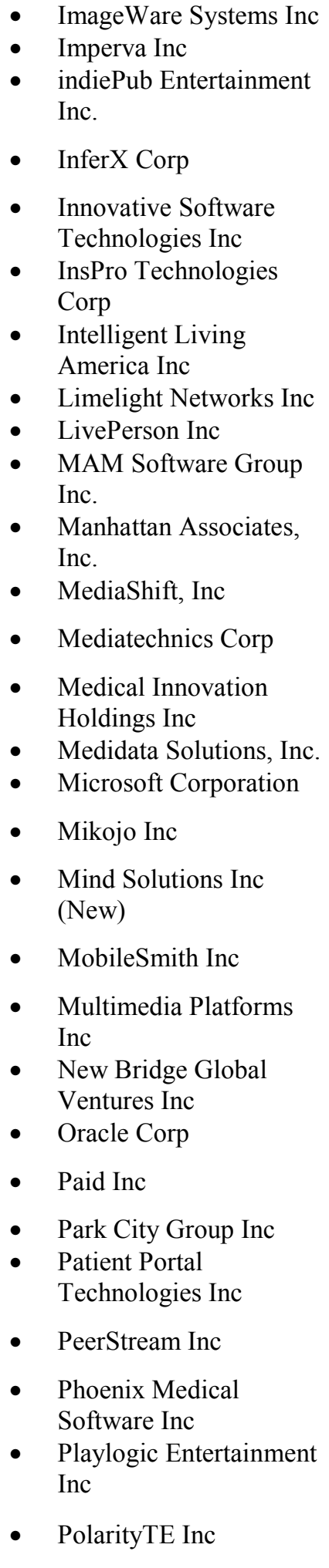 & 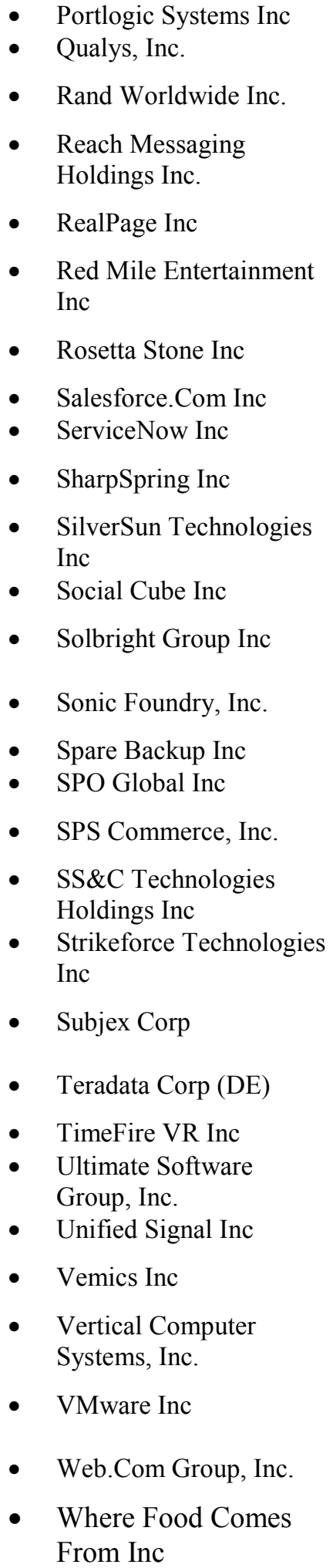 \\
\hline
\end{tabular}


Table 3.3: Summary statistics

\begin{tabular}{|c|c|c|c|c|c|}
\hline Variable & Mean & Std. Dev. & Min & Max & Observations \\
\hline \multicolumn{6}{|l|}{ Share_rev } \\
\hline Overal & .0290376 & .0866065 & $4.72 \mathrm{e}-10$ & .6694659 & $\mathrm{~N}=1245$ \\
\hline between & & .0785922 & $5.21 \mathrm{e}-08$ & .5824478 & $\mathrm{n}=150$ \\
\hline within & & .015346 & .0993172 & .1868604 & $\mathrm{~T}-\mathrm{bar}=803$ \\
\hline \multicolumn{6}{|l|}{ L1.Share_ad } \\
\hline Overal & .0321973 & .1218707 & 0 & .8804904 & $\mathrm{~N}=1098$ \\
\hline between & & .0981961 & 0 & .7139917 & $\mathrm{n}=150$ \\
\hline within & & .0570371 & -.4648891 & .719819 & $\mathrm{~T}-\mathrm{bar}=7.32$ \\
\hline \multicolumn{6}{|l|}{ L3.Share_rd } \\
\hline Overal & .0328885 & .0889147 & 0 & .6880826 & $\mathrm{~N}=796$ \\
\hline between & & .0801954 & 0 & .616457 & $\mathrm{n}=150$ \\
\hline within & & .0180241 & -.1167585 & .1701537 & $\mathrm{~T}-\mathrm{bar}=5.768$ \\
\hline \multicolumn{6}{|l|}{ lasset } \\
\hline Overal & 17.10791 & 3.174143 & 4.990433 & 25.98955 & $\mathrm{~N}=1232$ \\
\hline between & & 3.182357 & 6.933907 & 25.45103 & $\mathrm{n}=150$ \\
\hline within & & .7931161 & 12.17155 & 23.55505 & $\mathrm{~T}-\mathrm{bar}=8.213$ \\
\hline \multicolumn{6}{|l|}{ Concen } \\
\hline Overal & .3585167 & .1264429 & .1191912 & .9202917 & $\mathrm{~N}=1283$ \\
\hline between & & .0909744 & .1664705 & .4992311 & $\mathrm{n}=150$ \\
\hline within & & .0919882 & .2147674 & 1.042778 & $\mathrm{~T}-$ bar $=8.553$ \\
\hline
\end{tabular}


Table 3.4: The results of the Fisher unit-root test

Fisher-type unit-root test

Based on augmented Dickey-Fuller tests

Ho: All panels contain unit-roots

Number of panels $=150$

Ha: At least one panel is stationary

Avg. number of periods $=8.30$

AR parameter: Panel-specific

Asymptotics: T -> Infinity

ADF regressions

\begin{tabular}{|l|lllll|}
\hline \multirow{2}{*}{$\begin{array}{l}\text { Inverse chi- } \\
\text { squared }\end{array}$} & Share-rev & L1.Share-ad & L3.Share-rd & lasset & Concen \\
\cline { 2 - 6 } & 748.2876 & 562.7748 & 798.1253 & 524.0621 & 298.4940 \\
Inverse normal & $(0.0000)$ & $(0.0000)$ & $(0.0000)$ & $(0.0000)$ & $(0.5137)$ \\
& -4.2659 & -6.1239 & -3.9589 & 0.0882 & 2.2942 \\
& $(0.0000)$ & $(0.0000)$ & $(0.0000)$ & $(0.5351)$ & $(0.9891)$ \\
\hline Inverse logit & -10.7134 & -13.4701 & -17.5760 & -3.1323 & 1.5173 \\
& $(0.0000)$ & $(0.0000)$ & $(0.0000)$ & $(0.0009)$ & $(0.9352)$ \\
\hline Modified inv. & 18.3009 & 12.2048 & 24.8917 & 9.2599 & -0.0615 \\
chi-squared & $(0.0000)$ & $(0.0000)$ & $(0.0000)$ & $(0.0000)$ & $(0.5245)$ \\
\hline
\end{tabular}


Table 3.5: The results of the Fisher unit-root test after the first difference

Fisher-type unit-root test

Based on augmented Dickey-Fuller tests

Ho: All panels contain unit-roots

Number of panels $=150$

$\mathrm{Ha}$ : At least one panel is stationary

Avg. number of periods $=8.30$

AR parameter: Panel-specific

Asymptotics: T -> Infinity

ADF regressions

\begin{tabular}{|l|ll|}
\hline \multirow{2}{*}{ Inverse chi-squared } & D.lasset & D.Concen \\
\cline { 2 - 3 } & 894.9501 & 523.4452 \\
& $(0.0000)$ & $(0.0000)$ \\
\hline Inverse normal & -14.6643 & -7.2520 \\
& $(0.0000)$ & $(0.0000)$ \\
\hline Inverse logit & -18.9455 & -8.8136 \\
& $(0.0009)$ & $(0.0000)$ \\
\hline Modified inv. chi-squared & 26.5257 & 10.1667 \\
& $(0.0000)$ & $(0.0000)$ \\
\hline
\end{tabular}


Table 3.6: The results of the Kao test for cointegration

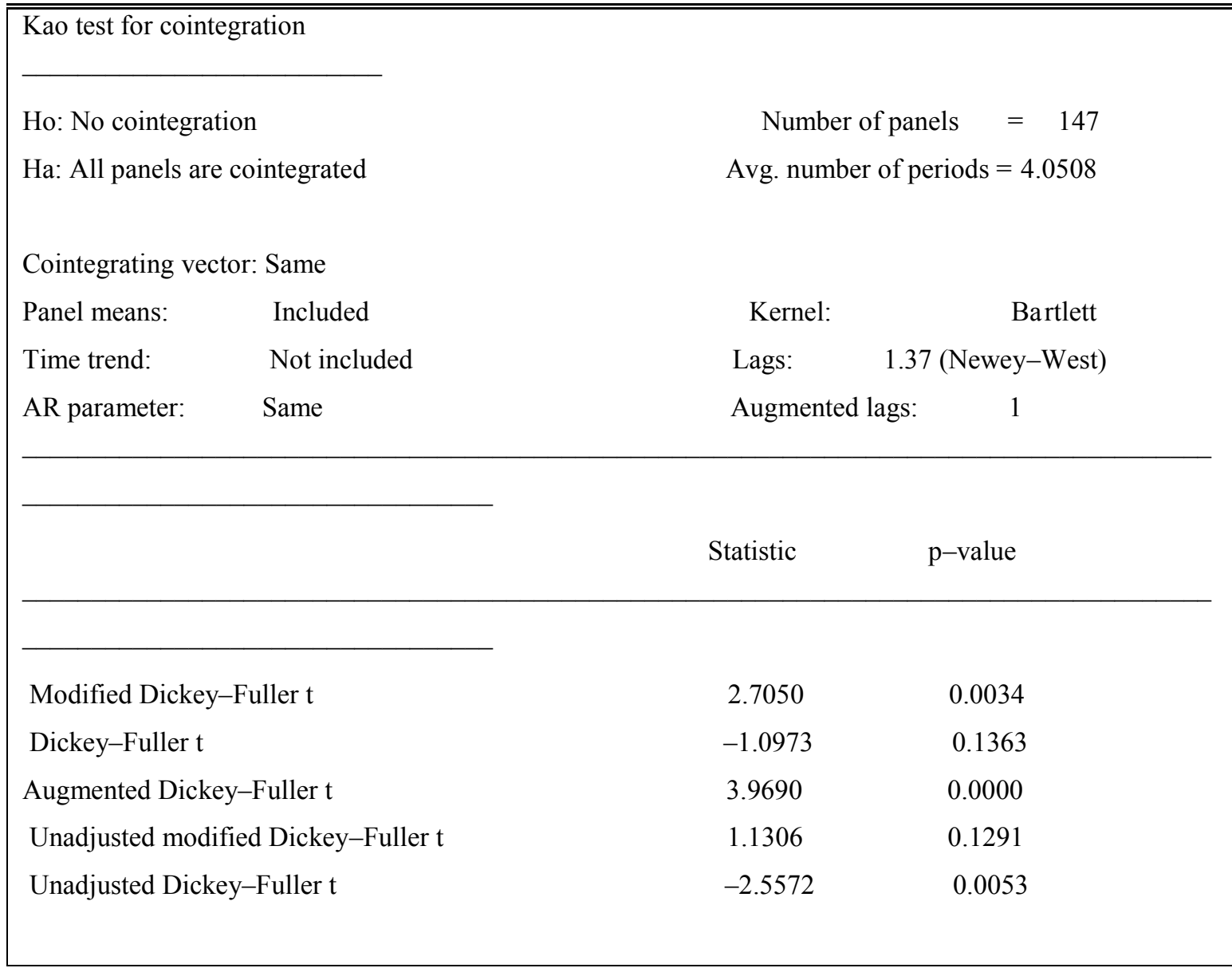


Table 3.7: The results of the Pearson correlation test

\begin{tabular}{l|lllll}
\hline \hline & Share_rv & L1.Share_ad & L3.Share_rd & D1.lasset & D1.Concen \\
\hline Share_rv & 1.0000 & & & & \\
L1.Share_ad & 0.5397 & 1.0000 & & & \\
L3.Share_rd & 0.4980 & 0.3190 & 1.0000 & & \\
D1.lasset & 0.0871 & 0.0227 & 0.0511 & 1.0000 & \\
D1.Concen & -0.0095 & -0.0046 & 0.0107 & -0.0437 & 1.0000
\end{tabular}


Table 3.8: The results of OLS estimation for manufacturing companies

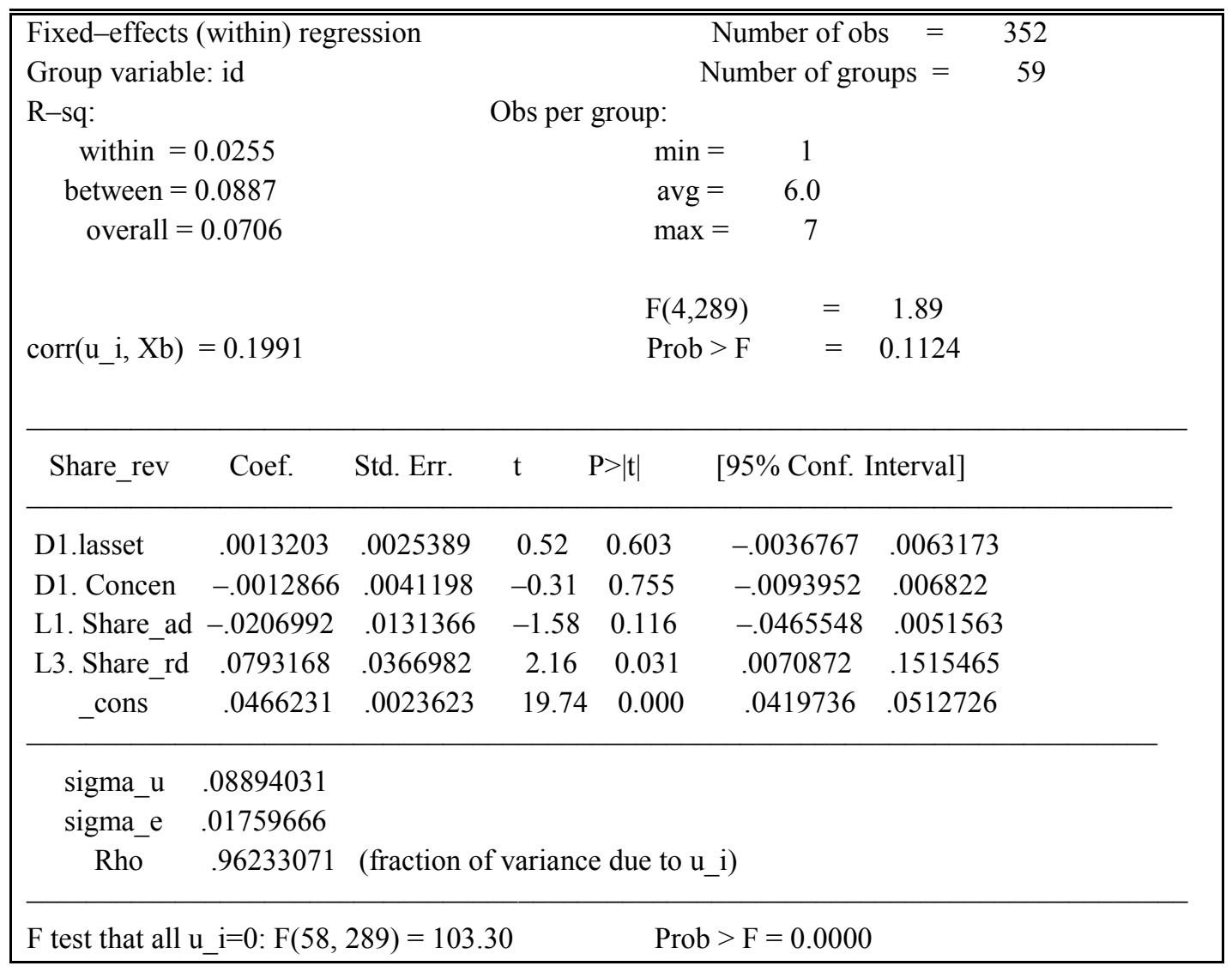


Table 3.9: The results of OLS estimation for non-manufacturing companies

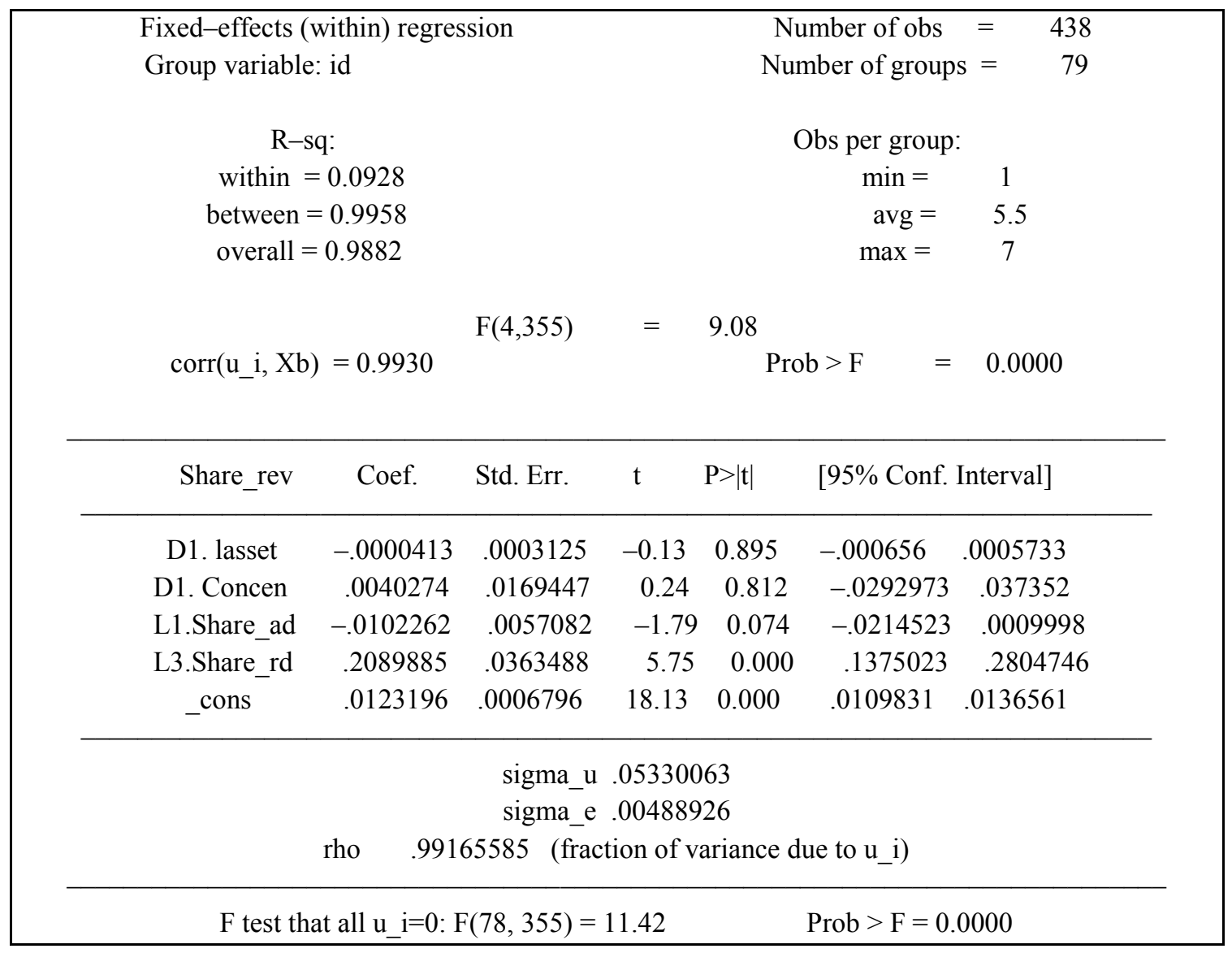


Illustration 3.1: Mean of variables of interest for manufacturing companies

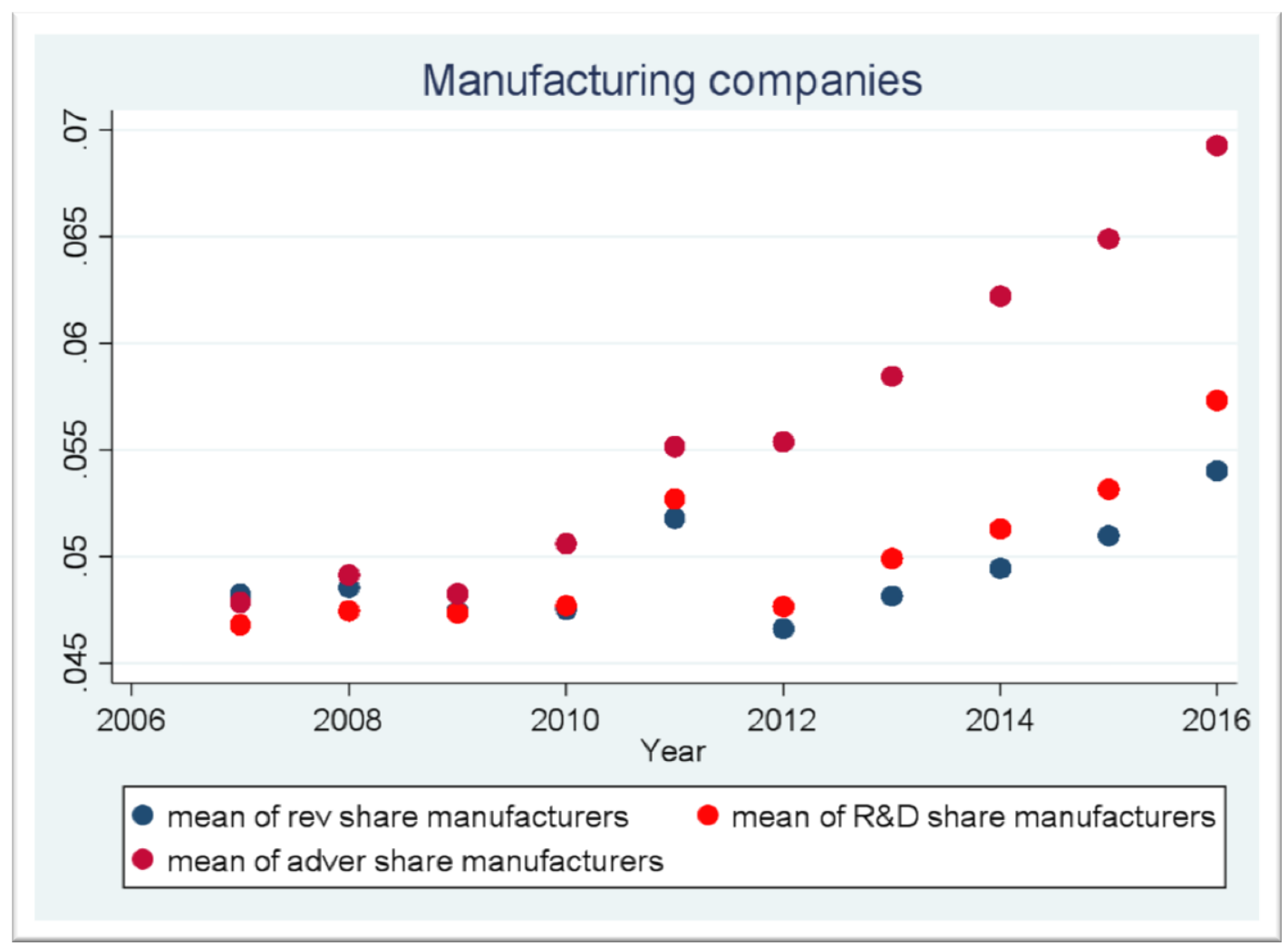


Illustration 3.2: Mean of variables of interest for non-manufacturing companies

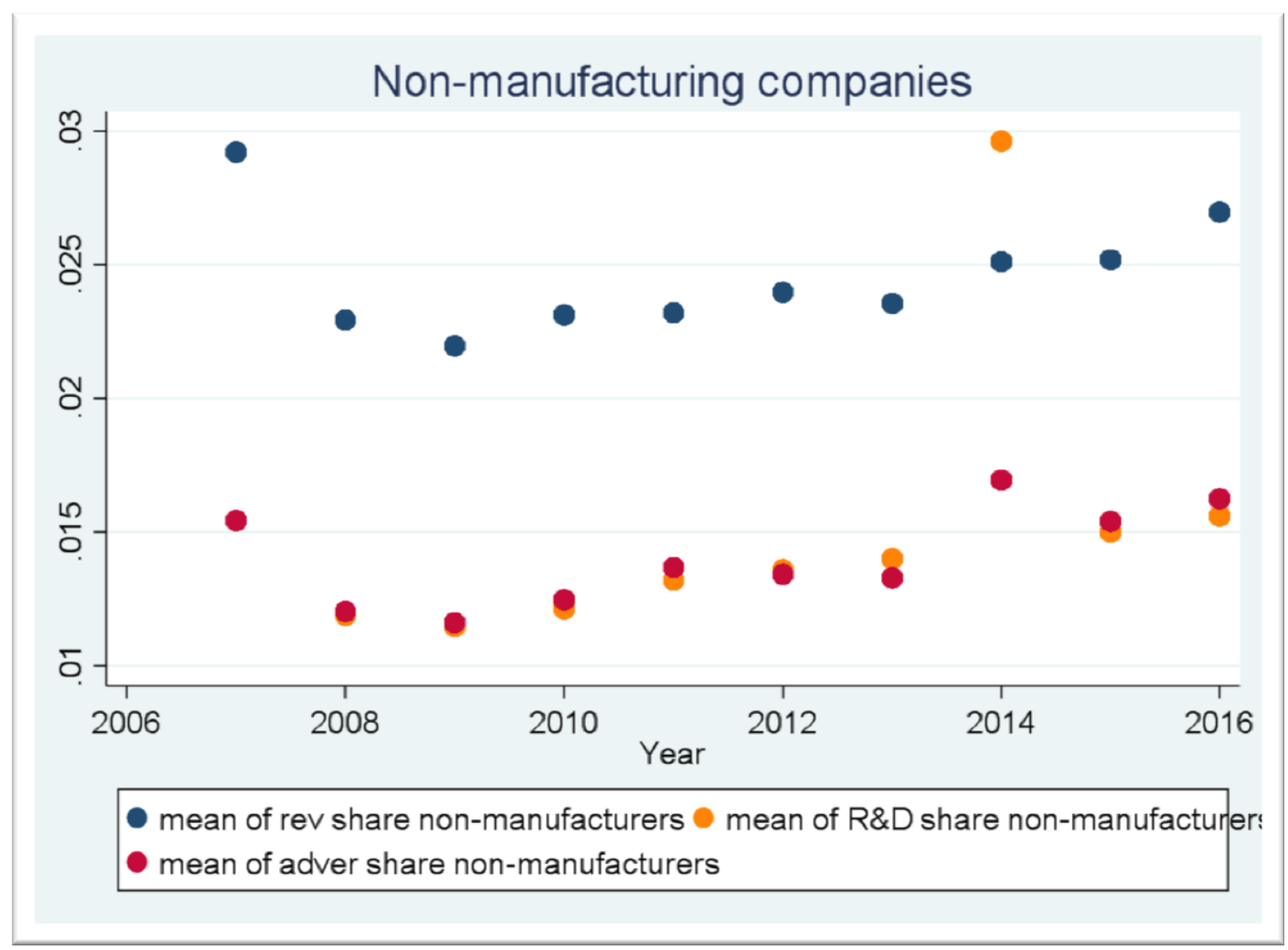




\title{
Appendices
}

\author{
Appendix A
}

\section{Appendix for Chapter 1}

\section{A.1 Proof of Proposition 1.}

$$
\begin{aligned}
& \begin{array}{c}
x_{r i}^{N C}=\frac{(a-r-s)(2(h-5-4 v)+b(5 h+4 v-1))}{26+2 h(8-5 h)-72 u+9 b^{3} u+68 v-4 h v+32 v^{2}-b\left[4 h+5 h^{2}+36 u+2 v+14 h v+8 v^{2}-1\right]} \\
+2 b^{2}\left[h^{2}+9 u+h(v-1)-(2+v)(1+2 v)\right]
\end{array} \\
& x_{s i}^{N C}=\frac{2\left(4-b^{2}\right)(a-r-s)(-2+h-v)}{26+2 h(8-5 h)-72 u+9 b^{3} u+68 v-4 h v+32 v^{2}-b\left[4 h+5 h^{2}+36 u+2 v+4 h v+8 v^{2}-1\right]} \\
& +2 b^{2}\left[h^{2}+9 u+h(v-1)-(2+v)(1+2 v)\right] \\
& X^{N C}=\frac{(2(a-r-s)(10 h-b(1-5 h-2 b(2-h+v)-4 v)-16 v-26))}{26+2 h(8-5 h)-72 u+9 b^{3} u+68 v-4 h v+32 v^{2}-b\left[4 h+5 h^{2}+36 u+2 v+14 h v+8 v^{2}-1\right]} \\
& +2 b^{2}\left[h^{2}+9 u+h(v-1)-(2+v)(1+2 v)\right] \\
& Y^{N C}=\frac{12 u\left(4-b^{2}\right)(a-r-s)}{\left(72 u-9 b^{3} u-68 v+4 h v-32 v^{2}-26-2 h(8-5 h)+b[4 h+5\right.} \\
& \frac{\left(72 u-9 b^{3} u-68 v+4 h v-32 v^{2}-26-2 h(8-5 h)+b\left[4 h+5 h^{2}+36 u+2 v+14 h v+8 v^{2}-1\right]\right.}{} \\
& -2 b^{2}\left[h^{2}+9 u+h(v-1)-(2+v)(1+2 v)\right] \\
& W^{N C}= \\
& 2 u(a-r-s)^{2}\left\{36 b^{3} u\left(b^{2}-8\right)+4 b\left[26 h-5 h^{2}+144 u+16 v(1+h)+16 v^{2}-5\right]-2 b^{4}\left[2 h^{2}-45 u-4 h(2+v)+2(2+v)^{2}\right]\right. \\
& \left.-4\left[89+17 h^{2}-360 u+8 v(13+4 v)-2 h(37+20 v)\right]+b^{2}\left[127+7 h^{2}-720 u+8 v(17+2 v)-2 h(59+52 v)\right]\right\} \\
& \left(26+2 h(8-5 h)-72 u+9 b^{3} u+68 v-4 h v+32 v^{2}-b\left[4 h+5 h^{2}+36 u+2 v+14 h v+8 v^{2}-1\right]^{2}\right. \\
& \left.+2 b^{2}\left[h^{2}+9 u+h(v-1)-(2+v)(1+2 v)\right]\right) \\
& P^{N C}=\frac{\begin{array}{c}
a\left[26+2 h(8-5 h)-48 u+3 b^{3} u+68 v-4 h v+32 v^{2}-b\left(h(4+5 h)+12 u+2 v+14 h v+8 v^{2}-1\right)\right. \\
\left(26+2 h(8-5 h)-72 u+9 b^{3} u+68 v-4 h v+32 v^{2}-b\left(4 h+5 h^{2}+36 u+2 v+14 h v+8 v^{2}-1\right)\right. \\
\left.+2 b^{2}\left(h^{2}+9 u+h(v-1)-(2+v)(1+2 v)\right)\right)
\end{array}}{\text {. }} \\
& x_{r i}^{H C}=\frac{4(a-r-s)(1+h+2 v)}{9 b^{2} u-8(h+2 v)^{2}-4(2+4 h-9 u+8 v)-2 b\left[h^{2}-18 u+(1+2 v)^{2}+h(2+4 v)\right]} \\
& x_{s i}^{H C}=\frac{2(2+b)(a-r-s)(1+h+2 v)}{9 b^{2} u-8(h+2 v)^{2}-4(2+4 h-9 u+8 v)-2 b\left[h^{2}-18 u+(1+2 v)^{2}+h(2+4 v)\right]} \\
& X^{H C}=\frac{(4(4+b)(a-r-s)(1+h+2 v))}{9 b^{2} u-8(h+2 v)^{2}-4(2+4 h-9 u+8 v)-2 b\left[h^{2}-18 u+(1+2 v)^{2}+h(2+4 v)\right]}
\end{aligned}
$$




$$
\begin{aligned}
& Y^{H C}=\frac{12 u(2+b)(a-r-s)}{\left(9 b^{2} u-8(h+2 v)^{2}-4(2+4 h-9 u+8 v)-2 b\left[h^{2}-18 u+(1+2 v)^{2}+h(2+4 v)\right]\right.} \\
& W^{H C}= \\
& \frac{4 u(a-r-s)^{2}\left\{9 u(1+b)(2+b)^{2}-2\left(4 h^{2}-9 u(2+b)^{2}+8 h(1+2 v)+4(1+2 v)^{2}\right)+(2+b)^{2}\right.}{\left(9 b^{2} u-8(h+2 v)^{2}-4(2+4 h-9 u+8 v)-2 b\left[h^{2}-18 u+(1+2 v)^{2}+h(2+4 v)\right]\right)^{2}}
\end{aligned}
$$

$$
P^{H C}=\frac{[6 u(1+b)(2+b)(r+s)]+a u(4+b)\left[-2+3(2+b)-8 v-2\left[h(2+h)+4 h v+4 v^{2}\right]\right]}{9 b^{2} u-8(h+2 v)^{2}-4(2+4 h-9 u+8 v)-2 b\left[h^{2}-18 u+(1+2 v)^{2}+h(2+4 v)\right]}
$$

$$
x_{r i}^{V C}=\frac{(a-r-s)(b[b+5 h+b h+2 v(2+b)-1]-2(7+h+8 v))}{72 u-34-32 h-9 b^{3} u-100 v+2(h-16 v)(h+2 v)-b^{2}\left(h^{2}-4 h+18 u-2 v(7+h)-8 v^{2}-5\right)+b(1+h(8+7 h)}
$$

$$
x_{s i}^{V C}=\frac{2(2-b)(a-r-s)[5-h+b(2-h+v)+4 v]}{72 u-34-32 h-9 b^{3} u-100 v+2(h-16 v)(h+2 v)-b^{2}\left(h^{2}-4 h+18 u-2 v(7+h)-8 v^{2}-5\right)+b(1+h(8+7 h)}
$$

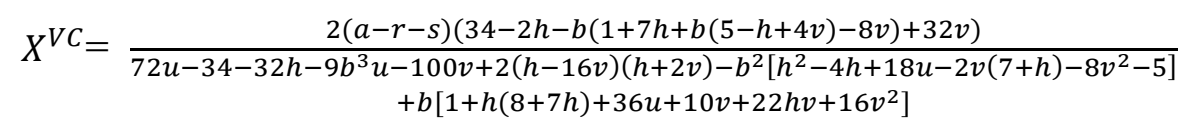

$$
Y^{V C}=\frac{12 u\left(4-b^{2}\right)(a-r-s)}{72 u-34-32 h-9 b^{3} u-100 v+2(h-16 v)(h+2 v)-b^{2}\left[h^{2}-4 h+18 u-2 v(7+h)-8 v^{2}-5\right]}
$$

$$
\begin{aligned}
& W^{V C}= \\
& 4 u(a-r-s)^{2}\left\{27 b^{5} u-2 b^{3}\left[7+h(8+h)+108 u+22 v+10 h v+16 v^{2}\right]+4 b\left[13+h(50+h)+108 u+76 v+52 h v+64 v^{2}\right]\right. \\
& -b^{4}\left[17+5 h^{2}-81 u-4 v(5+2 v)+2 h(7+2 v)\right]-4\left[149+5 h^{2}-324 u-2 h(13+8 v)\right. \\
& \left.+16 v(17+8 v)]+3 b^{2}\left[61-3 h^{2}-216 u+32 v(3+v)-h(26+32 v)\right]\right\} \\
& \left(34+32 h-72 u+9 b^{3} u+100 v-2(h-16 v)(h+2 v)+b^{2}\left[h^{2}-4 h+18 u-2 v(7+h)-8 v^{2}-5\right]^{2}\right. \\
& \left.-b\left[1+h(8+7 h)+36 u+10 v+22 h v+16 v^{2}\right]\right) \\
& P^{V C}=\frac{\begin{array}{c}
u(b-2)(1+b)(2+b)(r+s)+a\left\{34+32 h-48 u+3 b^{3} u+100 v-2(h-16 v)(h+2 v)\right. \\
34+32 h-72 u+9 b^{3} u+100 v-2(h-16 v)(h+2 v)+b^{2}\left[h^{2}-4 h+18 u-2 v(7+h)-8 v^{2}-5\right]
\end{array}}{-b\left[1+h(8+7 h)+36 u+10 v+22 h v+16 v^{2}\right]}
\end{aligned}
$$

Taking the derivative of Eqs A.1, A.2, A.3, A.4, and A.5 with respect to $v$ and evaluating for any value of parameters shows that $\partial x_{r i}^{N C} / \partial v>0, \partial x_{s i}^{N C} / \partial v>0, \partial X^{N C} / \partial v>0$, and $\partial Y^{N C} / \partial v>0$. To prove that $\partial W^{N C} / \partial v>0$, for any parameter value, evaluating the 
validity of $u$ is required. Thus, $P^{N C}$ for the same parameter values must be evaluated to find whether $u$ meets the required threshold. Note that output is positive if $a>r+s$. Evaluating $P^{N C}$ and $W^{N C}$ at the same parameter values shows that the required $u$ making $\partial W^{N C} / \partial v>0$ is met.

Taking the derivative of Eqs A.7, A.8, A.9, A.10, and A.11 with respect to $v$ and evaluating for any value of parameters shows that $\partial x_{r i}^{H C} / \partial v>0, \partial x_{s i}^{H C} / \partial v>0$, $\partial X^{H C} / \partial v>0$, and $\partial Y^{H C} / \partial v>0$. To prove that $\partial W^{H C} / \partial v>0$, for any value of parameters evaluating the validity of $u$ is required. Thus, $P^{H C}$ at the same parameter values must be evaluated to find whether $u$ meets the required threshold. Note that output is positive if $a>r+s$. Evaluating $P^{H C}$ and $W^{H C}$ at the same parameter values shows that for any value of parameters, the required value for $u$ making $\partial W^{H C} / \partial v>0$ is met.

Taking the derivative of Eqs A.13, A.14, A.15, A.16, and A.17 with respect to $v$ and evaluating for any value of parameters shows that $\partial x_{r i}^{V C} / \partial v>0, \partial x_{s i}^{V C} / \partial v>0$, $\partial X^{V C} / \partial v>0$, and $\partial Y^{V C} / \partial v>0$. To prove that $\partial W^{V C} / \partial v>0$, for any value of parameters evaluating the validity of $u$ is required. Thus, $P^{V C}$ at the same parameter values must be evaluated to find whether $u$ meets the required threshold.

\section{A.2 Proof of Proposition 2.}

For any parameter values $\frac{\partial x_{s i}^{N C}}{\partial v}-\frac{\partial x_{r i}^{N C}}{\partial v}>0$ thus, $\frac{\partial x_{s i}^{N C}}{\partial v}>\frac{\partial x_{r i}^{N C}}{\partial v}$ is concluded. If $b=0$ and $h=$ 1, then $\frac{\partial x_{s i}^{N C}}{\partial v}=\frac{\partial x_{r i}^{N C}}{\partial v}$.

For any parameter values $\frac{\partial x_{s i}^{H C}}{\partial v}-\frac{\partial x_{r i}^{H C}}{\partial v}>0$ thus, $\frac{\partial x_{s i}^{H C}}{\partial v}>\frac{\partial x_{r i}^{H C}}{\partial v}$ is concluded. If $b=0$, then $\frac{\partial x_{s i}^{H C}}{\partial v}=\frac{\partial x_{r i}^{H C}}{\partial v}$. 
For any parameter values $\frac{\partial x_{s i}^{V C}}{\partial v}-\frac{\partial x_{r i}^{V C}}{\partial v}>0$ thus, $\frac{\partial x_{s i}^{V C}}{\partial v}>\frac{\partial x_{r i}^{V C}}{\partial v}$ is concluded. If $h=1$, then $\frac{\partial x_{s i}^{V C}}{\partial v}=\frac{\partial x_{r i}^{V C}}{\partial v}$.

\section{A.3 Proof of Proposition 3.}

Taking the derivative of Eqs A.1, A.2, A.3, A.4, and A.5 with respect to $h$ and evaluating for any value of parameters shows that $\partial x_{r i}^{N C} / \partial h<0, \partial x_{s i}^{N C} / \partial h<0, \partial X^{N C} / \partial h<0$, $\partial Y^{N C} / \partial h \lessgtr 0$, and $\partial W^{N C} / \partial h \lessgtr 0$. To evaluate the validity of $u, P^{N C}$ must be evaluated at the same parameter values which shows that $u$ can be either higher or lower than the required threshold and thereby $\partial Y^{N C} / \partial h \lessgtr 0$ and $\partial W^{N C} / \partial h \lessgtr 0$ is concluded.

Taking the derivative of Eqs A.7, A.8, A.9, A.10, and A.11 with respect to $h$ and evaluating for any value of parameters shows that $\partial x_{r i}^{H C} / \partial h>0, \partial x_{s i}^{H C} / \partial h>0$, $\partial X^{H C} / \partial h>0, \partial Y^{H C} / \partial h>0$, and $\partial W^{H C} / \partial h>0$. Evaluating $P^{H C}$ and $W^{H C}$ at the same parameter values shows that for any value of $b$ the required value for $u$ making $\partial W^{H C} /$ $\partial h>0$ is met.

Taking the derivative of Eqs A.13, A.14, A.15, A.16, and A.17 with respect to $h$ and evaluating for any value of parameters shows that $\partial x_{r i}^{V C} / \partial h>0, \partial x_{s i}^{V C} / \partial h \lessgtr 0$, $\partial X^{V C} / \partial h \lessgtr 0, \partial Y^{V C} / \partial h>0$, and $\partial W^{V C} / \partial h>0$. Evaluating $P^{V C}$ at the same parameter values as $\partial x_{s i}^{V C} / \partial h$ and $\partial X^{V C} / \partial h$ to examine the validity of $u$ shows that $u$ can be either higher or lower than the required threshold for $\partial x_{s i}^{V C} / \partial h$ and $\partial X^{V C} / \partial h$. Thus, $\partial x_{s i}^{V C} / \partial h \lessgtr 0$ and $\partial X^{V C} / \partial h \lessgtr 0$.

\section{A.4 Proof of Proposition 4.}

To prove that $\partial x_{s i}^{N C} / \partial h>\partial x_{r i}^{N C} / \partial h$, consider $\left(\frac{\partial x_{s i}^{N C}}{\partial h}-\frac{\partial x_{r i}^{N C}}{\partial h}\right)$. Evaluating the equation 
requires evaluating the validity of $u$ at the same parameter values. It shows that if $b=0$, then $u$ is lower than the threshold and thereby $\frac{\partial x_{s i}^{N C}}{\partial h}<\frac{\partial x_{r i}^{N C}}{\partial h}$. If $b>0$, then $u$ is higher than the threshold and thereby $\frac{\partial x_{s i}^{N C}}{\partial h}>\frac{\partial x_{r i}^{N C}}{\partial h}$.

To prove that $\partial x_{s i}^{H C} / \partial h>\partial x_{r i}^{H C} / \partial h$, consider $\left(\frac{\partial x_{s i}^{H C}}{\partial h}-\frac{\partial x_{r i}^{H C}}{\partial h}\right)$. Evaluating the equation shows that the difference increases with $b$, and reaches zero when $b=0$.

To prove that $\partial x_{s i}^{V C} / \partial h>\partial x_{r i}^{V C} / \partial h$, consider $\left(\frac{\partial x_{s i}^{V C}}{\partial h}-\frac{\partial x_{r i}^{V C}}{\partial h}\right)$. Evaluating the equation shows that the difference is negative, decreases with $b$, and reaches zero when $b=1$.

\section{A.5 Proof of Proposition 5.}

$$
\begin{aligned}
& \pi_{r i}=\frac{2\left(a-r-s+(1+h+2 v)\left(x_{r i}+x_{r j}\right)+(1+h+2 v)\left(x_{s i}+x_{s j}\right)\right)^{2}}{9(2+b)^{2}}-u x_{r i}^{2} \\
& \pi_{s i}=\frac{\left((1+h+2 v)\left(x_{r i}+x_{r j}\right)+2\left(a-r-s+(2-h+v) x_{s i}+(-1+2 h+v) x_{s j}\right)^{2}\right.}{18(2+b)}-u x_{s i}^{2}
\end{aligned}
$$

To compute the strategic interaction, $\partial^{2} \pi_{r i} / \partial x_{r i} \partial x_{r j}, \partial^{2} \pi_{r i} / \partial x_{r i} \partial x_{s i}, \partial^{2} \pi_{s i} / \partial x_{s i} \partial x_{s j}$, and $\partial^{2} \pi_{s i} / \partial x_{s i} \partial x_{r i}$ for different values of the parameters are evaluated. The results show that $\frac{\partial^{2} \pi_{r i}}{\partial x_{r i} \partial x_{r j}} \lessgtr 0$ and $\frac{\partial^{2} \pi_{s i}}{\partial x_{s i} \partial x_{s j}} \lessgtr 0$, while $\frac{\partial^{2} \pi_{r i}}{\partial x_{r i} \partial x_{s i}}>0$ and $\frac{\partial^{2} \pi_{s i}}{\partial x_{s i} \partial x_{r i}}>0$.

\section{A.6 Proof of Proposition 6.}

To prove that $\left(X_{V C}=X_{H C}\right)>X_{N C}$, using Eqs A.3, A.9, and A.15 first consider $\left(X_{V C}-\right.$ $X_{H C}$ ) which is always positive and reaches zero when $h=1$. If $h<1$, for any values of parameters, $X_{V C}>X_{H C}$. Now, consider $\left(X_{V C}-X_{N C}\right)$. Evaluating the equation for any 
parameter values shows that $X_{V C}>X_{N C}$.

From the above $\left(X_{V C}-X_{H C}\right)$ is always positive. Now, consider $\left(X_{H C}-X_{N C}\right)$ which shows that it is positive when $h$ is high; otherwise, that is negative.

\section{A.7 Proof of Proposition 7}

$$
\begin{gathered}
\pi_{r i}^{N C}=\frac{\begin{array}{c}
u(a-r-s)^{2}\left(36 b^{4} u-4 b(5-h+4 v)(1-5 h-4 v)-b^{2}\left(25 h^{2}+288 u+(1-4 v)^{2}-10 h(1-4 v)\right)\right. \\
{\left[26+2 h(8-5 h)-72 u+9 b^{3} u+68 v-4 h v+32 v^{2}+b\left(1-h(4+5 h)+36 u+2 v+14 h v+8 v^{2}\right)^{2}\right.} \\
\left.+2 b^{2}\left(h^{2}+9 u-h(1-v)-(2+v)(1+2 v)\right)\right]
\end{array}}{(A)} \\
\pi_{r i}^{H C}=\frac{4 u(-a+r+s)^{2}\left(9(2+b)^{2} u-4 h^{2}-8 h(1+2 v)-4(1+2 v)^{2}\right)}{\left[-9 b^{2} u+8(h+2 v)^{2}+4(2+4 h-9 u+8 v)+2 b\left(h^{2}-18 u+(1+2 v)^{2}+h(2+4 v)\right]^{2}\right.} \\
\pi_{r i}^{V C}=\frac{\left.\left.-b^{4}\left(h^{2}-36 u+(1+2 v)^{2}+h(2+4 v)\right)-4\left(h^{2}-144 u+2 h(7+8 v)+(7+8 v)^{2}\right)\right)\right]}{\left[34+32 h-72 u+9 b^{3} u+100 v-2(h-16 v)(h+2 v)+b^{2}\left(-5-4 h+h^{2}+18 u-2(7+h) v-8 v^{2}\right)^{2}\right.} \\
\left.-b\left(1+h(8+7 h)+36 u+10 v+22 h v+16 v^{2}\right)\right]
\end{gathered}
$$

To prove Proposition 7 for each set of parameter values, using Eqs A.21. A.22, and A.23, evaluating the differences between profits are required (i.e. consider $\left(\pi_{r i}^{V C}-\pi_{r i}^{N C}\right)$ if $b=0, h=0$ and $v=0$ show that for these parameter values $\pi_{r i}^{V C}>\pi_{r i}^{N C}$ ).

\section{A.8 Proof of Proposition 8}

$$
\begin{gathered}
\pi_{s i}^{N C}=\frac{\left(2 u\left(4-b^{2}\right)^{2}(a-r-s)^{2}\left(-2 h^{2}+9 u(2+b)+4 h(2+v)-2(2+v)^{2}\right)\right)}{\left(26+2(8-5 h) h-72 u+9 b^{3} u+68 v-4 h v+32 v^{2}-b\left(-1+h(4+5 h)+36 u+2 v+14 h v+8 v^{2}\right)^{2}\right.} \\
\left.+2 b^{2}\left(h^{2}+9 u+h(-1+v)-(2+v)(1+2 v)\right)\right)
\end{gathered}
$$




$$
\begin{aligned}
& 2 u(2-b)^{2}(a-r-s)^{2}\left(-50+20 h+72 u+9 b^{3} u-2(h-4 v)^{2}-80 v-2 b^{2}\left(h^{2}-27 u-2 h(2+v)+(2+v)^{2}\right)\right. \\
& \pi_{s i}^{V C}=\frac{\left.-4 b\left(h^{2}-27 u+(2+v)(5+4 v)-h(7+5 v)\right)\right)}{\left(34+32 h-72 u+9 b^{3} u+100 v-2(h-16 v)(h+2 v)+b^{2}\left(-5-4 h+h^{2}+18 u-2(7+h) v-8 v^{2}\right)-b\left(1+h(8+7 h)^{2}\right.\right.} \\
& \left.\left.+36 u+10 v+22 h v+16 v^{2}\right)\right)
\end{aligned}
$$

To prove Proposition 8 for each set of parameter values, using Eqs A.24, A.25, and A.26, evaluating the differences between profits are required (i.e. consider $\left(\pi_{s i}^{H C}-\pi_{s i}^{N C}\right)$ if $b=0, h=0$ and $v=0$ show that for these parameter values $\pi_{r i}^{H C}>\pi_{r i}^{N C}$ ). 


\section{Appendix B}

\section{Appendix for Chapter 2}

\section{B.1 Proof of Proposition 1}

$$
\begin{aligned}
& \frac{\partial X^{N N}}{\partial \beta}=\frac{4 \lambda(k-\alpha)\left(\left(2(2-b \beta)^{2}-2 b \gamma(1+\theta)(2-b \theta)+b \gamma \lambda(2-b)(2+b)^{2}\right)\right)}{\left(2 \gamma(1+\theta)(2-b \theta)+2 \lambda(1+\beta)(2-b \beta)-\gamma \lambda(2-b)(2+b)^{2}\right)^{2}} \\
& \frac{\partial a^{N N}}{\partial \beta}=\frac{8 \gamma(k-\alpha)(2-b-2 b \beta)(2-b \theta)}{\left(\gamma(2-b)(2+b)^{2}-2(1+\beta)(2-b \beta)-2 \gamma(1+\theta)(2-b \theta)\right)^{2}} \\
& \frac{\partial \pi^{N N}}{\partial \beta}=\frac{\left(4 \gamma \lambda^{2}(k-\alpha)^{2}\left[2 \gamma(2-b \theta)(4+b(b \theta(1+\beta)-\beta(4+b)))+2 \lambda(2-b \beta)^{3}+\gamma \lambda(2-b)(2+b)^{2}(4+b(2-b+\beta(4-b)))\right]\right.}{\left(2 \gamma(1+\theta)(2-b \theta)+2 \lambda(1+\beta)(2-b \beta)-\gamma \lambda(2-b)(2+b)^{2}\right)^{3}} \\
& \frac{\partial Y^{N N}}{\partial \beta}=\frac{4 \gamma\left(4-b^{2}\right)(k-\alpha)(2-b-2 b \beta)}{\left(2(1+\beta)(2-b \beta)-\gamma(2-b)(2+b)^{2}+2 \gamma(1+\theta)(2-b \theta)\right)^{2}} \\
& \frac{\partial W^{N N}}{\partial \beta}= \\
& \frac{4 \gamma \lambda^{2}(k-\alpha)^{2}\left[4 \gamma(2-b \theta)(4+b(b \theta(1+\beta)-\beta(4+b)))+4 \lambda(2-b \beta)^{3}-\gamma \lambda(2-b)(2+b)^{2}\left(12-b\left(4+b-b^{2}+2 \beta\left(6-b^{2}\right)\right)\right]\right.}{\left.2 \gamma(1+\theta)(2-b \theta)+2 \lambda(1+\beta)(2-b \beta)-\gamma \lambda(2-b)(2+b)^{2}\right)^{3}} \\
& P^{N N}=\frac{2 \alpha \gamma(1+\theta)(2-b \theta)+\lambda\left(2 k(1+\beta)(2-b \beta)-\gamma\left(4-b^{2}\right)(k+\alpha+b \alpha)\right)}{2 \gamma(1+\theta)(2-b \theta)+2 \lambda(1+\beta)(2-b \beta)-\gamma \lambda(2-b)(2+b)^{2}} \\
& \frac{\partial X^{R N}}{\partial \beta}=\frac{4 \lambda(2-b)(k-\alpha)\left[\lambda(2-b)\left(2(1+\beta)^{2}+\gamma(2+b)^{2}\right)-2 \gamma(1+\theta)(2-b \theta)\right]}{\left(2 \gamma(1+\theta)(2-b \theta)+\lambda(2-b)\left(2(1+\beta)^{2}-\gamma(2+b)^{2}\right)^{2}\right.} \\
& \frac{\partial a^{R N}}{\partial \beta}=\frac{16 \gamma(2-b)(k-\alpha)(1+\beta)(2-b \theta)}{\left((2-b)\left[2(1+\beta)^{2}-\gamma(2+b)^{2}\right]-2 \gamma(1+\theta)(2-b \theta)\right)^{2}} \\
& \frac{\partial \pi^{R N}}{\partial \beta}=\frac{\left(4 \gamma \lambda^{2}(2-b)(k-\alpha)^{2}(1+\beta)\left[2 \gamma(2+b)(1-\theta)(2-b \theta)+\lambda(2-b)^{2}\left(2(1+\beta)^{2}-\gamma(2+b)^{2}\right)\right]\right.}{\left(2 \gamma(1+\theta)(2-b \theta)+\lambda(2-b)\left[2(1+\beta)^{2}-\gamma(2+b)^{2}\right]\right)^{3}} \\
& \frac{\partial Y^{R N}}{\partial \beta}=\frac{8 \gamma(2-b)^{2}(2+b)(k-\alpha)(1+\beta)}{\left((2-b)\left(2(1+\beta)^{2}-\gamma(2+b)^{2}\right)+2 \gamma(1+\theta)(2-b \theta)\right)^{2}}
\end{aligned}
$$

)




$$
\begin{aligned}
& \frac{\partial W^{R N}}{\partial \beta}=\frac{8 \gamma \lambda^{2}(2-b)(k-\alpha)^{2}(1+\beta)\left[2 \lambda(2-b)^{2}(1+\beta)^{2}+\gamma(2+b)\left(2(1-\theta)(2-b \theta)-\lambda\left(4-b^{2}\right)^{2}\right]\right.}{\left(2 \gamma(1+\theta)(2-b \theta)+\lambda(2-b)\left(2(1+\beta)^{2}-\gamma(2+b)^{2}\right)\right)^{3}} \\
& P^{R N}=\frac{(k-\alpha)^{2} \gamma \lambda\left(\lambda(2-b)^{2}\left(\gamma(2+b)^{2}-2(1+\beta)^{2}\right)-2 \gamma(2-b \theta)^{2}\right)}{\left(2 \gamma(1+\theta)(2-b \theta)+\lambda(2-b)\left(2(1+\beta)^{2}-\gamma(2+b)^{2}\right)\right)^{2}} \\
& \frac{\partial X^{N A}}{\partial \beta}=\frac{4 \lambda(k-\alpha)\left(2 b \gamma(2-b)(1+\theta)^{2}+\lambda\left[2(2-b \beta)^{2}-b \gamma(2-b)(2+b)^{2}\right]\right)}{\left(2 \lambda(1+\beta)(2-b \beta)+\gamma(2-b)\left[2(1+\theta)^{2}-\lambda(2+b)^{2}\right]\right)^{2}} \\
& \frac{\partial a^{N A}}{\partial \beta}=\frac{8 \gamma(2-b)(k-\alpha)(2-b-2 b \beta)(1+\theta)}{\left(2(1+\beta)(2-b \beta)+\gamma(2-b)\left(2(1+\theta)^{2}-(2+b)^{2}\right)\right)^{2}} \\
& \frac{\partial \pi^{N A}}{\partial \beta}=\frac{4 \gamma \lambda^{2}(k-\alpha)^{2}\left(2 \lambda(2-b \beta)^{3}+\gamma(2-b)(4-b(2-b+\beta(4-b)))\left(2(1+\theta)^{2}-\lambda(2+b)^{2}\right)\right)}{\left(2 \lambda(1+\beta)(2-b \beta)+\gamma(2-b)\left(2(1+\theta)^{2}-\lambda(2+b)^{2}\right)\right)^{3}} \\
& \frac{\partial Y^{N A}}{\partial \beta}=\frac{4 \gamma\left(4-b^{2}\right)(k-\alpha)(2-b-2 b \beta)}{\left(2(1+\beta)(2-b \beta)+\gamma(2-b)\left(2(1+\theta)^{2}+(2+b)^{2}\right)\right)^{2}} \\
& \frac{\partial W^{N A}}{\partial \beta}= \\
& \frac{4 \gamma \lambda^{2}(k-\alpha)^{2}\left(4 \lambda(2+b \beta)^{3}+\gamma(2-b)\left[4(4-b(2-b-\beta(4-b)))(1+\theta)^{2}-\lambda(2+b)^{2}\left(12-b\left(4+b-b^{2}+2 \beta\left(6-b^{2}\right)\right)\right]\right)\right.}{\left(2 \lambda(1+\beta)(2-b \beta)+\gamma(2-b)\left(2(1+\theta)^{2}-\lambda(2+b)^{2}\right)\right)^{3}} \\
& \begin{array}{l}
P^{N A}=\frac{\left(2 \alpha \gamma(2-b)(1+\theta)^{2}-\left(2 k(1+\beta)(2-b \beta)+\left(4-b^{2}\right)(k+\alpha+b \alpha) \gamma\right) \lambda\right)}{\left(2 \lambda(1+\beta)(2-b \beta)+\gamma(2-b)\left(2(1+\theta)^{2}-\lambda(2+b)^{2}\right)\right)} \\
\frac{\partial X^{R A}}{\partial \beta}=\frac{4 \lambda(k-\alpha)\left(2 \lambda(1+\beta)^{2}-2 \gamma(1+\theta)^{2}+\gamma \lambda(2+b)^{2}\right)}{\left(2 \gamma(1+\theta)^{2}+2 \lambda(1+\beta)^{2}-\gamma \lambda(2+b)^{2}\right)^{2}}
\end{array} \\
& \frac{\partial a^{R A}}{\partial \beta}=\frac{16 \gamma(k-\alpha)(1+\beta)(1+\theta)}{\left(2 \gamma(1+\theta)^{2}+2(1+\beta)^{2}-(2+b)^{2} \gamma\right)^{2}} \\
& \frac{\partial \pi^{R A}}{\partial \beta}=\frac{4 \gamma(k-\alpha)^{2}(1+\beta)}{\left(2 \gamma(1+\theta)^{2}+2(1+\beta)^{2}-\gamma(2+b)^{2}\right)^{2}} \\
& \frac{\partial Y^{R A}}{\partial \beta}=\frac{8 \gamma(k-\alpha)(2+b)(1+\beta)}{\left(2 \gamma(1+\theta)^{2}+2(1+\beta)^{2}-(2+b)^{2} \gamma\right)^{2}} \\
& \frac{\partial W^{R A}}{\partial \beta}=\frac{8 \gamma \lambda^{2}(k-\alpha)^{2}(1+\beta)\left(2 \gamma(1+\theta)^{2}+2 \lambda(1+\beta)^{2}-\gamma \lambda(2+b)^{3}\right)}{\left(2 \gamma(1+\theta)^{2}+2 \lambda(1+\beta)^{2}-\gamma \lambda(2+b)^{2}\right)^{3}} \\
& P^{R A}=\frac{2 \alpha \gamma(1+\theta)^{2}+2 k(1+\beta)^{2}-\gamma(2+b)(k+\alpha+b \alpha)}{2 \gamma(1+\theta)^{2}+2(1+\beta)^{2}-\gamma(2+b)^{2}}
\end{aligned}
$$


Note that to simplify the analysis, $\lambda$ is fixed at $\lambda=1$ by assumption. Output is positive if $k>\alpha$. Considering $k=\alpha \& \lambda=1$ and evaluating $p$ at different parameter values indicates the validity of $\gamma$ and shows that whether it meets the required thresholds where it is required.

Evaluating the above equations for any value of parameters shows that, $R \& D$ spillovers have a positive impact on innovation, output, profit, and welfare when firms cooperate in $R \& D$. Otherwise, the impact is positive if the R\&D spillovers are low enough.

\section{B.2 Proof of Proposition 2}

$$
\begin{aligned}
& \frac{\partial X^{N N}}{\partial \theta}=\frac{8 \gamma(k-\alpha)(2-b \beta)(2-b-2 b \theta)}{\left(2 \gamma(1+\theta)(2-b \theta)+2(1+\beta)(2-b \beta)-(2-b)(2+b)^{2} \gamma\right)^{2}} \\
& \frac{\partial a^{N N}}{\partial \theta}=\frac{4 \gamma(k-\alpha)\left(2 \gamma(2-b \theta)^{2}+2 \lambda b(1+\beta)(2-b \beta)-b \gamma \lambda(2-b)(2+b)^{2}\right)}{\left(2 \gamma(1+\theta)(2-b \theta)+2 \lambda(1+\beta)(2-b \beta)+\gamma \lambda(2-b)(2+b)^{2}\right)^{2}} \\
& \frac{\partial \pi^{N N}}{\partial \theta}=\frac{4 \gamma^{2} \lambda(k-\alpha)^{2}\left[2 \gamma(2-b \theta)^{3}-\lambda \gamma(2-b)(2+b)^{2}(4-b(2-b+\theta(4-b)))+2 \lambda(2-b \beta)\left(4-4 b \theta+b^{2}(\beta-\theta(1-\beta))\right)\right]}{\left(2 \gamma(1+\theta)(2-b \theta)+2 \lambda(1+\beta)(2-b \beta)-\gamma \lambda(2-b)(2+b)^{2}\right)^{3}} \\
& \frac{\partial Y^{N N}}{\partial \theta}=\frac{4 \gamma^{2}\left(4-b^{2}\right)(k-\alpha)(2-b-2 b \theta)}{\left(2 \gamma(1+\theta)(2-b \theta)+2(1+\beta)(2-b \beta)-\gamma(2-b)(2+b)^{2}\right)^{2}} \\
& \frac{\partial W^{N N}}{\partial \theta}= \\
& \frac{4 \gamma^{2} \lambda(k-\alpha)^{2}\left[4 \gamma(2-b \theta)^{3}-\gamma \lambda(2-b)(2+b)^{2}\left(12-b\left(4+b-b^{2}-2 \theta\left(6-b^{2}\right)\right)\right)+4 \lambda(2-b \beta)\left(4-4 b \theta+b^{2}(\beta-\theta(1-\beta))\right)\right]}{\left(2 \gamma(1+\theta)(2-b \theta)+2 \lambda(1+\beta)(2-b \beta)-\gamma \lambda(2-b)(2+b)^{2}\right)^{3}}
\end{aligned}
$$

$$
\frac{\partial X^{R N}}{\partial \theta}=\frac{8 \gamma(2-b)(k-\alpha)(1+\beta)(2-b-2 b \theta)}{\left(2 \gamma(1+\theta)(2-b \theta)+(2-b)\left(2(1+\beta)^{2}+\gamma(2+b)^{2}\right)\right)^{2}}
$$




$$
\begin{aligned}
& \frac{\partial a^{R N}}{\partial \theta}=\frac{4 \gamma(k-\alpha)\left(2 \gamma(2-b \theta)^{2}+\lambda b(2-b)\left(2(1+\beta)^{2}-\gamma(2+b)^{2}\right)\right)}{\left(2 \gamma(1+\theta)(2-b \theta)+\lambda(2-b)\left(2(1+\beta)^{2}-\gamma(2+b)^{2}\right)\right)^{2}} \\
& \frac{\partial \pi^{R N}}{\partial \theta}=\frac{4 \gamma^{2} \lambda(k-\alpha)^{2}\left[2 \gamma(2-b \theta)^{3}+\lambda(2-b)\left(2(1+\beta)^{2}-\gamma(2+b)^{2}\right)(4-b(2-b-\theta(4-b)))\right]}{\left(2 \gamma(1+\theta)(2-b \theta)+\lambda(2-b)\left(2(1+\beta)^{2}-\gamma(2+b)^{2}\right)\right)^{3}} \\
& \frac{\partial Y^{R N}}{\partial \theta}=\frac{4 \gamma^{2}\left(4-b^{2}\right)(k-\alpha)(2-b-2 b \theta)}{\left(2 \gamma(1+\theta)(2-b \theta)+(2-b)\left(2(1+\beta)^{2}-\gamma(2+b)^{2}\right)\right)^{2}} \\
& \frac{\partial W^{R N}}{\partial \theta}= \\
& \frac{4 \gamma^{2} \lambda(k-\alpha)^{2}\left[4 \gamma(2-b \theta)^{3}+4 \lambda(2-b)(1+\beta)^{2}(4-b(2-b+\theta(4-b)))-\lambda \gamma(2-b)(2+b)^{2}\left(12-b\left(4+b-b^{2}-2 \theta\left(6-b^{2}\right)\right)\right)\right]}{\left(2 \gamma(1+\theta)(2-b \theta)+\lambda(2-b)\left(2(1+\beta)^{2}-(2+b)^{2} \gamma\right)\right)^{3}}
\end{aligned}
$$$$
\frac{\partial X^{N A}}{\partial \theta}=\frac{16 \gamma(2-b)(k-\alpha)(2-b \beta)(1+\theta)}{\left(2(1+\beta)(2-b \beta)+\gamma(2-b)\left(2(1+\theta)^{2}-(2+b)^{2}\right)\right)^{2}}
$$$$
\frac{\partial a^{N A}}{\partial \theta}=\frac{4 \gamma(2-b)(k-\alpha)\left(\gamma(2-b)\left(2(1+\theta)^{2}+\lambda(2+b)^{2}\right)-2 \lambda(1+\beta)(2-b \beta)\right)}{\left(2 \lambda(1+\beta)(2-b \beta)+\gamma(2-b)\left(2(1+\theta)^{2}-\lambda(2+b)^{2}\right)\right)^{2}}
$$$$
\frac{\partial \pi^{N A}}{\partial \theta}=\frac{4 \gamma^{2} \lambda(2-b)(k-\alpha)^{2}\left[(1+\theta)\left(2 \lambda(2+b)(1-\beta)(2-b \beta)+\gamma(2-b)^{2}\left(\lambda(2+b)^{2}-2(1+\theta)^{2}\right)\right]\right.}{\left(2 \lambda(1+\beta)(2-b \beta)+\gamma(2-b)\left(2(1+\theta)^{2}-\lambda(2+b)^{2}\right)\right)^{3}}
$$$$
\frac{\partial Y^{N A}}{\partial \theta}=\frac{8 \gamma^{2}(k-\alpha)(1+\theta)(2-b)^{2}(2+b)}{\left(2(1+\beta)(2-b \beta)+\gamma(2-b)\left(2(1+\theta)^{2}-(2+b)^{2}\right)\right)^{2}}
$$$$
\frac{\partial W^{N A}}{\partial \theta}=\frac{8 \gamma^{2} \lambda(2-b)(k-\alpha)^{2}(1+\theta)\left[2 \lambda(2+b)(1-\beta)(2-b \beta)-\gamma(2-b)^{2}\left(2(1+\theta)^{2}-\lambda(2+b)^{3}\right)\right]}{\left(2 \lambda(1+\beta)(2-b \beta)+\gamma(2-b)\left(2(1+\theta)^{2}-\lambda(2+b)^{2}\right)\right)^{3}}
$$$$
\frac{\partial X^{R A}}{\partial \theta}=\frac{16(k-\alpha)(1+\beta) \gamma(1+\theta)}{\left(2 \gamma(1+\theta)^{2}+2(1+\beta)^{2}-\gamma(2+b)^{2}\right)^{2}}
$$$$
\frac{\partial a^{R A}}{\partial \theta}=\frac{4 \gamma(k-\alpha)\left(2 \gamma(1+\theta)^{2}-2(1+\beta)^{2} \lambda+(2+b)^{2} \gamma \lambda\right)}{\left(2 \gamma(1+\theta)^{2}+2(1+\beta)^{2} \lambda-(2+b)^{2} \gamma \lambda\right)^{2}}
$$$$
\frac{\partial \pi^{R A}}{\partial \theta}=\frac{4 \gamma^{2}(k-\alpha)^{2}(1+\theta)}{\left(2 \gamma(1+\theta)^{2}+2(1+\beta)^{2}-\gamma(2+b)^{2}\right)^{2}}
$$$$
\frac{\partial Y^{N A}}{\partial \theta}=\frac{8 \gamma^{2}(2+b)(k-\alpha)(1+\theta)}{\left(2 \gamma(1+\theta)^{2}+2(1+\beta)^{2}-\gamma(2+b)^{2}\right)^{2}}
$$$$
\frac{\partial W^{R A}}{\partial \theta}=\frac{8 \gamma^{2} \lambda(k-\alpha)^{2}(1+\theta)\left[2 \gamma(1+\theta)^{2}+2 \lambda(1+\beta)^{2}-\gamma \lambda(2+b)^{3}\right]}{\left(2 \gamma(1+\theta)^{2}+2 \lambda(1+\beta)^{2}-\gamma \lambda(2+b)^{2}\right)^{3}}
$$ 
Evaluating the above equations for any value of parameters shows that, advertising spillovers have a positive impact on innovation, output, profit, and welfare when firms cooperate in advertising. Otherwise, the impact is positive if the advertising spillovers are low enough.

\section{B.3 Proof of Proposition 3}

$$
\pi_{i}=\frac{\left[(2-b)(k-\alpha)-b \theta a_{i}-b \beta x_{i}+2\left(a_{i}+x_{i}\right)+a_{j}(2 \theta-b)+x_{j}(2 \beta-b)\right]^{2}}{\left(4-b^{2}\right)^{2}}-\frac{1}{2} \lambda a_{i}^{2}-\frac{1}{2} \gamma x_{i}^{2} \quad i=1,2
$$

Taking derivative of Eq B.45 with respect to R\&D and advertising of own and the competitor to evaluate the strategic interaction shows that:

(1) $\frac{\partial^{2} \pi_{i}}{\partial x_{i} \partial x_{j}}>0$ if $(2 \beta-b)>0$; otherwise, it is negative

(2) $\frac{\partial^{2} \pi_{i}}{\partial x_{i} \partial a_{j}}>0$ if $(2 \theta-b)>0$; otherwise, it is negative.

(3) $\frac{\partial^{2} \pi_{i}}{\partial a_{i} \partial x_{j}}>0$ if $(2 \beta-b)>0$; otherwise, it is negative.

(4) $\frac{\partial^{2} \pi_{i}}{\partial a_{i} \partial a_{j}}>0$ if $(2 \theta-b)>0$; otherwise, it is negative.

\section{B.4 Proof of Proposition 4}

$$
\begin{array}{rr}
x_{i}^{N N}=\frac{2 \lambda(k-\alpha)(2-b \beta)}{2 \gamma(1+\theta)(2-b \theta)+2 \lambda(1+\beta)(2-b \beta)-\gamma \lambda(2-b)(b+2)^{2}} & i=1,2 \\
x_{i}^{R N}=\frac{2 \lambda(k-\alpha)(\beta+1)(2-b)}{\lambda(2-b)\left[\gamma(b+2)^{2}-2(1+\beta)^{2}\right]-2 \gamma(1+\theta)(2-b \theta)} & i=1,2 \\
x_{i}^{N A}=\frac{2 \lambda(k-\alpha)(2-b \beta)}{\gamma(2-b)\left[\lambda(b+2)^{2}-2(1+\theta)^{2}\right]-2 \lambda(1+\beta)(2-b \beta)} & i=1,2
\end{array}
$$




$$
x_{i}^{R A}=\frac{2 \lambda(k-\alpha)(\beta+1)}{2 \gamma(1+\theta)^{2}+2 \lambda(1+\beta)^{2}-\lambda \gamma(b+2)^{2}} \quad i=1,2
$$

Taking the deduction of each pair of equations show that:

(1) $X_{N A}>X_{R A}$ if $\theta<-b / 2$ and $\beta<b / 2$

(2) $X_{R N}>X_{N A}$ if $\theta<-b / 2$ and $\beta<b / 2$

(3) $X_{R A}>X_{R N}$ if $\theta>b / 2$

(4) $X_{N A}>X_{N N}$ if $\theta>b / 2$

(5) $X_{R N}>X_{N N}$ if $\beta>b / 2$

(6) $X_{R N}>X_{N A}$ if $\theta<\beta$

(7) $X_{N A}>X_{R A}$ if $\theta<b / 2$ and $\beta<b / 2$

(8) $X_{N N}>X_{R A}$ if $\theta<b / 2$ and $\beta<b / 2$ 
Appendix C

\section{Appendix for Chapter 3}

\section{C.1 Instrument Validity and Relevance}

It is difficult to find variables that can serve as valid instruments. In fact, variables that have an effect on included endogenous variables most likely also have a direct effect on the dependent variable. Stock and Yogo (2005) provide useful rules of thumb for evaluating the weakness of instruments based on a statistic due to Cragg and Donald (1993). To interpret the result, the critical value of $F$-statistic should be considered. If the $F$-statistic of the Stock and Yogo (2005) test is greater than the critical values of $F-$ statistic of the Wald tests, the null hypothesis of weak instruments is rejected.

The second issue arises where there are fewer instruments than regressors, called under-identified instruments. The Anderson test which is based on the Pearson correlation examines the identification of the instruments (Anderson 1987). In fact, the instruments, which are uncorrelated with the endogenous regressors increase bias in the estimated IV coefficients (Hahn and Hausman 2004) and induce worsening of the largesample approximations to the finite-sample distributions. Serious problems arise if the correlations between the excluded instruments and endogenous regressors are not zero but they are "weak". Standard IV method of estimating $\beta_{1}$ suffers from serious finite sample bias problems. Rejection of the null hypothesis of the Anderson Canon test 
implies that the equation is identified. In Anderson's approach, the test statistic is distributed chi-squared with $(L-K+1)$ degrees of freedom ${ }^{29}$.

The Cragg-Donald (1993) statistic is an alternative and closely related test that can also be used to test for under-identification which is also distributed chi-squared with $(L-K+1)$ degrees of freedom. Moreover, the third test statistic proposed by Stock and Yogo (2005) is the $F$-statistic form of the Cragg and Donald (1993) statistic. The null hypothesis of Stock and Yogo (2005) is that the estimator is weakly identified such that it is subject to bias meaning that it is associated with unacceptably large statistics. The Stock-Yogo (2005) tests come in two types: maximal relative bias and maximal size where the null indicates that the instruments do not suffer from the specified bias. Thus, rejecting the null hypothesis indicates that there is no weak-instruments problem. The first type is based on the ratio of the bias of the estimator to the bias of OLS. The null is that instruments are weak in which weak instruments are defined as instruments that can lead to an asymptotic relative bias. The second type of the Stock-Yogo (2005) tests are based on the function of the Wald test statistic for $\beta_{1}$. The test statistic is based on the rejection rate $r$ at most $10 \%$. The critical values for the two weak-identification tests for the IV estimator are given in Stock-Yogo (2005). To reject the null hypothesis, the Cragg-Donald $F$-statistic must exceed the critical value.

\footnotetext{
${ }^{29}$ Where $K$ denotes the number of exogenous regressors and $L$ denotes the number of excluded instruments. The equation is said to be exactly identified if $L=K$, it is over-identified if $L>K$.
} 
Finally, Anderson and Rubin (1949) propose a test for the significance of endogenous regressors in the structural equation which is robust to weak instruments and relies heavily on the orthogonality of the excluded instruments $Z_{1}$. The null hypothesis indicates whether the coefficient $\beta_{1}$ of the endogenous regressors $X_{1}$ in the structural equation are jointly equal to zero ${ }^{30}$ which leads to having correct size even in the presence of weak instruments. The Stock and Wright (2000) statistic is a Lagrange multiplier version of the Anderson-Rubin (1949) weak-instruments-robust test. The Anderson-Rubin (1949) test rejects the null hypothesis if the orthogonality conditions are violated. Under the null hypothesis and weak instruments, it tests if the parameters of the endogenous variables, $\beta_{1}$, are jointly significant in the main equation.

\section{C.2 The Sargan-Hansen Endogeneity Test for Manufacturers}

The analysis proceeds using IV estimators. Assuming that firm revenue is affected by the first lag of advertising and marketing activities while the effects are increasing at the

\footnotetext{
${ }^{30}$ The test essentially substitutes the reduced-form equations into the structural equation and tests for the joint significance of the excluded instruments in $Z_{1}$. Write the set of reduced-form

(first stage) equations for the regressors $X$ as: $X=Z \Pi+v$

Partitioning of $X$ and $Z$, it can be rewritten as: $X_{1}=\left[Z_{1} Z_{2}\right]\left[\Pi_{11}^{\prime} \Pi_{12}^{\prime}\right]^{\prime}+v_{1}$

Substitute the reduced-form for the endogenous regressors $X_{1}$ into the main equation of the model $y=X \beta+u=X_{1} \beta_{1}+Z_{2} \beta_{2}+u \Rightarrow\left(\left[Z_{1} Z_{2}\right]\left[\Pi_{11}^{\prime} \Pi_{12}^{\prime}\right]^{\prime}+v_{1}\right) \beta_{1}+Z_{2} \beta_{2}+u$ and rearrange to obtain: $y=\left[Z_{1} \Pi_{11} \beta_{1}+Z_{2}\left(\Pi_{12} \beta_{1}+\beta_{2}\right)\right]+\left(v_{1} \beta_{1}+u\right)$

Consider estimating a reduced-form equation for $y$ with the full set of instruments as regressors: $y=Z_{1} \gamma_{1}+Z_{2} \gamma_{2}+\eta$. If the null $H_{0}: \beta_{1}=0$ is correct, $\Pi_{11} \beta_{1}=0$ and therefore, $\gamma_{1}=0$. Thus the Anderson and Rubin (1949) test of the null $H_{0}: \beta_{1}=0$ is obtained by estimating the reduced form for $y$ and testing that the coefficient $\gamma_{1}$ of the excluded instrument $Z_{1}$ is jointly equal to zero. If the result fails to reject $\gamma_{1}=0$ then that also fails to reject $\beta_{1}=0$.
} 
beginning of the period and deteriorating over time, the first lag of the squared advertising share and the first lag of the R\&D share are identified as instrumental variables. The validation and identification power of the instruments are estimated. Table C. 1 shows the summary of the results.

The results of the first stage regression show that the instruments are valid and perfectly relevant. Comparing the $F$-statistics of the instruments with the critical value $\left(F>F_{0.1}=19.93\right)$ of the Wald test (Stock and Yogo 2005) helps to reject the null hypothesis that the instruments are under-identified and (or) are weakly identified.

The second test also evaluates the instruments for under-identification based on the Anderson (1987) test. The result shows that the null hypothesis that the instruments are under-identified is rejected (chi-squared $=44.93, P=0$ ).

Comparing the $F$-statistics of the Cragg-Donald (1993) statistic $(F=26.17)$ with the critical values of $F$-statistic $\left(F_{0.1}=7.03\right)$ of the Stock and Yogo (2005) test, indicates that the null hypothesis that the equation is weakly identified is rejected.

Ultimately, the null hypothesis of Anderson-Rubin (1949) Wald test that orthogonality conditions are valid is rejected due to the significant $p$-values $(P<0.05)$. This result shows that the endogenous regressors in the main equation are jointly significant in the presence of weak instruments.

The results show that the considered instruments of variables are valid and appropriately identified. Additionally, the structural equation is well identified in which the endogenous regressors are jointly significant even in the presence of weak instruments. 
The results of the second stage of IV estimation show that advertising share has a negative effect on manufacturers' revenue share $\left(\beta_{0}=-.009, p<0.6\right)$. The estimates imply that, surprisingly, revenue share decreases by $0.9 \%$ for each additional dollar invested in advertising share. Although the statistical result is insignificant, the negative sign shows that advertising activities do not benefit manufacturers. However, the R\&D share has a positive effect on market share $\left(\beta_{1}=0.57, p=0\right)$. In fact, revenue share increases by $57 \%$ for each additional dollar invested in R\&D share. The statistics show that firm size has a positive effect on revenue share $\left(\theta_{1}=.004, p<0.21\right)$. Although the statistical result is not significant, it shows that if a firm's asset value increases by a dollar the firm's revenue share increases by $0.4 \%$. Industry concentration has a negative effect on manufacturers' revenue share $\left(\theta_{2}=-.00048, p<0.93\right)$. However, the statistic of $p$-value shows that the effect of industry concentration on revenue share is not significant. Table C.2 shows the results.

Furthermore, the statistics of the Anderson test which evaluates the test for underidentification shows that the null hypothesis of under-identification is rejected (chisquared $=44.93, P=0)$. Comparing the Cargg-Donald Wald F-statistic test $(F=$ $26.17)$ with the critical values of the Stock-Yogo test $\left(F>F_{0.1}=7.03\right)$ indicates that the null hypothesis of weakly identification should be rejected. The first Sargan statistic shows that the equation is perfectly identified. The second Sargan statistic tests for the endogeneity of endogenous regressors and rejects the null hypothesis that the regressors are exogenous (chi-squared $=37.75, P=0$ ). The rejection of the null hypothesis indicates that the regressors do not need instrumenting and the OLS method is good enough. 
Table C.1: The first stage of IV (2SLS) estimation, manufacturing companies

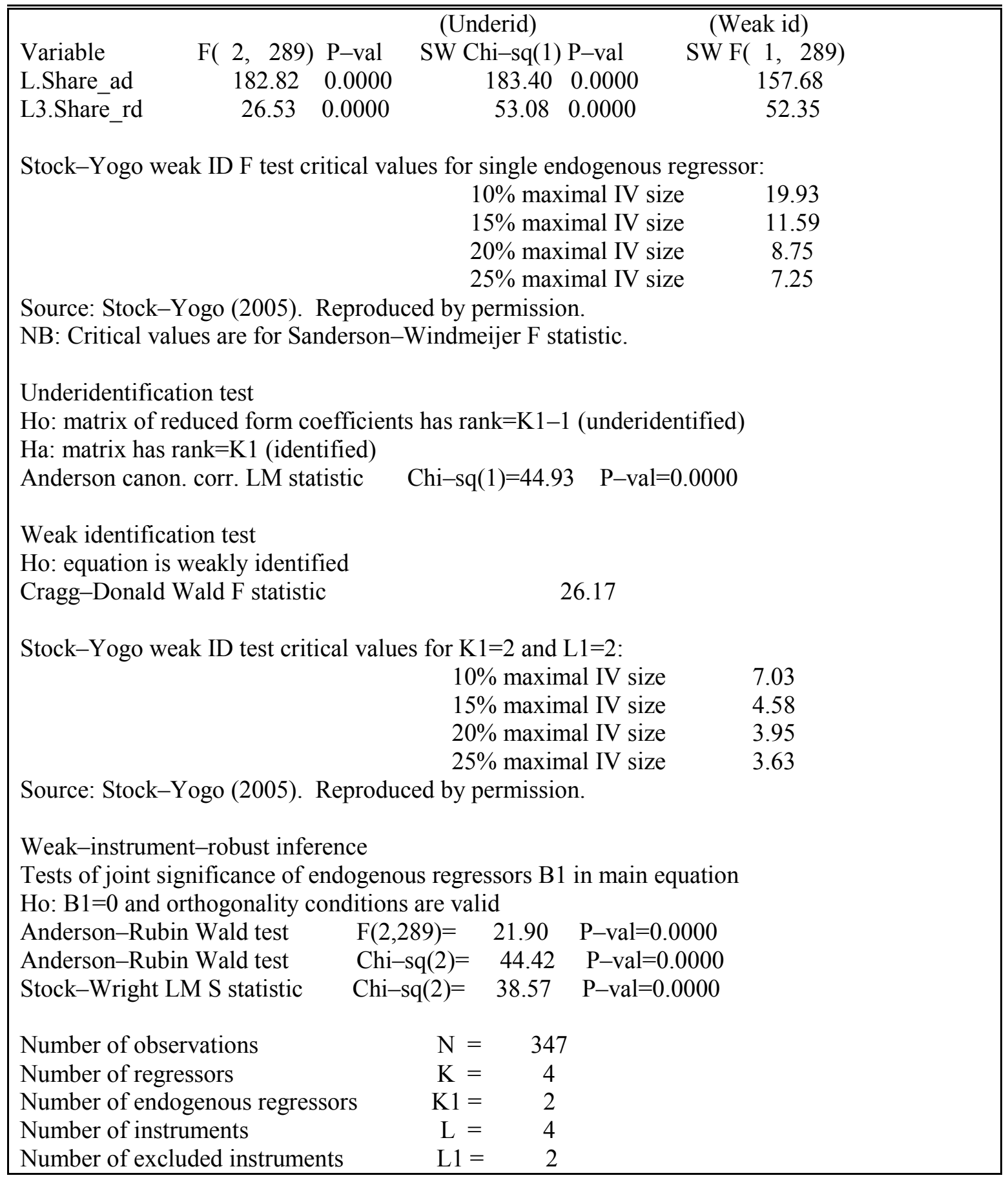


Table C.2: The results of IV (2SLS) estimation, manufacturing companies

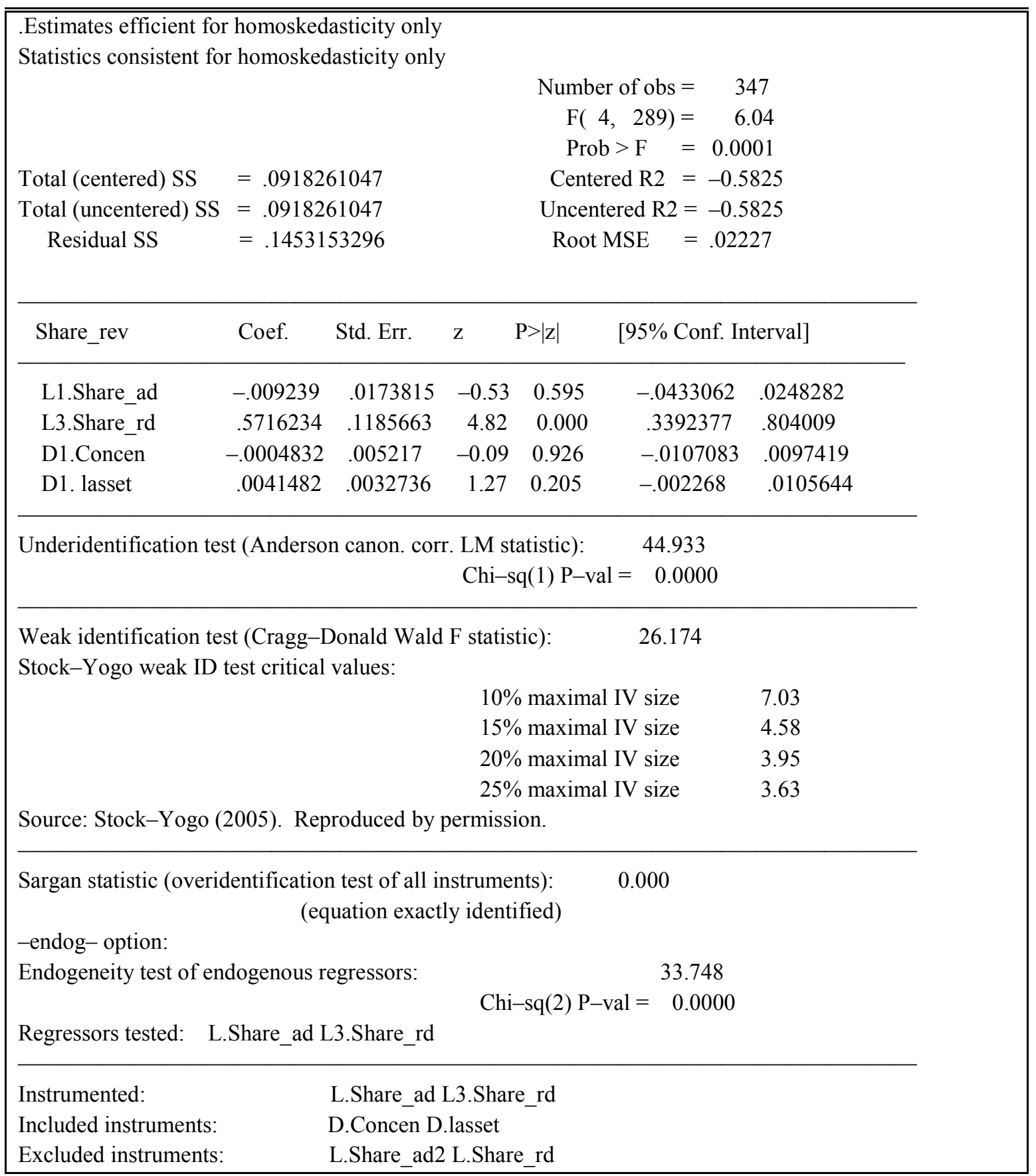




\section{C.3 The Sargan-Hansen Endogeneity Test for Non-manufacturers}

To estimate the parameters of the model using IV estimators, the first lag of advertising share and the third lag of R\&D are instrumented. Assuming that advertising activities by non-manufacturing high tech companies come into operation faster the squared advertising share is considered as the instrument of variable. Thus, the first lag of R\&D and the squared advertising share are defined as instruments. The validation and identification power of the instruments are estimated. Table C.3 shows the statistical result.

The results of the first stage regression show that the validity and applicability of the instruments are not a problem. Comparing the $F$-statistics of the instruments with the critical value $\left(F>F_{0.1}=19.93\right)$ of the Wald test (Stock and Yogo 2005) helps to reject the null hypothesis that the instruments are under-identified and (or) weakly identified.

The results of the second test, evaluating the instruments for under-identification based on the Anderson (1987) test, also show that the null hypothesis that the instruments are under-identified is rejected (chi-squared $=41.80, P=0$ ).

The $F$-statistics of the Cragg-Donald (1993) statistic $(F=23.39)$, compared with the critical value with the critical values of $F$-statistic $\left(F_{0.1}=7.03\right)$ of stock and Yogo (2005) rejects the null hypothesis that equation is weakly identified.

Finally, the null hypothesis of Anderson-Rubin (1949) Wald test that orthogonality conditions are valid is rejected due to the significant $\mathrm{p}$-values $(P<0.05)$. This result shows that the endogenous regressors in the main equation are jointly significant in the presence of weak instruments. 
The results of the second stage of the IV estimation show that advertising share has a negative effect on non-manufactures' revenue share $\left(\beta_{0}=-.0065, p<0.76\right)$. The estimates imply that, surprisingly, revenue share decreases by $0.66 \%$ for each additional dollar investment in advertising share. Although the statistical result is insignificant, the negative sign shows that advertising activities do not benefit nonmanufacturing companies as well as manufactures. However, the R\&D share has a significant effect on market share $\left(\beta_{1}=.61, p=0\right)$. In fact, revenue share increases by $61 \%$ for each additional dollar invested in R\&D share. The statistics show that firm size has a negative effect on revenue share $\left(\theta_{1}=-.00003, p<0.94\right)$, such that if a firm's asset value increases by a dollar the firm's revenue share decreases by $0.003 \%$. However, the effect of firm size on the revenue share of non-manufacturing companies is insignificant. Industry concentration has a positive effect on non-manufactures' revenue share $\left(\theta_{2}=.0016, p<0.94\right)$. However, the statistic of $p$-value shows that the effect of industry concentration on revenue share is not significant. Table C.4 presents a summary of the statistics.

Furthermore, the statistics of the Anderson test which evaluates the test for underidentification shows that the null hypothesis of under-identification is rejected (chisquared $=41.8, P=0)$. Comparing the Cargg-Donald Wald $F$-statistic test $(F=23.4)$ with the critical values of the Stock-Yogo test $\left(F>F_{0.1}=7.03\right)$ indicates that the null hypothesis of weakly identification should be rejected. The first Sargan statistic also shows that the equation is perfectly identified. The second Sargan statistic tests for the endogeneity of endogenous regressors and rejects the null hypothesis that the regressors 
are exogenous (chi-squared $=158.33, P=0$ ). The rejection of the null hypothesis indicates that the regressors do not require instrumenting and the OLS method is reliable. 
Table C.3: The first stage of IV (2SLS) estimation, non-manufacturing companies

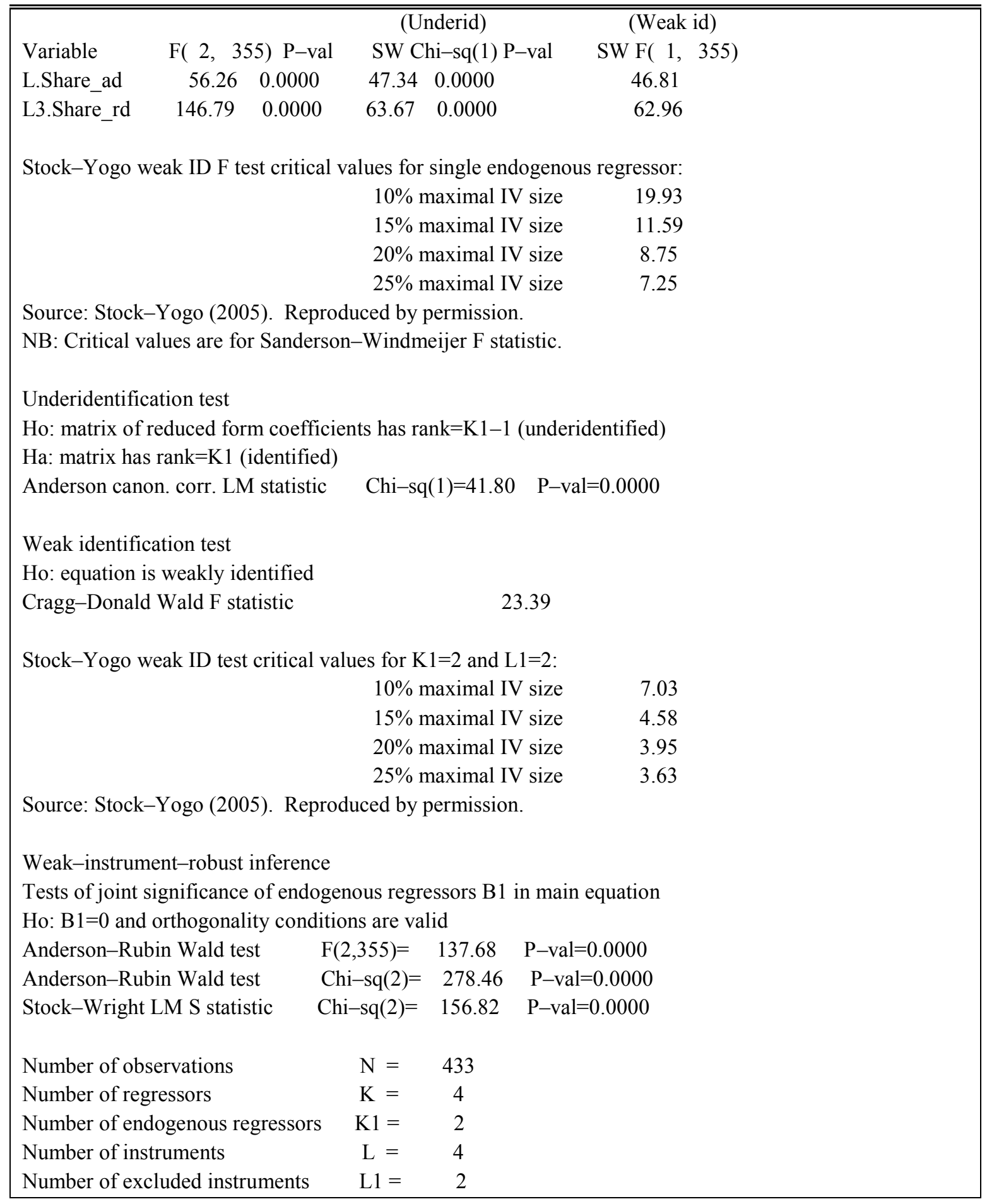


Table C.4: The results of IV (2SLS) estimation, non-manufacturing companies

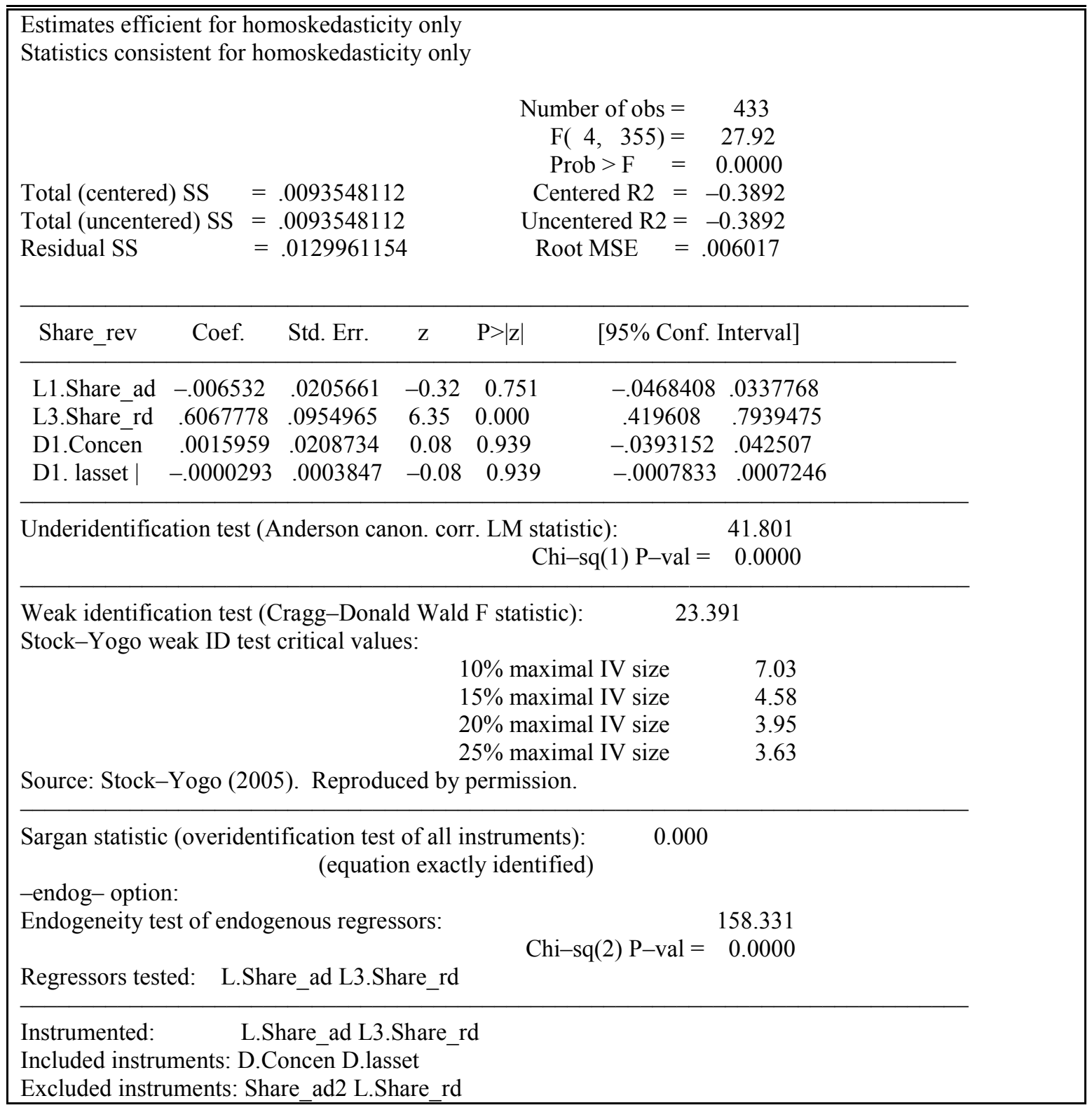




\section{Bibliography or References}

Adams, J. D., and M. Mircea. 2004. "R\&D Sourcing, Joint Ventures and Innovation: A Multiple Indicators Approach.” Working Paper No 10474, National Bureau of Economic Research, Cambridge, MA.

Allison, P. D. 2009. Fixed Effects Regression Models $1^{\text {st }}$ edition, Newbury Park, CA, SAGE.

Anderson, S. P., F. Ciliberto, J. Liaukonyte, and R. Renault. 2016. "Push-Me Pull-You: Comparative Advertising in the OTC Analgesics Industry." The Rand Journal of Economics 47(4): 1- 47.

Anderson, T. W. 1987. “Generation of Random Orthogonal Matrices.” SIAM Journal on Scientific and Statistical Computing 8(4): 625-629.

Anderson, T. W. 1951. "Estimating Linear Restrictions on Regression Coefficients for Multivariate Normal Distributions." Annals of Mathematical Statistics 22: $327-$ 351.

Anderson, T. W., and H. Rubin. 1949. "Estimators of the Parameters of a Single Equation in a Complete Set of Stochastic Equations." Annals of Mathematical Statistics 21: $570-582$.

Arvanitis, S., and T. Bolli. 2009. "A Comparison of Firm-Level Innovation Cooperation in Five European Countries." Working Papers No. 232, KOF Swiss Economic Institute, ETH Zürich.

Aschhoff, B., and T. Schmidt. 2008. "Empirical Evidence on the Success of R\&D Cooperation-Happy Together?" Review of Industrial Organization 33(1): 41-62.

Askenazy, P., T. Breda, and D. Irac. 2016. “Advertising and R\&D: Theory and Evidence from France.” Economics of Innovation and New Technology 25(1): 33-56.

Atallah, G. 2002. "Vertical R\&D Spillovers, Cooperation, Market Structure, and Innovation.” Economics of Innovation and New Technology 11: 179-209.

Bagwell, K. 2007. "The Economic Analysis of Advertising." Handbook of Industrial Organization 3: 1701-1844.

Baum, C. F., M. E. Schaffer, and S. Stillman. 2003. "Instrumental Variables and GMM: Estimation and Testing." The Stata Journal 3: 1-31. 
Becker, W., and J. Dietz. 2004. "R\&D Cooperation and Innovation Activities of FirmsEvidence for the German Manufacturing Industry." Research Policy 33(2): 209223.

Becker, W., and J. Peters. 1996. "R\&D Competition between Vertical Corporate Networks: Structure, Efficiency and R\&D Spillovers." Economics of Innovation and New Technology 6: 51-72.

Becker, G., and K. M. Murphy. 1993. "A Simple Theory of Advertising as a Good or Bad." The Quarterly Journal of Economics 108(4): 941-964.

Belderbos, R., M. Carree, and B. Lokshin. 2004. "Co-operative R\&D and Firm Performance." Research Policy 33(10): 1477-1492.

Belderbos, R., M. Carree, B. Diederen, B. Lokshin, and R. Veugelers. 2004. "Heterogeneity in R\&D Cooperation Strategies." International Journal of Industrial Organization 22(8-9): 1237-1263.

Bloom, N., and J. Van Reenen. 2002. "Patents, Real Options and Firm Performance." Economic Journal 112: C97-C116.

Bottazzi, G., G. Dosi, M. Lippi, F. Pammolli, and M. Riccaboni. 2001. "Innovation and Corporate Growth in the Evolution of the Drug Industry." International Journal of Industrial Organization 19: 1161-1187.

Boulding, W., and R. Staelin 1995. "Identifying Generalizable Effects of Strategic Actions on Firm Performance." Marketing Science 14(3): G222-G236.

Boulding, W., and R. Staelin. 1990. "Environment, Market Share, and Market Power." Management Science 36(10): 1160-1177.

Brouwer, E., and A. Kleinknecht. 1999. Innovative Output and a Firm's Propensity to Patent: An Exploration of CIS Micro Data." Research Policy 28(6): 615-624.

Cassiman, B., and R. Veugelers. 1998. Complementarity between Technology Make and Buy in Innovation Strategies." Working Paper, Department of Economics and Business, Katholieke Universiteit Leuven.

Cassiman, B., and R. Veugelers. 1999. R\&D Cooperation and Spillovers: Some Empirical Evidence." American Economics Review 92(4): 1169-1184. 
Cellini, R., and L. Lambertinis. 2002. "Advertising with Spillover Effects in a Differential Oligopoly Game with Differentiated Goods." Working Paper. Department of Economics, University of Bologna, Italy, January.

Chan, K. C., J. Lakonishok, and T. Sougiannis. 2001. "The Stock Market Valuation of Research and Development Expenditure," Journal of Finance 56: 2431-2456.

Chauvin, K. W., and M. Hirschey. 1993. "Advertising, R\&D Expenditures and the Market Value of the Firm." Financial Management 22: 128-140.

Choi, I. 2001. "Unit Root Tests for Panel Data." Journal of International Money and Finance 20: 249-272.

Clark, K., W. Chew, and T. Fujimoto. 1987. "Product Development in the World Auto Industry." Brookings Papers on Economic Activity 18(3): 729-781.

Coad, A., and R. Rao. 2008. "Innovation and Firm Growth in High-Tech Sectors: A Quantile Regression Approach." Research Policy 37(4): 633-648.

Cockburn, I., and R. Henderson. 1996. "Scale, Scope, and Spillovers: The Determinants of Research Productivity in Drug Discovery." RAND Journal of Economics 27(1): $32-59$.

Commuri, S. 2009. "The Impact of Counterfeiting on Genuine-Item Consumers' Brand Relationships." Journal of Marketing 73(3): 86-98.

Cragg, J. G., and S. G. Donald. 1993. "Testing Identifiability and Specification in Instrumental Variable Models." Econometric Theory 9(2): 222-240.

d'Aspremont, C., and A. Jacquemin. 1988. Cooperative and Non-cooperative R\&D in Duopoly with Spillovers." American Economic Review 78(5): 1133-1137.

Darby, M. R., L. G. Zucker, and A. Wang. 2003. "Universities, Joint Ventures and Success in the Advanced Technology Program." Working Paper No 9463, National Bureau of Economic Research, Cambridge, MA.

De Bondt, R., P. Slaets, and B. Cassiman. 1992. "Spillovers and the Number of Rivals for Maximum Effective R\&D.” International Journal of Industrial Organisation 10(1): 35-54.

Demir, Ö. 2005. "Entelektüel Sermayenin Işletmelerin Piyasa Değerlerine Olan Etkisi." Doğu Anadolu Bölgesi Araştırmaları 77-82. 
Drucker, P. 1954. "The Business Enterprise Has Two-and only These Two-Basic Functions: Marketing and Innovation." Practice Paper. The Practice of Management: New York, February.

Drucker, P. 1954. The Practice of Management. New York, Harper \& Row.

Dugal, S. S., and G. K. Morbey. 1995. "Revisiting Corporate R\&D Spending During a Recession.” Research Technology Management 38: 23-27.

Durbin, J. 1954. "Errors in Variables." Review of the International Statistical Institute 22: $23-32$.

Dutta, S., O. Narasimhan, and S. Rajiv. 1999. "Success in High-Technology Markets: Is Marketing Capability Critical?” Marketing Science 18(4): 547-568.

Dyer, J. H., and W. G. Ouchi. 1993. "Japanese Style Partnerships: Giving Companies a Competitive Edge.” Sloan Management Review (Fall): 51-63.

Erickson, G., and R. Jacobson. 1992. "Gaining Comparative Advantage through Discretionary Investments: The Returns to R\&D and Advertising." Management Science 38(9): 1264-1279.

Fitjar, R. D., and A. Rodriguez-Pose. 2011. "Firm Collaboration and Modes of Innovation in Norway." Discussion Paper No DP8484, Centre for Economic Policy Research, London.

Freel, M. S. 2000. “Do Small Innovating Firms Outperform Non-innovators?” Small Business Economics 14: 195-210.

Frenz, M., and G. Ietto-Gillies. 2009. "The Impact on Innovation Performance of Different Sources of Knowledge: Evidence from the UK Community Innovation Survey." Research Policy 38(7): 1125-1135.

Friedman, J. W. 1983. "Advertising and Oligopolistic Equilibrium." The Bell Journal of Economics 14 (2): 464-473.

Fritsch, M., and R. Lukas. 2001. "Who Cooperates on R\&D?” Research Policy 30: 297312.

Gasmi F., J. J .Laffont, Q. Vuong. 1992. Econometric Analysis of Collusive Behaviour in a Soft-Drink Market." Journal of Economics and Management Strategy 1(2): 277-311. 
Geroski, P. A., and S. Machin. 1992. "Do Innovating Firms Outperform Noninnovators?" Business Strategy Review Summer 79-90.

Geroski, P. A., and S. Toker. 1996. "The Turnover of Market Leaders in the UK Manufacturing Industry, 1979-86." International Journal of Industrial Organization 14: 141-158.

Gilbert, B. A., P. P. McDougall, and D. B. Audretsch. 2008. "Clusters, Knowledge Spillovers, and New Venture Performance: An Empirical Examination.” Journal of Business Venturing 23(4): 405-422.

Gou, Q., J. Zhang, L. Liang, Z. Huang, and A. Ashley. 2014. "Horizontal Cooperative Programmes and Cooperative Advertising." International Journal of Production Research 52(3): 691-712.

Griffin, A., and J. R. Hauser. 1996. "Integrating R\&D and Marketing: A Review and Analysis of the Literature." Journal of Product Innovation Management 13(3): 191-215.

Hadri, K. 2000. "Testing for Stationarity in Heterogeneous Panel Data." Econometrics Journal 3: 148-161.

Hahn, J., J. Hausman, and G. Kuersteiner. 2004. "Estimation with Weak Instruments: Accuracy of Higher-order Bias and MSE Approximations." Econometrics Journal 7: 272-306.

Hall, B. H. 1993. "The Stock Market's Valuation of R\&D Investment During the 1980's." American Economics Reviews 83: 259-264.

Hansen, L., J. Heaton, and A. Yaron. 1996. "Finite Sample Properties of Some Alternative GMM Estimators." Journal of Business and Economic Statistics 14(3): 262-280.

Hanssens, D. M., L. J. Parsons, and R. L. Schultz. 2001. Market Response Models: Econometric and Time Series Analysis, $2^{\text {nd }}$ edition. Kluwer Academic Publishers, Boston.

Harabi, N. 2010. "The Impact of Vertical R\&D Cooperation on Firm Innovation: An Empirical Investigation." Economics of Innovation and New Technology 11(2): 93-108. 
Harhoff, D. 1991. “R\&D Incentives and Spillovers in a Two Industry Model.” Discussion Paper. Center for European Economic Research, June.

Hausman, J. 1978. "Specification Tests in Econometrics." Econometrica 46(6): 12511271.

Hippel, E. V. 1988. The Source of Innovation, Reprint edition, Oxford University Press, New York.

Hirschey, M., and J. J. Weygandt. 1985. "Amortization Policy for Advertising and Research and Development Expenditures." Journal of Accounting Research 23(1): $326-335$.

Hirschey, M., and J. J. Weygandt. 1985. "Amortization Policy for Advertising and Research and Development Expenditures." Journal of Accounting Research 23: $326-335$.

Hirschey, M., H. Skiba, and M. B. Wintoki. 2012. "The Size, Concentration, and Evolution of Corporate R\&D Spending in U.S. Firms from 1976 to 2010: Evidence and Implications." Journal of Corporate Finance 18: 496-518.

Hou, J., and P. Mohnen. 2011. "Complementarity between In-house R\&D and Technology Purchasing: Evidence from Chinese Manufacturing Firms.” Working Paper No 048. United Nations University, Maastricht, The Netherlands.

Iansiti, M., and J. West. 1997. "Technology Integration: Turning Grate Research into Grate Products." Harvard Business Review May-June 69-79.

Ishii, A. 2006. "Cooperative R\&D between Vertically Related Firms with Spillovers." International Journal of Industrial Organization 22: 1213-1235.

Janz, N., H. Lööf, and B. Peters. 2003. "Firm Level Innovation and Productivity - Is There a Common Story across Countries?” Working Paper No 26. Swedish Institute for Studies in Education and Research, Mannheim.

Jose, M. L., L. M. Nichols, and J. L. Stevens. 1986. "Contributions of Diversification, Promotion, and R\&D to the Value of Multiproduct Firms: a Tobin's-Q Approach." Financial Management 15: 33-42.

Kadiyali, V. 1996. "Entry, Its Deterrence, and Its Accommodation: A Study of the U.S. Photographic Film Industry.” RAND Journal of Economics 27(3): 452-478. 
Kafouros, M. I., and P. J. Buckley. 2008. "Under What Conditions Do Firms Benefit from the Research Efforts of other Organizations?" Research Policy 37(2): 225239.

Kaiser, U. 2005. "A Microeconometric Note on Product Innovation and Product Innovation Advertising." Economics of Innovation and New Technology 14(7): $573-582$.

Kamien, M. I., E. Muller, and I. Zang. 1992. "Research Joint Ventures and R\&D Cartels." American Economic Review 82: 1293-1306.

Kao, C. 1999. "Spurious Regression and Residual-based Tests for Cointegration in Panel Data." Journal of Econometrics 90: 1-44.

Karlsson, S., and M. Lothgren. 2000. "On the Power and Interpretation of Panel Unit Root Tests.” Economics Letters 66: 249-255.

Kemp, R. M. G., M. Folkeringa, J. P. J. de Jong, and E. F. M. Wubben. 2003. "Innovation and Firm Performance." Research Report H2000207. SCientific AnaLysis of Entrepreneurship and SMEs, Zoetermeer.

Kleinknecht, A., and J. O. N. Reijnen. 1992. "Why Do Firms Cooperate on R\&D? An Empirical Study." Research Policy 21: 347-360.

Kremp, E., and J. Mairesse. 2004. "Knowledge Management, Innovation and Productivity." Working Paper No 10237, National Bureau of Economic Research, Cambridge, MA.

Kwoka, J. E. Jr. 1993. “The Sales and Competitive Effects of Styling and Advertising Practices in the U.S. Auto Industry." The Review of Economics and Statistics 75(4): 649-656.

Kwong, W. J., and E. C. Norton. 2007. "The Effect of Advertising on Pharmaceutical Innovation.” Review of Industrial Organization 31(3): 221-236.

Lee, K. R. 1996. "The Role of User Firms in the Innovation of Machine Tools: The Japanese Case.” Research Policy 25(4): 491-507.

Levin, R. C., A. K. Klevorick, R. R. Nelson, and S. G. Winter. 1987. “Appropriating the Returns from Industrial R\&D.” Brookings Papers on Economic Activity 1987(3): 783-820. 
Lipczynski, J., J. Wilson, and J. Goddard. 2005. Industrial Organization: Competition, Strategy, Policy, $2^{\text {nd }}$ edition. Financial Times-Prentice Hall, Harlow, UK.

Lokshin, B., R. Belderbos, and M. Carree. 2008. The Productivity Effects of Internal and External R\&D: Evidence from a Dynamic Panel Data Model." Oxford Bulletin of Economics and Statistics 70: 399-413.

Lööf, H., and A. Heshmati. 2002. "Knowledge Capital and Performance Heterogeneity: A Firm-level Innovation Study." International Journal of Production Economics 76(1): 61-85.

Mansfield, E. 1962. "Entry, Gibrat's Law, Innovation, and the Growth of Firms." The American Economic Review 52(5): 1023-1051.

Matraves, C. 1999. "Market Structure, R\&D and Advertising in the Pharmaceutical Industry." Journal of Industrial Economics 47(2): 169-194.

Mizik, N., and R. Jacobson. 2003. "Trading off between Value Creation and Value Appropriation: The Financial Implications of Shifts in Strategic Emphasis." Journal of Marketing 67(1): 63-76.

Morbey, G. K. 1988. "R\&D: Its Relationship to Company Performance." Journal of Product Innovation Management 5: 191-200.

Motohashi, K. 2008. "Growing R\&D Collaboration of Japanese Firms and Policy Implications for Reforming the National Innovation System." Asian Pacific Business Review 14(3): 1-27.

Motohashi, K. 2007. "The Changing Autarky Pharmaceutical R\&D Process, Causes and Consequences of Growing R\&D Collaboration in Japanese Firms." International Journal of Technology Management 39(1-2): 1-27.

Mowery D. C. 1998. "Collaborative R\&D: How Effective Is It?" Issues in Science and Technology 15(1): 1-14.

Mowery, D. C. 1983. "Industrial Research and Firm Size, Survival, and Growth in American Manufacturing, 1921-1946: An Assessment." Journal of Economic History 43(4): 953-980.

Narula, R. 2003. Multinational Enterprises, Innovative Strategies and Systems of Innovation. Edward Elgar, Cheltenham 129-152. 
Nerlove, M., and F. V. Waugh. 1961. "Advertising without Supply Control: Some Implications of a Study of the Advertising of Oranges." Journal of Farm Economics 43(4): 813-37.

Nielsen, B. B. 2002. "Cooperative Strategies and Alliances.” Journal of International Business Studies 34 (5): 489-491.

Nooteboom, B. 1999. Inter-Firm Alliances - Analysis and Design, $1^{\text {st }}$ edition. London, Routledge.

Ofek, E., and M. Sarvary. 2003. "R\&D, Marketing, and the Success of Next-Generation Products." Marketing Science 22 (3): 355-370.

Osinga, E. C., P. S. H Leeflang, S. Srinivasan, and J. E. Wieringa. 2011. "Why Do Firms Invest in Consumer Advertising with Limited Sales Response? A Shareholder Perspective." Journal of Marketing 75(1): 109-124.

Paton, D., and L. Vaughan Williams. 1999. "Advertising and Firm Performance: Some New Evidence from UK Firms.” Economic Issues 4(2): 89-106

Pearson, K. 1896. "Mathematical Contributions to the Theory of Evolution. III. Regression, Heredity, and Panmixia." Philosophical Transactions of the Royal Society of London 1(187): 253-318.

Pepall, L., D. Richards, and G. Norman. 2008. Industrial Organization: Contemporary Theory and Empirical Applications, $4^{\text {th }}$ edition. Blackwell, Malden, MA.

Peters, J. 1995. “Inter-industry R\&D-spillovers between Vertically Related Industries: Incentives, Strategic Aspects and Consequences." Working Paper No 139. Institut für Volkswirtschaftslehre, Universiät Augsburg.

Porter, M. E. 1979. "How Competitive Forces Shape Strategy.” Harvard Business Review 57(2): 137-145.

Powell, W. W., and S. Grodal. 2005. "Networks of Innovators." The oxford handbook of innovation. Oxford: Oxford University Press 56-85.

Ravenscraft, D., and F. M. Scherer. 1982. "The Lag Structure of Returns to Research and Development." Journal of Applied Economics 14(6): 603-620.

Reibstein, D. J., and D. R. Wittink. 2005. "Competitive Responsiveness.” Marketing Science 24(1): 8-11. 
Reilly, F. K., A. F. McGann, and R. A. Marquardt. 1977. "Advertising Decision and Stockholders' Wealth.” Journal of Advertising Research 17: 49-56.

Riggs, W., and E. V. Hippel. 1994. "Incentive to Innovate and the Sources of Innovation: The Case of Scientific Instruments.” Research Policy 23(4): 459-469.

Roberts, M. J., and L. Samuelson. 1988. “An Empirical Analysis of Dynamic, Non-Price Competition in an Oligopolistic Industry." RAND Journal of Economics 19(2): 200-220.

Röller, L., M. Tombak, and R. Siebert. 1997. "Why Firms form Research Joint Ventures: Theory and Evidence.” Discussion Paper. Social Science Research Center Berlin.

Roper, S. 1997. "Product Innovation and Small Business Growth: A Comparison of the Strategies of German, UK, and Irish Companies." Small Business Economics 9: $523-537$.

Rubera, G., and A. H. Kirca. 2012. "Firm Innovativeness and Its Performance Outcomes: A Meta-Analytic Review and Theoretical Integration." Journal of Marketing 76(3): 130-147.

Sahni, N. S. 2016. “Advertising Spillovers: Evidence from Online Field-Experiments and Implications for Returns on Advertising." Journal of Marketing Research 14: 152.

Sako, M. 1995. “Suppliers' Associations in the Japanese Automobile Industry: Collective Action for Technology." Cambridge Journal of Economics 20(6): 651-671.

Sargan, J. 1958. "The Estimation of Economic Relationships Using Instrumental Variables." Econometrica 26(3): 393-415.

Scherer, F. M. 1965. "Corporate Inventive Output, Profits, and Growth.” Journal of Political Economy 73(3): 290-297.

Seldon, B. J., and Khosrow D. 1989. "A Simultaneous Model of Cigarette Advertising: Effects of Demand and Industry Response to Public Policy." The Review of Economics and Statistics 71(4): 673-677.

Shapiro, B. T. 2018. "Positive Spillovers and Free Riding in Advertising of Prescription Pharmaceuticals: The Case of Antidepressants." Journal of Political Economy 126(1): 381-437. 
Siebert, R. 1996. "The Impact of Research Joint Ventures on Firm Performance: An Empirical Assessment.” Working Papers, Social Science Research Centre: Berlin, August.

Sridhar, S., S. Narayanan, and R. Srinivasan. 2014. "Dynamic Relationships among R\&D, Advertising, Inventory and Firm Performance." Journal of the Academy of Marketing Science 42(3): 277-290.

Stock, J. H., and M. Yogo. 2005. "Testing for Weak Instruments in Linear IV Regression-In Identification and Inference for Econometric Models: Essays in Honor of Thomas Rothenberg." Department of Economics, Cambridge University, Cambridge February 2010.

Stock, J. H., and M. Yogo. 2005. "Testing for Weak Instruments in Linear IV Regression." Working Paper. Department of Economics, Harvard University, New York, 2005. mayoral.iae-csic.org/IV_2015/stock_yogo_2005.pdf.

Sudiyatno, B., E. Puspitasari, and A. Kartika. 2012. "The Company's Policy, Firm Performance, and Firm Value: An Empirical Research on Indonesia Stock Exchange." American International Journal of Contemporary Research 2 (12): $30-41$.

Suzumura, K. 1992. "Cooperative and Non-cooperative R\&D in an Oligopoly with Spillovers." American Economic Review 82: 1307-1320.

Svetina, A. C., and I. Prodan. 2008. "How Internal and External Sources of Knowledge Contribute to Firms' Innovation Performance." Managing Global Transitions 6(3): 277-299.

Szymanski, D. M., S. G. Bharadwaj, and P. R. Varadarajan. 1993. "An Analysis of the Market Share-Profitability Relationship." Journal of Marketing 57(3): 1-18.

Tether, B. S. 2002. "Who Co-Operates for Innovation, and Why: An Empirical Analysis." Research Policy 31: 947-967.

Tubbs, M. 2007. "The Relationship between R\&D and Company Performance." Journal of Research-Technology Management 50(6): 23-30.

Veugelers, R. 1997. "Internal R\&D Expenditures and External Technology Sourcing." Research Policy 26: 303-315. 
Wang, S. S., T. P. Dhar, and K. W. Stiegert. 2004. "An Empirical Analysis of Strategic Pricing and Advertising for Differentiated Products." Conference Paper, Industrial Organization and the Food Processing Industry, France: Toulouse, June.

Wernerfelt, B. 1984. "A Resource-Based View of the Firm." Strategic Management Journal 5(2): 171-180.

Wiggins, S. N., and W. J. Lane 1983. "Quality Uncertainty, Search, and Advertising." The American Economic Review. 73(5): 881-889.

Winters, R., and E. Stam. 2007. "Innovation Networks of High Tech SMEs: Creation of Knowledge but no Creation of Value." Economic Research papers No 042. Friedrich-Schiller, University Jena.

Wu, D. M. 1973. "Alternative Tests of Independence between Stochastic Regressors and Disturbances." Econometrica 41(4): 733-750.

Yi, S. S. 1996. "The Welfare Effects of Cooperative R\&D in Oligopoly with Spillovers." Review of Industrial Organization 11(5): 681-393. 